OPEN ACCESS

Edited by:

Yang Zhou,

Brown University, United States

Reviewed by:

Mohamed Ghonim,

St. Jude Children's Research Hospital,

United States

Mehra Haghi,

University of Technology Sydney,

Australia

*Correspondence:

Cristina Estornut

cristina.estna@gmail.com

Javier Milara

xmilara@hotmail.com

tThese authors share senior authorship

Specialty section:

This article was submitted to Respiratory Pharmacology,

a section of the journal

Frontiers in Pharmacology

Received: 14 October 2021 Accepted: 10 December 2021

Published: 21 January 2022

Citation:

Estornut C, Milara J, Bayarri MA,

Belhadj N and Cortijo J (2022)

Targeting Oxidative Stress as a Therapeutic Approach for Idiopathic

Pulmonary Fibrosis.

Front. Pharmacol. 12:794997.

doi: 10.3389/fphar.2021.794997

\section{Targeting Oxidative Stress as a Therapeutic Approach for Idiopathic Pulmonary Fibrosis}

\author{
Cristina Estornut ${ }^{1 *}$, Javier Milara ${ }^{1,2,3 \dagger *}$, María Amparo Bayarri ${ }^{1}$, Nada Belhadj ${ }^{1}$ and \\ Julio Cortijo ${ }^{1,2,3,4 t}$
}

${ }^{1}$ Department of Pharmacology, Faculty of Medicine, University of Valencia, Valencia, Spain, ${ }^{2}$ Pharmacy Unit, University General Hospital Consortium, Valencia, Spain, ${ }^{3}$ CIBERES, Health Institute Carlos III, Valencia, Spain, ${ }^{4}$ Research and Teaching Unit, University General Hospital Consortium, Valencia, Spain

Idiopathic pulmonary fibrosis (IPF) is a chronic interstitial lung disease characterized by an abnormal reepithelialisation, an excessive tissue remodelling and a progressive fibrosis within the alveolar wall that are not due to infection or cancer. Oxidative stress has been proposed as a key molecular process in pulmonary fibrosis development and different components of the redox system are altered in the cellular actors participating in lung fibrosis. To this respect, several activators of the antioxidant machinery and inhibitors of the oxidant species and pathways have been assayed in preclinical in vitro and in vivo models and in different clinical trials. This review discusses the role of oxidative stress in the development and progression of IPF and its underlying mechanisms as well as the evidence of oxidative stress in human IPF. Finally, we analyze the mechanism of action, the efficacy and the current status of different drugs developed to inhibit the oxidative stress as anti-fibrotic therapy in IPF.

Keywords: IPF-idiopathic pulmonary fibrosis, fibrosis, oxidative stress, ROS-reactive oxygen species, antioxidant therapy

\section{INTRODUCTION}

\subsection{Idiopathic Pulmonary Fibrosis}

Among all the idiopathic interstitial pneumonias, the most common form is idiopathic pulmonary fibrosis (IPF), whose incidence is estimated to be ranged between 2.8 and 9.3 per 100,000 people per year in North America and Europe (Barratt et al., 2018). IPF occurs primarily in older adults, mainly in men; it is characterised by chronic and progressive fibrosis related to a decrease in pulmonary function, progressive respiratory distress, and a remarkable poor prognosis. It is generally nonresponsive to traditional therapies such as anti-inflammatory and immunomodulatory treatment (Richeldi et al., 1941; Day, 2008; Barratt et al., 2018; Lederer and Martinez, 2018).

As the disease progresses, some pathological changes appear, including fibrotic lesions and accumulation of fibroblast in focal zones called "fibroblast foci," which causes the characteristic "honeycomb" appearance. The etiologic stimulus that initiates the disease and the underlying mechanism of pulmonary fibrosis are still unknown or poorly understood. Current studies suggest that fibrosis may result from the presence of continuous stimuli (both endogenous and exogenous) or injury followed by an aberrant wound healing process and a dysregulated repair/remodelling of the lung (Kinnula et al., 2005; Kliment and Oury, 2010). 
Lung fibrosis is associated with accumulation of fibroblasts, myofibroblast activation or differentiation, alveolar reepithelization, extracellular matrix (ECM) dysregulation, oxidative stress, and inflammation (Phan, 2002; Manni and Oury, 2014). Thus, fibrosis development is mediated by interactions between various cell types such as fibroblasts; myofibroblasts; epithelial cells, especially type I and II alveolar epithelial cells (AECs); mesothelial and mesenchymal cells, as well as immune system cells. Although most studies have focused on the fibrotic process and the proliferation of fibroblast and myofibroblast, several studies suggest that increased oxidative stress may play a major role in the development and progression of IPF (Bocchino et al., 2010; Liguori et al., 2018; Cameli et al., 2020).

This review addresses the importance of the balance of oxidants/antioxidants in the pathogenesis of pulmonary fibrosis as well as the evidence of oxidative stress in human IPF with emphasis on the pharmacological approach targeting oxidative stress.

\subsection{Oxidative Stress in Idiopathic Pulmonary Fibrosis}

Oxidative stress arises as a result of an imbalance between reactive oxygen species (ROS) and reactive nitrogen species (RNS) production and antioxidant defence that leads to cellular dysfunction and tissue damage (Hosseinzadeh et al., 2018b). ROS are highly reactive oxygen metabolites; some examples are superoxide anion $\left(\mathrm{O}_{2}{ }^{--}\right)$, hydroxyl radical $\left(\mathrm{HO}^{\bullet}\right)$, and hydrogen peroxide $\left(\mathrm{H}_{2} \mathrm{O}_{2}\right)$. RNS are molecules derived from the reaction between nitric oxide (NO) and $\mathrm{O}_{2}$ and derivates, one example is peroxynitrite. RNS can generate oxidative stress but also the named nitrosative stress (Thomas et al., 2008; Otoupalova et al., 2020). Lungs, due to their anatomy, location, and function, are particularly susceptible to oxidative stress (Crapo, 2003; Kinnula et al., 2005; Hosseinzadeh et al., 2018b).

Exogenous oxidizing agents such as cigarette smoke, toxins, hyperoxia, asbestos fibres, drugs and radiation also induce the production of ROS/RNS. Exogenous or endogenous generated ROS/RNS may directly damage the alveolar epithelium, favouring fibrotic interstitial lung responses (Kinnula et al., 2005). In addition to directly damaging the lung epithelium, ROS/RNS may also favour the development of pulmonary fibrosis by altering the expression of mediators implicated in the pathogenesis of IPF, such as the pro-fibrotic growth factor, transforming growth factor $\beta$ (TGF- $\beta$ ). This growth factor is known to be modulated by ROS, indeed, experimental studies have evidenced that ROS can increase the secretion of TGF- $\beta$ from epithelial cells and directly activate it (Barcellos-Hoff and Dix, 1996; Bellocq et al., 1999; Pociask et al., 2004). In turn, TGF$\beta$ stimulates the proliferation of fibroblasts and its differentiation into myofibroblasts (Thannickal et al., 2003). Oxidants may also alter the nature of surrounding ECM (Larios et al., 2001). Both ROS and RNS play an important role in the regulation of ECM, degradation and turnover (Fu et al., 2003; Nelson and Melendez, 2004). In lungs, alveolar inflammatory cells including lymphocytes, macrophages and neutrophils also produce ROS/ RNS. In IPF patients, in addition to these inflammatory cells, fibroblasts and myofibroblast produce high levels of ROS/RNS in response to cytokines and growth factors and are involved in the underlying mechanism of fibrosis development Table 1 (Bergeron et al., 2003; Waghray et al., 2005).

The main producers of ROS/RNS include nicotinamide adenine dinucleotide phosphate oxidases (NADPH oxidases, NOXs), myeloperoxidase (MPO), xanthine oxidase, nitric oxide synthase (NOS), and the mitochondrial electron transport chain (Kinnula et al., 2005; Hosseinzadeh et al., 2018b). From the family members of the NOX, the isoforms Nox1, Nox2 and Nox4 have been found to be implicated in the pathogenesis of pulmonary fibrosis but not Nox3 (Masamune et al., 2008; Griffith et al., 2009; Amara et al., 2010). Nox4 is ubiquitously expressed in various cell types of lung tissues including macrophages and structural cells such as smooth muscle cells, endothelial cells, mesenchymal cells, and epithelial cells (Lee et al., 2010a; Harijith et al., 2017). In IPF patients, Nox4 is strongly expressed in fibroblast foci and increases the expression of $\alpha$-smooth muscle actin ( $\alpha$-SMA), fibronectin and procollagen, which are the most characteristic profibrotic molecules (Griffith et al., 2009; Hecker et al., 2009; Amara et al., 2010). Furthermore, Nox4 plays a critical role in myofibroblast tissue repair functions and fibrogenesis (Hecker et al., 2009). It is well known that TGF- $\beta$ induces Nox4-dependent ROS production, which, in turn, promotes fibroblast migration (Amara et al., 2010) and this ROS production is also involved in the acquisition of pro-fibrotic myofibroblast phenotypes, including differentiation, contraction, apoptotic resistance, and ECM deposition (Hecker et al., 2009; Cameli et al., 2020). Nox4 expression is also increased in IPF senescent fibroblasts/myofibroblasts (Jarman et al., 2014) and ROS generated by Nox4 promotes senescence and the apoptosis-resistant phenotype (Hecker et al., 2014). Hyperplastic type II AECs from IPF patients' lungs highly express this NOX isoform (Amara et al., 2010) and Nox4-dependent ROS generation induces epithelial-tomesenchymal transition (EMT) in alveolar epithelial cells (Hecker et al., 2009; Cameli et al., 2020). Other studies demonstrate that Nox4 is implicated in the profibrotic polarization of macrophages and the genetic removal of Nox4 in macrophages reduces ECM deposition protecting from induced pulmonary fibrosis ( $\mathrm{He}$ et al., 2019). In addition, Nox4, along with Nox1, Nox2, is also expressed in vascular smooth muscle cells (VSMCs) (Huetsch et al., 2019). A study has reported that Nox4 is highly expressed in thickened pulmonary arteries in IPF patients (Pache et al., 2011). It has been proved that VSMCs are activated by TGF- $\beta 1$ to induce Nox4, leading to increased VSMCs proliferation (Sturrock et al., 2006). Nox4 expression may be altered in VSMCs and is likely to mediate vascular remodelling that may generate pulmonary hypertension in lungs from IPF patients (Kato and Hecker, 2020). Vascular endothelial cells also express Nox4 (Bernard et al., 2014), ROS generated by Nox4 is implicated in the regulation of endothelial cell motility and angiogenesis. Furthermore, Nox4 expression is higher at sites of 
TABLE 1 | Summary of the molecules of the redox system and the implicated process in the IPF participating cells.

\begin{tabular}{|c|c|c|c|}
\hline Cell & $\begin{array}{l}\text { Redox system } \\
\text { molecule }\end{array}$ & Implicated process & Reference \\
\hline \multirow[t]{4}{*}{ (myo)fibroblasts } & NOX4 & 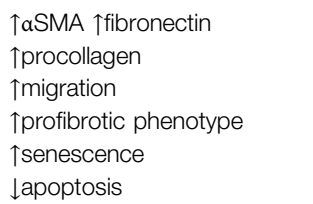 & $\begin{array}{l}\text { Hecker et al. (2009); Griffith et al. (2009); Amara et al. (2010); Hecker et al. (2014); Jarman et al. } \\
\text { (2014); Cameli et al. (2020) }\end{array}$ \\
\hline & iNOS (NO) & $\begin{array}{l}\uparrow T G F \beta \text { 个collagen } \uparrow \text { HSP47 } \\
\uparrow E C M \text {-degrading enzymes }\end{array}$ & Zeidler et al. (2004); Hsu et al. (2007); Kliment and Oury. (2010) \\
\hline & mtROS & Tprofibrotic genes & Jain et al. (2013) \\
\hline & Nrf2 & $\downarrow$ fibrotic progression & Artaud-Macari et al. (2013) \\
\hline \multirow[t]{5}{*}{ Epithelial cells } & NOX4 & †EMT & Hecker et al. (2009); Cameli et al. (2020) \\
\hline & mtROS & $\uparrow$ senescence $\uparrow$ apoptosis & Yoon et al. (2005); Panduri et al. (2009); Taslidere et al. (2014); Rangarajan et al. (2017) \\
\hline & $\mathrm{H}_{2} \mathrm{O}_{2}$ & Mimics TGF $\beta$ & Rhyu et al. (2005) \\
\hline & Catalase & $\downarrow \mathrm{H}_{2} \mathrm{O}_{2} \downarrow$ fibroblast activation & Waghray et al. (2005) \\
\hline & SOD & $\downarrow E C M$ oxidative degradation & Petersen et al. (2004) \\
\hline $\begin{array}{l}\text { Inflammatory } \\
\text { cells }\end{array}$ & NOX2 and NOX4 & †ECM deposition & He et al. (2019) \\
\hline VSMCs & NOX4 & $\begin{array}{l}\text { Tproliferation } \\
\text { †remodelling }\end{array}$ & Sturrock et al. (2006); Kato and Hecker. (2020) \\
\hline Endothelial cells & NOX 2 and NOX4 & †angiogenesis & Teng et al. (2012); Jarman et al. (2014) \\
\hline
\end{tabular}

$\alpha$ SMA, $\alpha$-smooth muscle actin; ECM, extracellular matrix; EMT, epithelial-to-mesenchimal transition; HSP47, heat-shock protein 47; iNOS, inducible NOS; mtROS, mitochondrial ROS; NO, nitric oxide: NOS, nitric oxide synthase; NOX, NADPH, oxidases; Nif2, nuclear factor erythroid 2-related factor 2; SOD, superoxide dismutase; TGF $\beta$, transforming growth factor $\beta$.

angiogenesis within fibrotic regions and adjacent to fibrotic foci (Jarman et al., 2014).

Whereas Nox4 is mainly expressed in fibroblasts and epithelial cells, Nox2, is primarily expressed by neutrophils and macrophages and, to a lesser extent, in structural cells (mesenchymal cells, smooth muscle cells, endothelial cells, and airway epithelial cells) (Harijith et al., 2017). In IPF patients, neutrophils show an increased expression of Nox2 subunits (Kato and Hecker, 2020) and genetic removal of some of these subunits partially protects from the development of fibrosis in lung fibrosis mice models (Manoury et al., 2005; Kato and Hecker, 2020). Nox2-mediated ROS in vascular endothelial cells is implicated in autophagy induction, which contributes to impaired angiogenesis (Teng et al., 2012).

In lungs, NOS is the major enzyme producer of NO. The NOS family includes three isoforms: endothelial (eNOS), neuronal (nNOS) and inducible (iNOS) (Ricciardolo et al., 2004). RNS are mostly generated by iNOS, which is expressed by a huge variety of cells from the respiratory system. In normal conditions, NO has biological roles such as the relaxation of smooth muscle cells in pulmonary and cardiovascular system, however high levels of $\mathrm{NO}^{\bullet}$ and NO-derived species may interact with different molecules and modify their function (Ricciardolo et al., 2006). In IPF, the high levels of iNOS expression and nitrotyrosine production in fibroblasts, as well as epithelial cells and macrophages, leads to unusual nitrosative stress. This nitrostive stress modifies different proteins in the lungs facilitating fibrogenesis and progression of the disease (Saleh et al., 1997).

Different studies have demonstrated that NO signal pathway may enhance TGF- $\beta$ expression in lung fibroblasts and increase the expression of collagen type I and heat-shock protein (HSP) 47
(Hsu et al., 2007; Kliment and Oury, 2010). Further studies have demonstrated NO also seems to promote the expression of ECMdegrading enzymes in fibroblasts (Zeidler et al., 2004; Kliment and Oury, 2010). Additionally, endothelial cells may be involved in lung fibrosis through the production of the free radical NO (Michiels, 2003).

As we have mentioned, mitochondria is a major source of ROS production due to the uncoupling of the electron transport chain (Osborn-Heaford et al., 2012) and this production increases with senescence and ageing (Lee et al., 2002; Kurundkar and Thannickal, 2016). ROS generated by mitochondria are released into the cytosol and have been proved to be crucial in mediating pulmonary fibrosis (Cheresh et al., 2013). The profibrotic factor, TGF- $\beta 1$, enhances mitochondrial ROS, which have been proven to induce the expression of pro-fibrotic genes during myofibroblast differentiation. Pulmonary fibroblasts from IPF patients show a higher generation of mitochondrial ROS and inhibition of the generation of mitochondrial ROS decreases profibrotic gene expression (Jain et al., 2013). Mitochondrial ROS generation is also increased in bleomycin-induced pulmonary fibrosis (Kim et al., 2016). Additionally, the epithelial cell damage occurring in IPF is linked with increased mitochondrial ROS (Kuwano et al., 2003). In turn, TGF- $\beta 1$ induces mitochondrial ROS generation through mitochondrial complex IV inhibition in lung epithelial cells (Yoon et al., 2005). Furthermore, upregulation of mitochondrial ROS by TGF- $\beta 1$ induce senescence in lung epithelial cells (Yoon et al., 2005; Taslidere et al., 2014). It has been suggested that mitochondrial impairment represents a key process for epithelial cell apoptosis in lung fibrosis (Panduri et al., 2009; Rangarajan et al., 2017).

The lung counteracts the damage induced by ROS with a wide variety of antioxidant defences. This endogenous antioxidant 
system includes small-molecular-weight antioxidants [vitamin E, melatonin, glutathione (GSH), uric acid, etc], classic antioxidant enzymes [superoxide dismutases (SODs), catalase, and glutathione peroxidase $(\mathrm{GPx})]$, other antioxidant enzymes [peroxiredoxins (PRXs), thioredoxins (TRXs)], phase II detoxifying enzymes [glutathione-S-transferase (GST) isozymes, $\mathrm{NADP}(\mathrm{H})$, quinone oxidoreductase (NQO1), etc], stress-response proteins [heme oxygenase (HO)-1, ferritin, etc.], mucins (MUC), and metal binding proteins (lactoferrin, transferrin, metallothionein, etc) (Walters et al., 2008). The nuclear factor erythroid 2-related factor 2 (Nrf2) induces the expression of most of the antioxidant and detoxifying enzymes, which makes this factor essential for activating the antioxidant defence system. Under normal conditions, Nrf2 is sequestered in the cytoplasm by binding to Kelch like-ECH-associated protein 1 (KEAP1). In response to stress signals, Nrf2 is released from KEAP1 and translocated into the nucleus, where induces the expression of hundreds of antioxidant genes. Additionally, Nrf2 regulates the expression of genes involved in inflammatory and fibrotic responses (Hybertson et al., 2011). Fibroblasts and myofibroblasts from IPF patients express lower levels of Nrf2 when compared to controls fibroblasts. Activators of Nrf2 inhibit TGF- $\beta 1$-induced pro-fibrotic effects in IPF fibroblasts and attenuate pulmonary fibrosis in animal models (Artaud-Macari et al., 2013).

In lungs, these antioxidant enzymes are expressed by the bronchial and alveolar epithelial cells and macrophages (Kinnula et al., 2005) and different studies suggest that overexpression of some of these antioxidant enzymes may protect against pulmonary fibrosis (Kang et al., 2003; Gao et al., 2008).

AECs in the lungs produce catalase, which exerts its activity via reducing $\mathrm{H}_{2} \mathrm{O}_{2}$ and, therefore, inhibits $\mathrm{H}_{2} \mathrm{O}_{2}$-mediated fibroblast activation in IPF lungs (Waghray et al., 2005). As well as epithelial cells, inflammatory cells also express the antioxidant enzyme catalase. It has been reported that intratracheal administration of catalase in asbestos-treated mice prevents the development of pulmonary fibrosis by inhibiting the generation of $\mathrm{H}_{2} \mathrm{O}_{2}$ in inflammatory cells (Murthy et al., 2009).

All three isoforms of superoxide dismutase, including extracellular-SOD (EC-SOD), are highly expressed in the lungs. In addition, they play a critical role in induced pulmonary fibrosis models by preventing oxidative stress (Bowler et al., 2002; Rabbani et al., 2005). It has been evidenced that EC-SOD exerts anti-fibrotic effects in lungs through prevention of oxidative degradation of ECM, avoiding the destructive effects of ECM degradation products on pulmonary epithelial and mesenchymal cells (Petersen et al., 2004).

Reduced GSH, a low-molecular weight antioxidant, is synthesized by bronchial epithelial cells and alveolar macrophages. Different studies supported that TGF- $\beta 1$ suppresses gene expression of glutamate cysteine ligases (GCL), an enzyme implicated in the biosynthesis of GSH, in alveolar epithelial cells (Arsalane et al., 1997; Jardine et al., 2002). Overexpression of the active form of TGF- $\beta 1$ in mice induces lung fibrosis, and it is associated with downregulation of GCL gene expression, decreased GSH levels in BALF, and increased oxidative stress (Liu et al., 2012).

\subsubsection{Evidence of Oxidative Stress Biomarkers in IPF Patients}

Given the accepted role of oxidative stress in IPF, it is essential to investigate the presence of oxidative stress biomarkers. These biomarkers could provide clues about the disease progression and prognosis as well as be useful in the clinical assessment of the patients. It was in 1987 when the presence of oxidative stress biomarkers was first described (Cantin et al., 1987) in IPF patients. Since then, several researchers have investigated oxidative stress indicators in this pathology, as is resumed in

Table 2.

GSH is one of the antioxidant small molecule par excellence and one of the most measured biomarkers. Levels of this antioxidant molecule and its oxidized form, GSSG, have been measured as indicators of oxidative stress in multiple diseases. Regarding IPF, most of the studies reported lower levels of total GHS (reduced (GSH) + oxidized (GSSG), tGSH) and reduced GSH in IPF patients than in controls (Cantin et al., 1989; Borok et al., 1991; Meyer et al., 1994; Rahman et al., 1999; Beeh et al., 2002; Muramatsu et al., 2016; Veith et al., 2017), just two studies found no differences in GSH or tGSH between IPF patients and controls (Meyer et al., 1994; Markart et al., 2009). GSSG levels are found to be similar between IPF patients and controls (Rahman et al., 1999; Veith et al., 2017) or higher in IPF (Markart et al., 2009; Muramatsu et al., 2016). Ratios between the different forms of GSH have also been measured and are shown in Table 2. Most of the studies found no correlation between GSH forms and lung function. However, Beeh et al. (2002) found an inverse relationship between GSH sputum levels and disease severity and a positive correlation between GSH and vital capacity (VC \%), Muramatsu et al. (2016) also found an inverse correlation between the change in GSSG and the change in forced vital capacity (FVC).

Another marker for oxidative stress is lipid peroxidation, usually determined through levels of thiobarbituric acid reactive substances (TBARS), and among all the lipid oxidation products the most studied is the malondialdehyde (MDA). These biomarkers were found to be higher in IPF patients when compared to healthy controls (Jack et al., 1996; Rahman et al., 1999). Jack et al. (1996) also found a significant negative correlation between the changes in lipid peroxidation and the changes in $\mathrm{VC}(\%)$. Isoprostanes are free radical-catalyzed prostaglandin isomers whose generation reflects lipid peroxidation in vivo and, thus, are biomarkers of oxidative stress (Lawson et al., 1999). Concentrations of isoprostanes, especially 8-isoprostane, have been found to be higher in IPF patients compared to controls (Psathakis et al., 2006; Jackson et al., 2010; Chow et al., 2012; Malli et al., 2013; Shimizu et al., 2014). In addition, carbonyl proteins serve as markers of oxidized proteins and concentrations have been found to be higher in IPF patients than in healthy in controls (Lenz et al., 1996; Lenz et al., 2004; Rottoli et al., 2005; Bargagli et al., 2007). 
TABLE 2 | Summary of the oxidative stress biomarkers analysed in different biological specimens of IPF patients.

\begin{tabular}{|c|c|c|c|c|}
\hline Specimen & Comparison (n) & Biomarker & $\begin{array}{l}\text { Lung function/severity disease } \\
\text { correlation }\end{array}$ & Reference \\
\hline ELF & IPF (15) vs. Ctrl (19) & $\begin{array}{l}\downarrow t G S H \\
\leftrightarrow \mathrm{GSH} / \mathrm{GSH}+\mathrm{GSSG}\end{array}$ & No correlation & Cantin et al. (1989) \\
\hline ELF & IPF (10) vs. Ctrl (19) & $\begin{array}{l}\downarrow \mathrm{tGSH} \\
\downarrow \mathrm{GSH}\end{array}$ & $\mathrm{N} / \mathrm{A}$ & Borok et al. (1991) \\
\hline $\begin{array}{l}\text { ELF } \\
\text { BALF }\end{array}$ & IPF (17) vs. Ctrl (14) & $\begin{array}{l}\downarrow \mathrm{tGSH} \\
\leftrightarrow \mathrm{tGSH}\end{array}$ & No correlation & Meyer et al. (1994) \\
\hline BALF & IPF (12) vs. Ctrl (31) & $\begin{array}{l}\downarrow \mathrm{GSH} \\
\leftrightarrow \mathrm{GSSG} \\
\downarrow \mathrm{GSH} / \mathrm{GSSG}\end{array}$ & $\mathrm{N} / \mathrm{A}$ & Rahman et al. (1999) \\
\hline $\begin{array}{l}\text { Sputum } \\
\text { Plasma }\end{array}$ & IPF (16) vs. Ctrl (15) & $\downarrow$ tGSH & $\begin{array}{l}\uparrow \text { disease severity } \\
\downarrow V C\end{array}$ & Beeh et al. (2002) \\
\hline BALF & IPF (16) vs. Ctrl (20) & $\begin{array}{l}\leftrightarrow \text { GSH } \\
\uparrow G S S G\end{array}$ & No correlation & Markart et al. (2009) \\
\hline Blood & IPF (22) vs. Ctrl (29) & $\begin{array}{l}\downarrow t G S H \\
\downarrow t G S H / G S S G \\
\uparrow G S S G\end{array}$ & $\begin{array}{l}\text { No correlation } \\
\text { ŁFVC }\end{array}$ & Muramatsu et al. (2016) \\
\hline Blood & IPF (11) vs. Ctrl (9) & $\begin{array}{l}\downarrow \mathrm{GSH} \\
\leftrightarrow \mathrm{GSSG}\end{array}$ & $\mathrm{N} / \mathrm{A}$ & Veith et al. (2017) \\
\hline Serum & IPF (37) vs. Ctrl (6) & 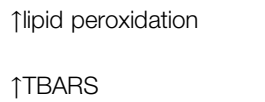 & $\begin{array}{l}\uparrow \text { disease severity } \\
\downarrow V C \\
\text { No correlation }\end{array}$ & Jack et al. (1996) \\
\hline $\begin{array}{l}\text { Plasma } \\
\text { BALF }\end{array}$ & IPF (12) vs. Ctrl (31) & $\begin{array}{l}\uparrow M D A \\
\downarrow T E A C\end{array}$ & $\mathrm{~N} / \mathrm{A}$ & Rahman et al. (1999) \\
\hline BALF & IPF non-smokers (14) vs Ctrl non-smokers (9) & $\uparrow$ Carbonyl proteins & N/A & Lenz et al. (1996) \\
\hline BALF & IPF (9) vs. Ctrl (5) & $\uparrow$ Carbonyl proteins & $\mathrm{N} / \mathrm{A}$ & Lenz et al. (2004) \\
\hline BALF & IPF (13) vs. Ctrl (5) & $\uparrow$ Carbonyl proteins & $\mathrm{N} / \mathrm{A}$ & Rottoli et al. (2005) \\
\hline BALF & IPF (15) vs. Ctrl (8) & $\uparrow$ Carbonyl proteins & $\mathrm{N} / \mathrm{A}$ & Bargagli et al. (2007) \\
\hline EBC & IPF (16) vs. Ctrl (15) & $\begin{array}{l}\uparrow 8 \text {-isoprostane } \\
\uparrow \mathrm{H}_{2} \mathrm{O}_{2}\end{array}$ & $\begin{array}{l}\text { No correlation } \\
\downarrow \text { DLCO }\end{array}$ & Psathakis et al. (2006) \\
\hline Plasma and urine & $\begin{array}{l}\text { IPF (29) vs. Ctrl (6) } \\
\text { IPF at rest (29) vs. IPF after physical exercise }\end{array}$ & $\begin{array}{l}\uparrow P l \text {-isoprostanes } \\
\leftrightarrow \text { Ur- } \mathrm{H}_{2} \mathrm{O}_{2} \\
\leftrightarrow \mathrm{Pl} \text {-isoprostanes } \\
\downarrow \text { PI-TAC } \\
\uparrow U r \text {-isoprostanes } \\
\leftrightarrow U r-\mathrm{H}_{2} \mathrm{O}_{2}\end{array}$ & $\mathrm{~N} / \mathrm{A}$ & Jackson et al. (2010) \\
\hline EBC & IPF (20) vs. Ctrl (20) & $\begin{array}{l}\uparrow 8 \text {-isoprostane } \\
\leftrightarrow \mathrm{NOx} \\
\leftrightarrow \mathrm{H}_{2} \mathrm{O}_{2} \\
\uparrow 3-\mathrm{NT}\end{array}$ & $\begin{array}{l}\text { No correlation } \\
\downarrow \text { FVE1, \FVC, \VC, \TLC }\end{array}$ & Chow et al. (2012) \\
\hline Serum and BALF & IPF (16) vs. Ctrl (17) & $\uparrow 8$-isoprostane & $\mathrm{N} / \mathrm{A}$ & Malli et al. (2013) \\
\hline EBC & IPF (6) vs. Ctrl (6) & $\uparrow 8$-isoPGF2 $a$ & $\mathrm{~N} / \mathrm{A}$ & Shimizu et al. (2014) \\
\hline Plasma & IPF (21) vs. Ctrl (12) & 个hydroperoxides & $\begin{array}{l}\uparrow \text { dyspnea severity } \\
\downarrow \text { FVC } \downarrow \text { DLCO }\end{array}$ & Daniil et al. (2006) \\
\hline Serum & IPF (43) vs. Ctrl (30) & 个hydroperoxides & $\begin{array}{l}\downarrow F V C \downarrow D L C O \\
\text { †acute exacerbation }\end{array}$ & Matsuzawa et al. (2015) \\
\hline BALF & IPF (16) vs. Ctrl (20) & 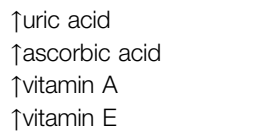 & $\mathrm{N} / \mathrm{A}$ & Markart et al. (2009) \\
\hline Blood & IPF (11) vs. Ctrl (9) & $\begin{array}{l}\text { \uric acid (not sig) } \\
\downarrow \text { ascorbic acid (not sig) } \\
\downarrow \text { TEAC }\end{array}$ & $\mathrm{N} / \mathrm{A}$ & Veith et al. (2017) \\
\hline Lung tissue & $\begin{array}{l}\text { IPF (10) vs. Ctrl (5) } \\
\text { IPF fibrotic areas vs IPF normal areas }\end{array}$ & $\begin{array}{l}\leftrightarrow E C S O D \\
\downarrow E C S O D\end{array}$ & N/A & Kinnula et al., 2006 \\
\hline Lung tissue & IPF (10) vs. Ctrl (310) & $\leftrightarrow$ Prxll & N/A & Vuorinen et al. (2008) \\
\hline Lung tissue & $\begin{array}{l}\text { IPF (7) vs. Ctrl (7) } \\
\text { IPF hyperplastic epithelium vs IPF normal epithelium }\end{array}$ & $\begin{array}{l}\leftrightarrow \text { NRF2 } \\
\uparrow S R X 1 \\
\uparrow N R F 2 \\
\uparrow K E A P 1\end{array}$ & N/A & Mazur et al. (2010) \\
\hline
\end{tabular}

3-NT, 3-nitrotyrosine; BALF, bronchoalveolar lavage fluid; Ctrl, control; DLCO, diffusing capacity of the lungs for carbon monoxide; EBC, expired breath condensate; ECSOD, Extracellular Superoxide Dismutase; ELF, epithelial lining fluid; FEV, forced expiratory volume; FVC, forced vital capacity; GSH, glutathione; GSSG, oxidized glutathione; IPF, idiopathic pulmonary fibrosis; KEAP1, Kelch likeECH-associated protein 1; MDA, malondialdehyde; NA, not available; not sig, not significative; NOx, NADPH, oxidases; NRF2, nuclear factor erythroid 2-related factor 2; Pl, plasma; Prxll, peroxiredoxin Il; SRX1, sulfiredoxin-1; TAC, total antioxidant capacity; TBARS, thiobarbituric acid reactive substances; TEAC, trolox equivalent antioxidant capacity; tGSH, total glutathione; Ur, urine. 
Some studies have also measured the levels of $\mathrm{H}_{2} \mathrm{O}_{2}$ and in some cases, concentrations of this marker are higher in IPF patients, and a negative correlation between $\mathrm{H}_{2} \mathrm{O}_{2}$ and diffusing capacity of the lungs for carbon monoxide (DLCO) was observed (Psathakis et al., 2006). Other studies, on the other hand, reported no differences between groups (Jackson et al., 2010; Chow et al., 2012).

Hydroperoxide measurements, though are less common, are also used as oxidative stress biomarkers. Concentrations of these biomarkers are significantly higher in IPF patients than in controls. It has also been found a significant positive correlation between concentrations of hydroperoxides and severity of dyspnea or acute exacerbation and a negative correlation between the concentrations of hydroperoxides, FVC, and DLCO (Daniil et al., 2006; Matsuzawa et al., 2015).

Small-molecular-weight antioxidant molecules play a significant role in lung antioxidant defences. These small molecules include GSH, as we have mentioned above, but also other molecules such as vitamins and acid uric, which are also used as oxidative stress biomarkers. A study performed by Markart et al. (2009) reported significantly higher levels of uric acid, ascorbic acid (vitamin $\mathrm{C}$ ), retinol (vitamin A), and tocopherol (vitamin E) in IPF patients when compared to healthy controls. However, a more recent study has reported that concentrations of uric acid and vitamin $\mathrm{C}$ were slightly, but not significantly, lower in IPF patients than in controls (Veith et al., 2017).

The antioxidant capacity can be also measured as an oxidative stress biomarker and, in some studies, it has been found to be significantly lower in IPF patients (Rahman et al., 1999; Jackson et al., 2010; Veith et al., 2017). Another molecule useful in oxidative stress measurements is 3-nitrotyrosine (3-NT) and it has been found to be higher in IPF patients compared to controls. Additionally, it is reported that there is an inverse correlation between 3-NT concentrations and forced expiratory volume (FEV1) (\%), FVC (\%), VC (\%), and total lung capacity (TLC, \%) (Chow et al., 2012).

When the biological specimen used is lung tissue, the studied oxidative stress biomarker is usually the expression of proteins or transcription factors implicated in different antioxidant pathways, such as the antioxidant enzyme SOD or the transcription factor Nrf2. ECSOD expression was found to be significantly lower in fibrotic areas when compared to nonfibrotic areas (Kinnula et al., 2006). Furthermore, regarding the antioxidant enzyme peroxiredoxin (PRX) II, it was found that there was no major Prx II oxidation in IPF lungs compared with the normal lung (Vuorinen et al., 2008). On the other hand, Mazur et al. (2010) analysed the Nrf2 -sulfiredoxin-1 (SRX1) pathway. The authors found non-specific cell variability in the expression of the Nrf2 pathway in healthy and fibrotic lungs. By contrast, the expression of SRX1 was increased in IPF compared to controls. Furthermore, the morphometric evaluation revealed that Nrf2 and KEAP1 were significantly increased in the hyperplastic alveolar epithelium compared to the normal alveolar epithelium (Mazur et al., 2010).

A huge number of oxidative stress biomarkers have been described in patients with IPF. Here we have just highlighted the most commonly analysed. The evaluation of these biomarkers could help in the clinical assessment of patients with IPF.

\section{ANTIOXIDANT THERAPY IN IDIOPATHIC PULMONARY FIBROSIS}

Considering oxidative stress plays a central role in the development and progression of IPF, antioxidant therapies have been proposed for many years. There are a few publications that review the use of antioxidant molecules or NOX inhibitors, naturals and synthetics, as potential therapeutics for lung fibrosis (Kinnula et al., 2005; Day, 2008; Kato and Hecker, 2020; Wang et al., 2021). In this review, we have selected the most advanced studies that include in vitro, in vivo and human evidence that could be translated into future treatments of IPF Summarized in Table 3.

\subsection{NOX Inhibitors}

\subsubsection{Diphenyleneiodonium}

Diphenyleneiodonium (DPI) is a potent inhibitor of NOX, which specifically and irreversibly binds to flavin, the membranous component of the NOX. It is the most commonly used and well-studied Nox inhibitor; however, its irreversible binding, lack of specific, poor solubility and toxicity in vivo do not make it the suitable candidate for a therapeutic option (O'Donnell et al., 1993; Kato and Hecker, 2020) (Figure 1).

Even so, DPI has been reported to inhibit collagen type I deposition and proliferation of pulmonary cells after stimulation with IPF sera (Fois et al., 2018). Another study has demonstrated that DPI decreases MPO activity, iNOS expression, intracellular ROS levels, the number of inflammatory cells, and cytokines TNF- $\alpha$ and IL-6 in lipopolysaccharide (LPS)-induced acute lung injury rats (Kim et al., 2019).

\subsubsection{VAS2870}

Vas2870 was first described as a Nox2 inhibitor but later was described as a pan-NADPH oxidase inhibitor, with no selectivity for any NOX isoform (Wingler et al., 2012). It has been used in different cell models, but it has shown off-target effects due to its unspecific redox mode of action (Kato and Hecker, 2020). However, VAS2870 has been proved to reduce ROS generation restore epithelium barrier integrity and preserve cell viability in LPS-induced injury in alveolar epithelial cells (Li et al., 2020). It has also been reported to protect human pulmonary microvascular endothelial cells against LPS-induced inflammation through inhibiting the generation of ROS ( $\mathrm{Li}$ et al., 2020); to inhibit phenotypic changes in fibrotic cells, including $\alpha$-SMA and vimentin expression (Choi et al., 2016); and to suppress growth factor-mediated ROS liberation and migration in VSMC (ten Freyhaus et al., 2006) (Figure 1).

\subsubsection{GKT137831 and GKT136901}

GKT137831 and GKT136901 were developed by Genkyotex (Geneva, Switzerland) through a high-throughput screening approach to discover small-molecule inhibitors targeting NOX enzymes (Laleu et al., 2010). Both small molecules are Nox4/ 
TABLE 3 | Summary of potential therapeutic antioxidants for IPF reviewed in this study.

\begin{tabular}{|c|c|c|c|c|}
\hline Drug & Class & $\begin{array}{l}\text { Mechanism of } \\
\text { action }\end{array}$ & $\begin{array}{c}\text { Clinical } \\
\text { trial identifier NCT }\end{array}$ & Reference \\
\hline DPI & NOX inhibitor & Pan-NOXs inhibitor & & O’Donnell et al. (1993); Kato and Hecker. (2020) \\
\hline Vas2870 & NOX inhibitor & Pan-NOXs inhibitor & & Kato and Hecker, (2020) \\
\hline GKT137831 & NOX inhibitor & $\begin{array}{l}\text { NOX } 4 / \text { NOX1 dual } \\
\text { inhibitor }\end{array}$ & NCT03865927 & Gaggini et al. (2011) \\
\hline GKT136901 & NOX inhibitor & $\begin{array}{l}\text { NOX4/NOX1 dual } \\
\text { inhibitors }\end{array}$ & & Gaggini et al. (2011) \\
\hline Apocynin & NOX inhibitor & $\begin{array}{l}\text { NOX2 inhibitor } \\
\text { ROS scavenger }\end{array}$ & & Heumüller et al. (2008); Augsburger et al. (2019) \\
\hline Metformin & $\begin{array}{l}\text { NOX inhibitor } \\
\text { Anti-diabetic }\end{array}$ & NOX4 inhibitor & & Sato et al. (2016); Rangarajan et al. (2018) \\
\hline NAC & $\begin{array}{l}\text { Antioxidant } \\
\text { enhancer }\end{array}$ & $\begin{array}{l}\text { ROS scavenger } \\
\text { GSH precursor } \\
---\mid \text { NFkB } \\
\uparrow \text { Nrf2 }\end{array}$ & $\begin{array}{l}\text { NCT00639496 } \\
\text { NCT00650091 } \\
\text { UMIN000015508 } \\
\text { NCT02707640 } \\
\text { NCT04300920 } \\
\text { NCT03720483 }\end{array}$ & $\begin{array}{l}\text { Watchorn et al. (1998); Parmentier et al. (1999); Cuzzocrea et al. } \\
\text { (2001); Sugiura et al. (2009); Ji et al. (2010) }\end{array}$ \\
\hline Quercetin & $\begin{array}{l}\text { Antioxidant } \\
\text { enhancer } \\
\text { Senolytic }\end{array}$ & $\begin{array}{l}\text { ROS scavenger } \\
\uparrow \mathrm{Nrf2}\end{array}$ & NCT02874989 & $\begin{array}{l}\text { Tanigawa et al. (2007); Veith et al. (2017); Cazzola et al. (2018); } \\
\text { Sellarés and Rojas. (2019) }\end{array}$ \\
\hline Salvianolic acid B & $\begin{array}{l}\text { Antioxidant } \\
\text { enhancer }\end{array}$ & $\begin{array}{l}\text { ROS scavenger } \\
\uparrow \text { Nrf2 } \\
---\mid \text { NOX2,4 }\end{array}$ & NCT03274544 & Xiao et al. (2020) \\
\hline EGCG & $\begin{array}{l}\text { Antioxidant } \\
\text { enhancer }\end{array}$ & $\begin{array}{l}\text { ROS scavenger } \\
\uparrow \text { Nrf2 } \\
\text { \nflammatory } \\
\text { mediators } \\
\downarrow \text { Lipid peroxidation }\end{array}$ & NCT03928847 & $\begin{array}{l}\text { Salah et al. (1995); Nanjo et al. (1999); Nagai et al. (2002a); } \\
\text { Negishi et al. (2004); Zhang et al. (2007a); Sriram et al. (2009a) }\end{array}$ \\
\hline $\begin{array}{l}\text { Tanshinone IIA and Sodium } \\
\text { tanshinone IIA sulfonate }\end{array}$ & $\begin{array}{l}\text { Antioxidant } \\
\text { enhancer }\end{array}$ & $\begin{array}{l}\text { ROS scavenger } \\
\uparrow \mathrm{Nrf2} \\
\uparrow \mathrm{GSH} \\
---\mid \mathrm{NOX} 4\end{array}$ & & Zhang and Wang. (2007); An et al. (2019) \\
\hline Resveratrol & $\begin{array}{l}\text { Antioxidant } \\
\text { enhancer }\end{array}$ & $\begin{array}{l}\text { ROS scavenger } \uparrow \\
\text { Nrf2 }\end{array}$ & & Zhu et al. (2017) \\
\hline Sulforaphane & $\begin{array}{l}\text { Antioxidant } \\
\text { enhancer }\end{array}$ & $\uparrow \mathrm{Nrf2}$ & & Elbarbry and Elrody. (2011); Kim and Park. (2016) \\
\hline Melatonin & $\begin{array}{l}\text { Antioxidant } \\
\text { enhancer }\end{array}$ & $\begin{array}{l}\text { ROS scavenger } \\
\uparrow \text { Nrf2 } \\
\downarrow \text { Inflammatory } \\
\text { mediators }\end{array}$ & & $\begin{array}{l}\text { Swiderska-Kołacz et al. (2006); Reiter et al. (2007); } \\
\text { Santofimia-Castaño et al. (2015); Goc et al. (2017) }\end{array}$ \\
\hline Curcumin & $\begin{array}{l}\text { Antioxidant } \\
\text { enhancer }\end{array}$ & $\begin{array}{l}\text { ROS scavenger } \\
\uparrow \text { Nrf2 } \\
\uparrow \text { Antioxidant } \\
\text { molecules }\end{array}$ & & Lee et al. (2010b); Zhou et al. (2011); Lelli et al. (2017) \\
\hline Pirfenidone & $\begin{array}{l}\text { Antifibrotic } \\
\text { Antioxidant } \\
\text { enhancer }\end{array}$ & $\begin{array}{l}\text { ROS scavenger } \\
\uparrow \text { Nrf2 } \\
\uparrow \text { Antioxidant } \\
\text { molecules } \\
\downarrow \text { Lipid peroxidation } \\
\downarrow \text { Inflammatory } \\
\text { mediators }\end{array}$ & $\begin{array}{l}\text { NCT00287716 } \\
\text { NCT00287729 } \\
\text { NCT01366209 }\end{array}$ & $\begin{array}{l}\text { Giri et al. (1999); Misra and Rabideau. (2000); Nakazato et al. } \\
\text { (2002); Oku et al. (2008); Ma et al. (2021) }\end{array}$ \\
\hline Thalidomide & $\begin{array}{l}\text { Antiemetic } \\
\text { Antioxidant } \\
\text { enhancer }\end{array}$ & $\begin{array}{l}\uparrow \text { Antioxidant } \\
\text { molecules }\end{array}$ & $\begin{array}{l}\text { NCT00162760 } \\
\text { NCT00600028 }\end{array}$ & Amirshahrokhi. (2013); Dong et al. (2017) \\
\hline Crocin & $\begin{array}{l}\text { Antioxidant } \\
\text { enhancer }\end{array}$ & $\begin{array}{l}\uparrow \text { Nrf2 } \\
\uparrow \text { Antioxidant } \\
\text { molecules }\end{array}$ & & Zaghloul et al. (2019); Mehrabani et al. (2020) \\
\hline Isorhamnetin & $\begin{array}{l}\text { Antioxidant } \\
\text { enhancer }\end{array}$ & $\begin{array}{l}\text { ROS scavenger } \\
\uparrow \text { Nrf2 }\end{array}$ & & $\begin{array}{l}\text { Chi et al. (2016); Zheng et al. (2019); Luo et al. (2019); Ren et al. } \\
\text { (2021) }\end{array}$ \\
\hline Echinochrome A & $\begin{array}{l}\text { Antioxidant } \\
\text { enhancer }\end{array}$ & $\begin{array}{l}\uparrow \text { Antioxidant } \\
\text { molecules } \\
\downarrow \text { Inflammatory } \\
\text { mediators }\end{array}$ & & Lebed'ko et al. (2015) \\
\hline
\end{tabular}


TABLE 3 | (Continued) Summary of potential therapeutic antioxidants for IPF reviewed in this study.

\begin{tabular}{llll}
\hline Drug & \multicolumn{1}{c}{ Class } & \multicolumn{1}{c}{$\begin{array}{c}\text { Mechanism of } \\
\text { action }\end{array}$} & $\begin{array}{c}\text { Clinical } \\
\text { trial identifier NCT }\end{array}$ \\
\hline AEOL 10150 & $\begin{array}{l}\text { Catalytic } \\
\text { antioxidant } \\
\text { mimetics }\end{array}$ & $\begin{array}{l}\text { Mimics SOD } \\
\text { Mimics CAT }\end{array}$ & Rabbani et al. (2007); Garofalo et al. (2014); MacVittie et al. \\
Catalytic & Mimics SOD & (2017); Zhang et al. (2018b) \\
antioxidant 10113 & $\begin{array}{l}\text { mimetics } \\
\text { Catalytic } \\
\text { antioxidant }\end{array}$ & Mimics SOD & Oury et al. (2001); Venkatadri et al. (2002) \\
mimetics & &
\end{tabular}

CAT, catalase; DPI, Diphenyleneiodonium; EGCG, Epigallocatechin gallate; NAC, n-acetyl cysteine; NFk $\beta$, nuclear factor kappa beta; NOX, NADPH, oxidase; NRF2, nuclear factor erythroid 2-related factor 2; ROS, reactive oxygen species; SOD, superoxide dismutase.

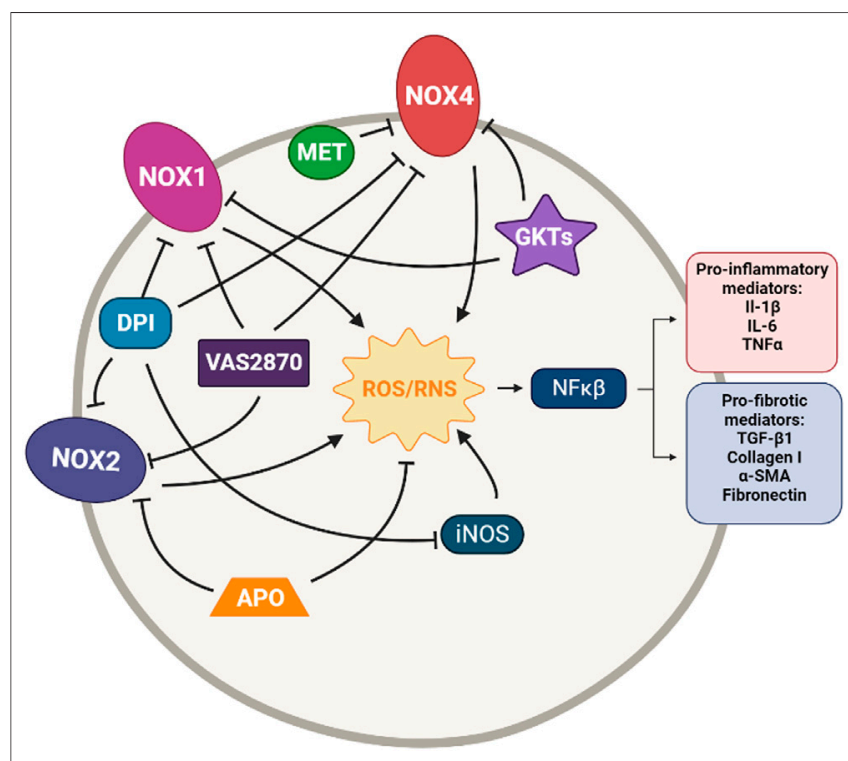

FIGURE 1 | Simplified diagram of the principal molecular mechanisms of the NOX inhibitors Diphenyleneiodonium (DPI), VAS2870, GKT137831 and GKT136901 (GKTs), Apocynin (APO) and Metformin (MET). aSMA: alpha smooth muscle actin; IL-1 $\beta$ : interleuquina 1beta; IL-6: interleuquina 6; iNOS: inducible nitrogen oxide synthase; $N F \kappa \beta$ : nuclear factor kappa beta; NOX1,2,4: NADPH oxidases; ROS/RNS: reactive oxygen species/reactive nitrogen species; TGF- $\beta 1$ : transforming growth factor beta 1; TNF $\alpha$ : tumoral necrosis factor alpha Created with Biorender.com.

Nox1 dual inhibitors. GKT137831 has been demonstrated to have strong antifibrotic activity at a low dose with much better efficacy than pirfenidone in curative model of bleomycin-induced pulmonary fibrosis in mice, as it is reported by the company (Gaggini et al., 2011). These Genkyotex compounds have also been reported to have protective effects in different pre-clinical in vitro and in vivo studies (Carnesecchi et al., 2011; Green et al., 2012; Jiang et al., 2012; Wan et al., 2016; Tanaka et al., 2017; Cui et al., 2018) (Figure 1).

In 2010, GKT137831 was granted orphan drug status for the treatment of IPF by the European Commission and is currently in clinical trials for IPF. A phase 2 clinical trial of GKT137831
[GKT137831 in IPF Patients With Idiopathic Pulmonary Fibrosis (GKT137831)] has recently started and it is a placebo-controlled, multicentre, randomized trial to test GKT137831 in ambulatory patients with IPF. The primary outcome is the reduction of the circulating concentrations of o,o'-dityrosine, an oxidative stress biomarker. Changes in concentrations of the collagen degradation and FVC are some of the secondary outcomes (ClinicalTrials.gov Identifier: NCT03865927).

\subsubsection{Other NOX Inhibitors}

Some other molecules are also claimed to be NOX inhibitors. It is the case of apocynin, a natural organic compound obtained from plants, that was found to have therapeutic effects in animal models of various diseases (Virdis et al., 2016). In particular, it shows a protective and therapeutic effect on bleomycin-induced lung fibrosis in rats (Kilic et al., 2015). However, although this compound is usually defined as a Nox 2 inhibitor, several studies have reported that apocynin would have intrinsic antioxidant properties rather than be a Nox inhibitor (Heumüller et al., 2008; Augsburger et al., 2019). On the other hand, we have metformin, an anti-diabetic drug not known primarily for its antioxidant potential, but a recent study has demonstrated that treatment with metformin inhibits TGF- $\beta 1$-induced Nox4 expression, ROS generation and myofibroblast differentiation in lung fibroblasts in vitro and also attenuates bleomycin-induced lung fibrosis (Sato et al., 2016; Rangarajan et al., 2018). Despite the lack of clinical trials regarding the efficacy of metformin in the treatment of IPF, there is a retrospective study in humans treated with pirfenidone along with metformin; however, its results are not particularly promising (Spagnolo et al., 2018). Only future trials could provide more clues about this (Figure 1).

On the other hand, numerous groups are currently working on the finding or development of new NOX inhibitors that may become a therapeutic option in treating IPF.

\subsection{Antioxidant Enhancers and Reactive Oxygen Species Scavenger}

\subsubsection{N-Acetyl Cysteine}

$\mathrm{N}$-acetyl cysteine (NAC) is an L-cysteine derived aminoacid with powerful reductive capacity. This aminothiol is not only a GSH 


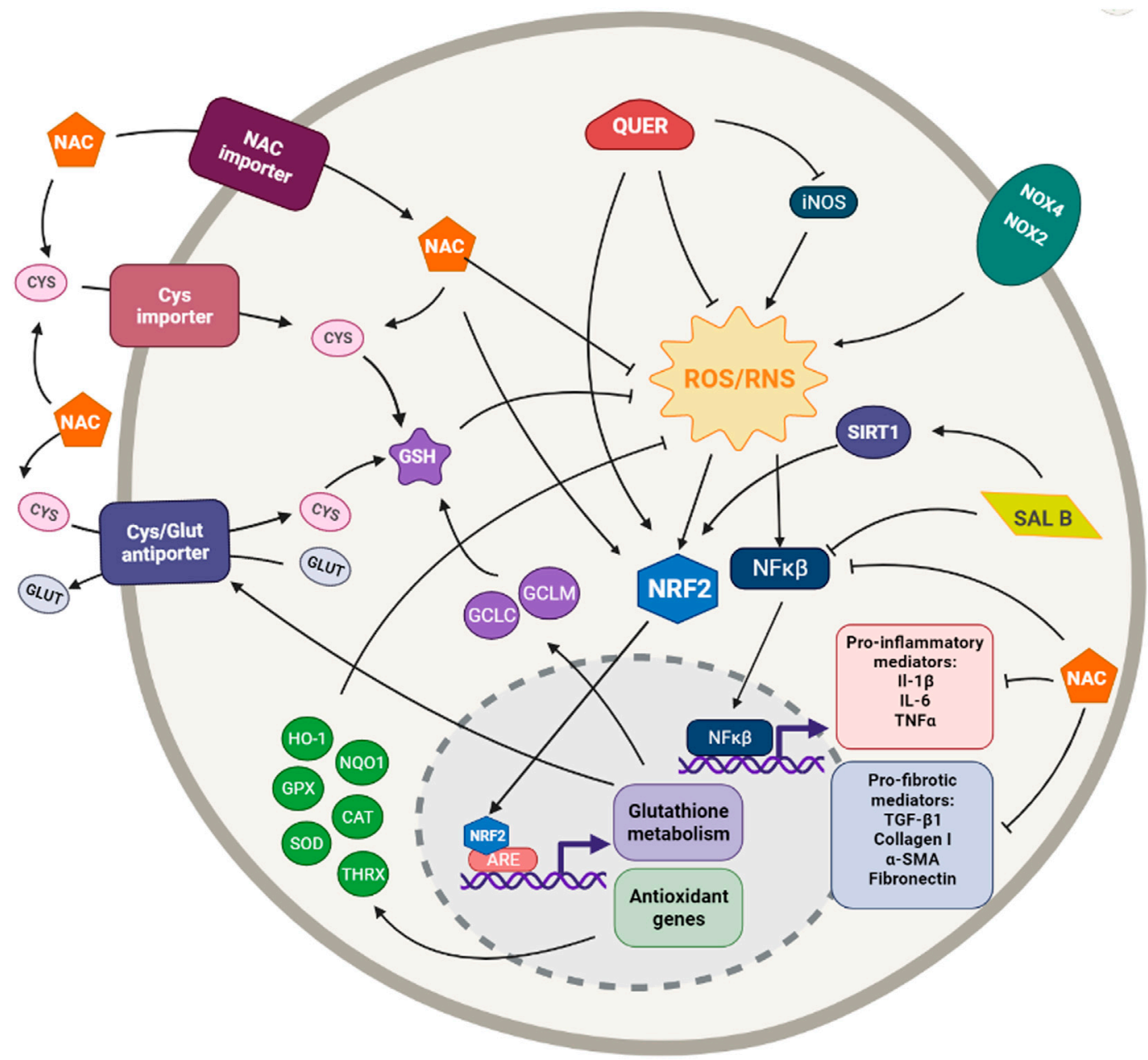

FIGURE 2|Simplified diagram of the principal molecular mechanisms of the antioxidant enhancers n-acetyl cysteine (NAC), Quercetin (QUER) and Salvianolic acid B (SAL B). aSMA: alpha smooth muscle actin; ARE: antioxidant responsive element; CAT: catalase; CYS: cysteine; GCLC: glutamate cysteine ligase catalytic subunit; GCLM: glutamate cysteine ligase modifier subunit; GLUT: glutamate; GPX: glutathione peroxidase; GSH: glutathione; HO-1: heme oxygenase 1; IL-1 $\beta$ : interleuquina 1beta; IL-6: interleuquina 6; iNOS: inducible nitrogen oxide synthase; NFk 3 : nuclear factor kappa beta; NOX1,2,4: NADPH oxidases; NQO1: NAD(P)H:quinone oxidoreductase 1; NRF2: nuclear factor erythroid 2-related factor 2; ROS/RNS: reactive oxygen species/reactive nitrogen species; TGF- $\beta 1$ : transforming growth factor beta 1; TNFa: tumoral necrosis factor alpha; SIRT: sirtuine 1; SOD: supeoxide dismutase Created with Biorender.com.

precursor but also presents a direct ROS-scavenging capacity and may induce Nrf2 expression (Cuzzocrea et al., 2001; Sugiura et al., 2009; Ji et al., 2010). These properties have made NAC a broadly used potent antioxidant (Figure 2).

\subsubsection{In vitro Cellular Studies}

Several in vitro assays have demonstrated that NAC prevents GSH depletion in various cell types such as macrophages, epithelial cells, and fibroblasts (Watchorn et al., 1998; Parmentier et al., 1999; Liu et al., 2004; Felton et al., 2009). NAC has also been reported to inhibit collagen production and EMT in TGF- $\beta 1$-stimulated murine embryo fibroblasts and rat alveolar epithelial cells, respectively (Liu et al., 2004; Felton et al., 2009). A further study found that NAC significantly diminishes TGF- $\beta 1$-induced fibronectin and VEGF production as well as $\alpha$ SMA expression in human lung fibroblasts (Sugiura et al., 2009).
These studies implied that NAC may affect the TGF- $\beta 1$-induced tissue remodelling or fibrotic process in vitro.

Numerous studies have demonstrated that NAC inhibits the production of different inflammatory mediators such as tumour necrosis factor alpha (TFNa), interleukin-8 (IL-8) and matrix metalloproteinase-9 (MMP-9) in epithelial cells, macrophages, and lymphocytes from patients with IPF (Watchorn et al., 1998; Parmentier et al., 1999; Cu et al., 2009; Radomska-Leśniewska et al., 2010).

\subsubsection{In vivo Animal Studies}

The first study that demonstrated the antifibrotic effect of NAC was performed by Shahzeidi et al. (1991). They showed that NAC inhibits collagen accumulation in lungs from rats with bleomycin-induced lung fibrosis (Shahzeidi et al., 1991). Since then, several studies have reported that NAC inhibits several 
TABLE 4 | Summary of clinical trials of antioxidant therapies of IPF.

\begin{tabular}{|c|c|c|c|c|c|c|}
\hline Drugs & $\begin{array}{l}\text { Identifier } \\
\text { (acronym) }\end{array}$ & $\begin{array}{l}\text { Study desing, } \\
\text { sample size }\end{array}$ & Primary endpoint & Secondary endpoints & Outcome & Observations \\
\hline $\begin{array}{l}\text { GKT137831 (400 mg } \\
\text { b.i.d) Vs.Placebo }\end{array}$ & NCT03865927 & $\begin{array}{l}\text { Phase } 2 \\
\text { Randomized } \\
\text { Double-Blind } \\
\text { Parallel } \\
\text { Assignment } \\
\text { Placebo- } \\
\text { Controlled } n=60\end{array}$ & $\begin{array}{l}\text { Changes in } \\
\text { concentrations of } \\
\text { circulating o,o'- } \\
\text { dityrosine at } 24 \text { weeks }\end{array}$ & $\begin{array}{l}\text { Changes in } \\
\text { concentrations of the } \\
\text { collagen degradation } \\
\text { product } \\
\text { FVC, } 6 \mathrm{MWD} \text { at } 24 \text { weeks }\end{array}$ & Recruiting & \\
\hline $\begin{array}{l}\text { NAC (oral } 600 \text { mg } \\
\text { t.i.d) + prednisone + } \\
\text { azathioprine Vs. } \\
\text { Placebo + } \\
\text { prednisone + } \\
\text { azathioprine }\end{array}$ & $\begin{array}{l}\text { NCT00639496 } \\
(\text { IFIGENIA) }\end{array}$ & $\begin{array}{l}\text { Phase } 3 \\
\text { Randomized } \\
\text { Double-Blind } \\
\text { Parallel } \\
\text { Assignment } \\
\text { Placebo- } \\
\text { Controlled } n=184\end{array}$ & $\begin{array}{l}\text { Changes in VC and } \\
\text { DLCO at } 6 \text { and } \\
12 \text { months }\end{array}$ & $\begin{array}{l}\text { CRP-score at } 6 \text { and } \\
12 \text { months }\end{array}$ & $\begin{array}{l}\text { Completed. Three- } \\
\text { drug therapy } \\
\text { preserved VC and } \\
\text { DLCO }\end{array}$ & \\
\hline $\begin{array}{l}\text { NAC (oral } 600 \text { mg } \\
\text { t.i.d) + prednisolone + } \\
\text { azathioprine Vs. NAC } \\
\text { (oral } 600 \text { mg t.i.d) + } \\
\text { placebo Vs. placebo }\end{array}$ & $\begin{array}{l}\text { NCT00650091 } \\
\text { (PANTHER) }\end{array}$ & $\begin{array}{l}\text { Phase } 3 \\
\text { Randomized } \\
\text { Double-Blind } \\
\text { Parallel } \\
\text { Assignment } \\
\text { Placebo- } \\
\text { Controlled } n=264\end{array}$ & $\begin{array}{l}\text { Changes in FVC at } \\
60 \text { weeks }\end{array}$ & $\begin{array}{l}\text { The time-to-death or a } \\
10 \% \text { decline in FVC, } \\
\text { acute exacerbations, } \\
\text { respiratory infections at } \\
60 \text { weeks }\end{array}$ & $\begin{array}{l}\text { Completed. NAC } \\
\text { offered no significant } \\
\text { benefit }\end{array}$ & $\begin{array}{l}\text { Three-drug regimen } \\
\text { was stopped due to } \\
\text { safety concerns }\end{array}$ \\
\hline $\begin{array}{l}\text { NAC (inhaled } \\
352.4 \text { mg b.i.d) + } \\
\text { pirfenidone Vs. } \\
\text { placebo + pirfenidone }\end{array}$ & UMIN000015508 & $\begin{array}{l}\text { Phase } 3 \\
\text { Randomized } \\
\text { Open-label } \\
\text { Parallel } \\
\text { Assignment } \\
\text { Placebo- } \\
\text { Controlled } n=150\end{array}$ & $\begin{array}{l}\text { Changes in FVC at } \\
48 \text { weeks }\end{array}$ & $\begin{array}{l}\text { Changes in } 6 \mathrm{MWD} \text {, VC, } \\
\text { TLC, DLCO at } 48 \text { weeks }\end{array}$ & $\begin{array}{l}\text { Completed. } \\
\text { Combination therapy } \\
\text { did not bring any } \\
\text { clinical benefit }\end{array}$ & \\
\hline $\begin{array}{l}\text { NAC (oral } 600 \text { mg } \\
\text { t.i.d) + pirfenidone Vs. } \\
\text { Placebo + pirfenidone }\end{array}$ & $\begin{array}{l}\text { NCT02707640 } \\
\text { (PANORAMA) }\end{array}$ & $\begin{array}{l}\text { Phase } 2 \\
\text { Randomized } \\
\text { Double-Blind } \\
\text { Parallel } \\
\text { Assignment } \\
\text { Placebo- } \\
\text { Controlled } n=123\end{array}$ & $\begin{array}{l}\text { Assessment of adverse } \\
\text { events at } 24 \text { weeks }\end{array}$ & $\begin{array}{l}\text { Changes in FVC, DLCO, } \\
6 \mathrm{MWD} \text { at } 24 \text { weeks }\end{array}$ & $\begin{array}{l}\text { Completed. NAC } \\
\text { does not alter } \\
\text { tolerability profile of } \\
\text { pirfenidone and is } \\
\text { unlikely to be } \\
\text { beneficial }\end{array}$ & \\
\hline $\begin{array}{l}\text { NAC (oral } 600 \text { mg } \\
\text { t.i.d) Vs. Placebo }\end{array}$ & $\begin{array}{l}\text { NCT04300920 } \\
\text { (PRECISIONS) }\end{array}$ & $\begin{array}{l}\text { Phase } 3 \\
\text { Randomized } \\
\text { Double-Blind } \\
\text { Parallel } \\
\text { Assignment } \\
\text { Placebo- } \\
\text { Controlled } n=200\end{array}$ & $\begin{array}{l}10 \% \text { relative decline } \\
\text { FVC, first respiratory } \\
\text { hospitalization, lung } \\
\text { transplant or death from } \\
\text { any cause at } 24 \text { months }\end{array}$ & $\begin{array}{l}\text { Time to first all-cause } \\
\text { hospitalization, } \\
\text { annualized rate of } \\
\text { respiratory } \\
\text { hospitalizations, changes } \\
\text { in DLCO at } 24 \text { months }\end{array}$ & Recruiting & \\
\hline $\begin{array}{l}\text { NAC (inhaled) Vs. } \\
\text { placebo }\end{array}$ & NCT03720483 & $\begin{array}{l}\text { Phase 1/2 } \\
\text { Randomized } \\
\text { Open-label } \\
\text { Crossover } \\
\text { Assignment, } n=0\end{array}$ & $\begin{array}{l}\text { Changes in FVC at week } \\
10 \text { and } 18\end{array}$ & $\begin{array}{l}\text { Changes in DLCO at } \\
\text { week } 10 \text { and } 18\end{array}$ & Withdrawn & $\begin{array}{l}\text { The study } \\
\text { encountered } \\
\text { challenges during } \\
\text { startup due to the } \\
\text { COVID-19 epidemic } \\
\text { and was withdrawn }\end{array}$ \\
\hline $\begin{array}{l}\text { Dasatinib (100 mg/d) } \\
\text { + Quercetin } \\
\text { (1250 mg/d) Vs. } \\
\text { Placebo }\end{array}$ & NCT02874989 & $\begin{array}{l}\text { Phase } 1 \\
\text { Randomized } \\
\text { Open-label } \\
\text { Parallel } \\
\text { Assignment, } \\
\text { Placebo- } \\
\text { Controlled } n=26\end{array}$ & $\begin{array}{l}\text { Retention rates and } \\
\text { completion rates for } \\
\text { planned clinical } \\
\text { assessments (e.g., } \\
\text { percentage of pro- } \\
\text { inflammatory expressing } \\
\text { cells, blood pressure, } \\
\text { weight, heart rate) at } \\
4 \text { weeks }\end{array}$ & $\begin{array}{l}\text { Safety and change in } \\
\text { functional and reported } \\
\text { health measures }\end{array}$ & $\begin{array}{l}\text { Completed. } \\
\text { Senolytics improved } \\
\text { 6MWD }\end{array}$ & \\
\hline $\begin{array}{l}\text { PROLUNG (contains } \\
\text { Salvianolic acid B) }\end{array}$ & NCT03720483 & $\begin{array}{l}\text { Open-label Single } \\
\text { Group } \\
\text { Assignment } n=6\end{array}$ & $\begin{array}{l}\text { Change in FVC at } 6 \\
\text { months }\end{array}$ & $\begin{array}{l}\text { Changes in SGRQ score, } \\
\text { SF-36 score, WHOQOL- } \\
\text { BREF score and in } \\
\text { adverse events over } \\
6 \text { months }\end{array}$ & Terminated & $\begin{array}{l}\text { Difficulty in recruiting } \\
\text { eligible patients }\end{array}$ \\
\hline
\end{tabular}


TABLE 4 | (Continued) Summary of clinical trials of antioxidant therapies of IPF.

\begin{tabular}{|c|c|c|c|c|c|c|}
\hline Drugs & $\begin{array}{l}\text { Identifier } \\
\text { (acronym) }\end{array}$ & $\begin{array}{l}\text { Study desing, } \\
\text { sample size }\end{array}$ & Primary endpoint & Secondary endpoints & Outcome & Observations \\
\hline EGCG (600 mg daily) & NCT03928847 & $\begin{array}{l}\text { Early Phase I } \\
\text { Open-label Single } \\
\text { Group } \\
\text { Assignment } n=35\end{array}$ & $\begin{array}{l}\text { LOXL2 activity and } \\
\text { TGFbeta1 signaling } \\
\text { biomarkers such as } \\
\text { Snail1 and pSmad3 at } \\
2 \text { weeks }\end{array}$ & $\begin{array}{l}\text { Maximum plasma } \\
\text { concentration of EGCG } \\
0,2,4,12 \mathrm{~h} \text { post dose } \\
\text { and adverse events at } \\
2 \text { weeks }\end{array}$ & Recruiting & \\
\hline $\begin{array}{l}\text { Pirfenidone (1197 or } \\
2403 \text { mg in divided } \\
\text { doses t.i.d) Vs. } \\
\text { placebo }\end{array}$ & $\begin{array}{l}\text { NCT00287716 } \\
\text { (CAPACITY: } \\
\text { study } 004\end{array}$ & $\begin{array}{l}\text { Phase } 3 \\
\text { Randomized } \\
\text { Double-Blind } \\
\text { Parallel } \\
\text { Assignment } \\
\text { Placebo- } \\
\text { Controlled } n=435\end{array}$ & $\begin{array}{l}\text { Changes in FVC at } \\
72 \text { weeks }\end{array}$ & $\begin{array}{l}\text { PFS, changes in 6MWD, } \\
\text { SpO2, DLCO, dyspnea } \\
\text { score and worsening of } \\
\text { IPF at } 72 \text { weeks }\end{array}$ & $\begin{array}{l}\text { Completed. } \\
\text { Improvement in lung } \\
\text { function, in PFS, and } \\
\text { in the associated } \\
\text { death }\end{array}$ & \\
\hline $\begin{array}{l}\text { Pirfenidone ( } 2403 \text { mg } \\
\text { in divided doses t.i.d) } \\
\text { Vs. placebo }\end{array}$ & $\begin{array}{l}\text { NCT00287729 } \\
\text { (CAPACITY: } \\
\text { study 006) }\end{array}$ & $\begin{array}{l}\text { Phase } 3 \\
\text { Randomized } \\
\text { Double-Blind } \\
\text { Parallel } \\
\text { Assignment } \\
\text { Placebo- } \\
\text { Controlled } n=344\end{array}$ & $\begin{array}{l}\text { Changes in FVC at } \\
72 \text { weeks }\end{array}$ & $\begin{array}{l}\text { PFS, changes in 6MWD, } \\
\text { SpO2, DLCO, dyspnea } \\
\text { score and worsening of } \\
\text { IPF at } 72 \text { weeks }\end{array}$ & $\begin{array}{l}\text { Completed. } \\
\text { Improvement in lung } \\
\text { function, in PFS, and } \\
\text { in the associated } \\
\text { death }\end{array}$ & \\
\hline $\begin{array}{l}\text { Thalidomide (400 mg } \\
\text { daily) }\end{array}$ & NCT00162760 & $\begin{array}{l}\text { Phase } 2 \text { Non- } \\
\text { Randomized } \\
\text { Open-label Single } \\
\text { Group } \\
\text { Assignment } n=19\end{array}$ & $\begin{array}{l}\text { Safety, feasibility and } \\
\text { efficacy of thalidomide } \\
\text { administered daily for } \\
1 \text { year }\end{array}$ & $\begin{array}{l}\text { changes in pulmonary } \\
\text { function tests, } \\
\text { radiographs, dyspnea } \\
\text { scales and quality of life } \\
\text { measures }\end{array}$ & $\begin{array}{l}\text { Completed. No } \\
\text { results available }\end{array}$ & \\
\hline $\begin{array}{l}\text { Thalidomide } \\
\text { (50-100 mg daily) Vs. } \\
\text { Placebo }\end{array}$ & NCT00600028 & $\begin{array}{l}\text { Phase } 3 \\
\text { Randomized } \\
\text { Double-Blind } \\
\text { Crossover } \\
\text { Assignment } \\
\text { Placebo- } \\
\text { Controlled } n=344\end{array}$ & $\begin{array}{l}\text { Suppression of cough } \\
\text { measured by the CQLQ } \\
\text { at } 6 \text { months }\end{array}$ & $\begin{array}{l}\text { Suppression of cough } \\
\text { measured by the VAS at } \\
6 \text { months }\end{array}$ & $\begin{array}{l}\text { Completed. } \\
\text { Thalidomide } \\
\text { improved cough and } \\
\text { respiratory quality of } \\
\text { life }\end{array}$ & \\
\hline
\end{tabular}

GMWD, 6-min walk distance; b.i.d, bis in die, twice a day; CQLQ, Cough Quality of Life Questionnaire; CRP -score, clinical, radiologic and physiologic score; DLCO, diffusion capacity for CO; EGCG, Epigallocatechin-3-gallate; FVC, forced vital capacity; NAC, N-acetylcysteine; PFS, progression-free survival; SF-36, 36-Item Short Form Survey; SGRQ, St. George's Respiratory Questionnaire; SpO2, oxygen saturation by pulse oximetry; t.i.d, ter in die, three times a day; TLC, total lung capacity; VAS, visual analog scale of cough; VC, vital capacity; WHOQOL-BREF, world Health Organization Quality of Life abbreviated version.

profibrotic mechanisms in bleomycin-induced fibrosis murine models (Myllärniemi and Kaarteenaho, 2015). For instance, aerosolized administration of NAC attenuated bleomycininduced lung fibrosis in mice via the decrease of the amounts of hydroxyproline, fibrosis and several cytokines' levels (Hagiwara et al., 2000). Further studies performed by our group showed that treatment with NAC, in bleomycinexposed rats, decreased the augmented collagen deposition and the inflammatory cells numbers. It also increased GSH levels and decreased MUC5a expression, fibrotic areas, TNF- $\alpha$ levels and MPO activity (Cortijo et al., 2001; Mata et al., 2003; SerranoMollar et al., 2003).

More recent animal studies on NAC using lung fibrosis murine models have been performed. In 2012, a study revealed that NAC treatment reversed lysyl oxidase activity to normal levels and increased GSH levels in the lung of bleomycininduced rats, inhibiting TGF- $\beta 1$ and $\alpha$-SMA expression, thus attenuating pulmonary fibrosis (Li et al., 2012). A posterior study demonstrated that administration of NAC-pre-treated human mesenchymal stem cells to nude mice with bleomycin-induced lung injury decreased the pathological grade of lung inflammation and fibrosis, hydroxyproline content and numbers of neutrophils and inflammatory cytokines in BALF and apoptotic cells (Wang et al., 2013). The therapeutic potential of NAC in pulmonary fibrosis was also studied in rats exposed to silica particles. It was demonstrated that NAC treated silicaexposed rats showed significantly lower fibrosis scores, as well as lower levels of hydroxyproline amounts and MDA. NAC also attenuated silica-induced increments in TNF- $\alpha$, IL-8, highsensitivity C-reactive protein and ROS content (Zhang et al., 2013; Zhang et al., 2014a).

\subsubsection{Human Clinical Trials}

In contrast to most cases of drug development, animal and human trials with NAC were conducted even earlier than in vitro ones. In vitro assays have shown, indeed, that NAC reduces fibrotic and remodelling processes in fibrosis models. Nevertheless, previously, in vivo animal trials had already suggested that NAC could be a good candidate for clinical trials. All clinical trials regarding NAC are summarized in Table 4.

In the 1990s, several open-label studies were conducted to analyse the efficacy of the short-term treatment of NAC in patients with various types of pulmonary fibrosis. These 
studies reported that total GSH levels increased and pulmonary function tests significantly improved after therapy with NAC (Meyer et al., 1994; Meyer et al., 1995; Behr et al., 1997).

The first clinical trial that assesses the effectiveness of NAC in IPF therapy was the IFIGENIA, which purpose was to determine whether NAC added to prednisone and azathioprine was more effective than the standard therapy with prednisone plus azathioprine. This study showed the three-drug therapy preserved VC and DLCO in IPF patients better than standard therapy (Demedts et al., 2005) (ClinicalTrials.gov Identifier: NCT00639496).

In the IFIGENIA trial, all patients received the combination of the three drugs but none, NAC alone. Thus, in order to study the effectiveness of NAC monotherapy for the treatment of IPF, it was conducted the PANTHER trial. Initially, subjects who have IPF were randomly assigned to receive: 1) three-drug regimen (NAC, prednisolone, and azathioprine), 2) NAC and placebo, or 3) placebo. After performing a midpoint analysis of the study, the three-drug regimen was stopped due to safety concerns. For this reason, the entire study was interrupted for 3 months but later continued. The primary outcome was the change in FVC over 60 weeks. Results showed that acetylcysteine offered no significant benefit concerning the preservation of FVC in patients with IPF when compared with placebo (Izumi et al., 2012; Martinez et al., 2014) (ClinicalTrials.gov number, NCT00650091).

Following this line, a phase III clinical trial evaluating the efficacy and safety of combined therapy with pirfenidone and inhaled NAC for IPF was conducted in Japan. The primary outcome was a change in FVC. Data showed there was no difference between the two groups in the change in FVC. Therefore, combination therapy did not bring any clinical benefit (Sakamoto et al., 2021) (University Hospital Medical Information Network registration number UMIN000015508). In addition to this study, a similar phase II trial was conducted, the PANORAMA study. The aim was to assess the safety and tolerability of NAC in IPF patients receiving background pirfenidone therapy. Again, findings suggested that the addition of NAC to pirfenidone does not substantially alter the tolerability profile of pirfenidone and is unlikely to be beneficial in IPF (Behr et al., 2016) (ClinicalTrials.gov Identifier: NCT02707640).

In 2015, a post hoc exploratory analysis of subjects enrolled in the PANTHER-IPF clinical trial was conducted to determine whether specific polymorphisms in toll-interacting protein (TOLLIP) and MUC5B genes modified the efficacy of NAC. These genes have been associated with IPF susceptibility and survival. TOLLIP encodes toll-interacting protein (TOLLIP), which is inhibitory of toll-like receptors, which are, in turn, responsible for the activation of inflammatory, oxidative and immune response pathways. This post hoc study showed that NAC might improve prognosis in genetically predisposed individuals, specifically, those carrying an rs3750920 (TOLLIP) TT genotype (Oldham et al., 2015). In order to assess this hypothesis, it has been proposed a genotype-stratified clinical trial: the PRECISIONS trial. The purpose of this study is to compare the effect of NAC plus standard care in patients diagnosed with IPF who have the TOLLIP rs3750920 TT genotype and it will compare the time to a composite endpoint of relative decline in lung function. Recruitment is ongoing and the study is estimated to finish in 2025. Thus, no results are published yet (ClinicalTrials.gov Identifier: NCT04300920).

Furthermore, a further phase I/II open label pilot study has been recently proposed to investigate the safety and tolerability of inhaled NAC in patients with IPF. It is titled "Pilot Study to Evaluate Inhaled N-Acetylcysteine in Pulmonary Fibrosis." The primary outcomes are changes in pulmonary function: FVC and DLCO. This study faced different challenges during enrolment due to the COVID-19 epidemic and it is withdrawn at this moment. It is estimated to start at the beginning of 2022 and finish at the end of 2023 (ClinicalTrials.gov Identifier: NCT03720483).

\subsubsection{Quercetin}

The antioxidant quercetin $\left(3,3^{\prime}, 4^{\prime}, 5,7\right.$-pentahydroxyflavone) is a polyphenolic plant flavonoid ubiquitously present in vegetables and fruit as well as tea and red wine (Formica and Regelson, 1995; D'Andrea, 2015). It is a potent direct ROS scavenger but, also, indirectly, exerts its antioxidant function via activating the $\mathrm{Nrf} 2$ pathway and inducing Nrf2-regulated genes, such as NQO1, HO1, GPX1, etc. (Tanigawa et al., 2007; Veith et al., 2017). However, quercetin has not only strong antioxidant but also antiinflammatory capacities (Boots et al., 2008; Impellizzeri et al., 2015) (Figure 2).

Quercetin is also known as a senolytic drug, which induces selective elimination of senescent cells. It is usually used in combination with dasatinib, a tyrosine kinase inhibitor used in the treatment of some cancers (Cazzola et al., 2018; Sellarés and Rojas, 2019).

\subsubsection{In vitro Cellular Studies}

Different studies have reported that quercetin induces expression of HO-1 in macrophages, preventing $\mathrm{H}_{2} \mathrm{O}_{2}$-induced apoptosis (Chow et al., 2005) and in mouse fibroblasts and normal human lung fibroblasts suppressing TGF- $\beta$-induced collagen production (Nakamura et al., 2011). Quercetin was also reported to inhibit the liberation of inflammatory cytokines such as TNF- $\alpha$, IL8 and IL6 in macrophages (Manjeet and Ghosh, 1999) and alveolar epithelial cells (Geraets et al., 2007; Gauliard et al., 2008).

Furthermore, several investigations have demonstrated that quercetin has antifibrotic properties and inhibit skin, liver, or kidney fibrosis (Lee et al., 2003; Phan et al., 2003; Ren et al., 2016). In lung cells, quercetin has been reported to inhibit proliferation and expression of TBF $\beta 1$ in human embryonic lung fibroblasts activated by silicotic alveolar macrophages (Peng et al., 2013). Quercetin also suppresses bleomycin-induced EMT and intracellular level of ROS in alveolar type II-like cells (Takano et al., 2020). It has also been that this flavonoid ameliorates pulmonary fibrosis in TGF- $\beta$-treated human embryonic lung fibroblast (Zhang et al., 2018c).

Finally, quercetin along with dasatinib have been proved to be a powerful senolytic cocktail. Studies in vitro and ex vivo using primary fibrotic mouse alveolar epithelial type II and primary 
human fibroblasts demonstrated that treatment with this senolytic combination attenuates fibrotic mediator expression, such as senescence-associated secretory phenotype factor and extracellular matrix markers (Lehmann et al., 2017; Schafer et al., 2017).

\subsubsection{In vivo Animal Studies}

Several studies have highlighted the protective effect of quercetin in various pulmonary fibrosis models, exercising antiinflammatory and antifibrotic effects. In 2008, a study demonstrated that quercetin, although not influencing collagen deposition, attenuates the pulmonary oxidative stress and inflammatory in bleomycin-induced lung fibrosis hamster model (Martinez et al., 2008). Liposomal quercetin was demonstrated to attenuate bleomycin-induced pulmonary fibrosis in vivo by the suppression of inflammatory cytokines (TNF- $\alpha$, IL-1 $\beta$, and IL-6) and the diminish of total cells and macrophage counts in BALF. Moreover, treatment with liposomal quercetin produced a significant reduction of hydroxyproline content and apparently lessened areas of lung fibrosis and collagen deposition (Baowen et al., 2010). Furthermore, quercetin treatment was shown to reduce the expression of collagen, fibronectin, and MMP-7, decrease the level of inflammatory cytokines such as TNF- $\alpha$ and enhance Nrf2-induced pulmonary antioxidant defences (Verma et al., 2013; Boots et al., 2020). Thus, this demonstrates quercetin exerts anti-fibrogenic and anti-inflammatory effects, possibly via modulation of the redox balance by inducing Nrf2.

The effect of quercetin was also studied on pulmonary fibrosis induced by silica particles in rat models. Quercetin was demonstrated to reduce hydroxyproline content, and increase catalase and GPx activity (Liu et al., 2014a). Quercetin and dihydroquercetin also showed a protective effect against inflammatory processes associated with pulmonary fibrosis in bleomycin mice models. It was reported inhibition of oedema formation and body weight loss, as well as amelioration of polymorphonuclear infiltration into the lung tissue and reduction of the number of inflammatory cells in BALF. Moreover, these polyphenols suppressed iNOS, preventing oxidative and nitrosative lung injury (Impellizzeri et al., 2015). Moreover, these polyphenols suppressed iNOS, preventing oxidative and nitrosative lung injury (Impellizzeri et al., 2015).

The effects of quercetin have also been studied in combination with other compounds. Schafer et al. (2017) demonstrated that the combination of quercetin with dasatinib, the senolytic cocktail, attenuates bleomycin-mediated lung injury in mice. Quercetin has also been combined with gallic acid, another potent natural antioxidant, to investigate their protective effect against bleomycin-induced pulmonary fibrosis in rats. The combination treatment demonstrated a remarkable decrease in lung hydroxyproline and TNF- $\alpha$ level and an increase in catalase activity. The combination treatment also significantly enhanced lung SOD activity and GSH level and decreased NO and IL-6 levels (Mehrzadi et al., 2020).

\subsubsection{Human Clinical Trials}

As mentioned in the previous paragraphs, quercetin is able to reduce oxidative stress and fibrotic processes such as EMT in different IPF effector cells. In addition, several in vivo studies have reported that quercetin has antifibrotic and anti-inflammatory effects through modulation of the redox balance probably by activation of Nrf2, among others. However, there are no human clinical trials testing quercetin treatment in IPF patients. On the other hand, the beneficial effect of quercetin supplementation on markers of oxidative stress and inflammation in other interstitial lung diseases, such as sarcoidosis, has been studied in different clinical trials (Boots et al., 2009; Boots et al., 2011) (ClinicalTrials. gov Identifier: NCT00402623 and NCT00512967).

Nevertheless, since in vitro and in vivo studies have demonstrated that the senolytic cocktail of quercetin and dasitinib is effective in IPF models, between 2016 and 2018, it was performed the first-in-human, small scale, pilot clinical trial to assess the feasibility, acceptability, best methods, and measurement characteristics of potential study outcomes for the senolytic drug combination dasatinib and quercetin in stable IPF patients. It was titled "Targeting Pro-Inflammatory Cells in Idiopathic Pulmonary Fibrosis: a Human Trial (IPF)" The primary endpoints were retention rates and completion rates for planned clinical assessments. Secondary endpoints were safety and change in functional and reported health measures. This first-in-humans open-label pilot study provided initial evidence that senolytics may improve the 6-min walk distance in IPF (Justice et al., 2019) (ClinicalTrials.gov identifier: NCT02874989) Summarized in Table 4.

\subsubsection{Salvianolic Acid B}

Salvianolic acid B (Sal B) is one most active phenolic acids extracted from Salvia miltiorrhiza, Danshen. It shows strong antioxidant, anti-inflammatory, antifibrotic, and anti-apoptotic capacities (Cao et al., 2012). It can exert its antioxidant effects by directly scavenging ROS or by increasing the expression of different antioxidant enzymes such as SOD, GPx, and HO-1 or inhibiting the expression of Nox2 and Nox4; being the regulation of the Nrf2 pathway the core target of these antioxidant mechanisms (Xiao et al., 2020) (Figure 2).

\subsubsection{In vitro Cellular Studies}

Sal B was found to inhibit TGF- $\beta 1$-induced cell proliferation, differentiation, expression collagen type I, endogenous TGF- $\beta 1$ production, and $\alpha$-SMA expression in lung fibroblasts (Jiang et al., 2009; Zhang et al., 2011; Zhang et al., 2014b; Liu et al., 2016c), as well as EMT of alveolar epithelial cells (Liu et al., 2016c). A recent study has demonstrated that Sal B exerts an antiinflammatory role by protecting endothelial cells from oxidative stress injury (Liu et al., 2018b). A further study has also demonstrated that Sal B inhibits LPS-induced inflammation in vitro, by down-regulating the protein expression of proinflammatory cytokine such as IL- $1 \beta$ and TNF- $\alpha$ (Jiang et al., 2020). Sal B treatment was also reported to reduce ROS production and inhibit myofibroblast transdifferentiation via 
the up-regulation of the Nrf2 pathway in human lung fibroblasts (Liu et al., 2018a).

\subsubsection{In vivo Animal Studies}

Results from various bleomycin-induced pulmonary fibrosis in vivo studies showed that Sal B treatment ameliorates lung fibrosis, inhibits inflammatory cell infiltration and diminishes inflammatory cytokine production. It also reduces collagen accumulation and $\alpha$-SMA expression, increases the expression of Nrf2 and protects endothelial cells against oxidative stress injury and inhibits endothelial cell apoptosis (Liu et al., 2015; Liu et al., 2016c; Liu et al., 2018b; Zhang et al., 2021). Sal B was also reported to protect against paraquat-induced pulmonary fibrosis by mediating Nrf2/Nox4 redox balance, as increased Nrf2 expression and reduced Nox4 one, and TGF- $\beta 1 / \mathrm{Smad} 3$ signalling (Liu et al., 2016a).

\subsubsection{Human Clinical Trials}

As we have reviewed above, Sal B has been reported to reduce different fibrotic processes such as proliferation, TGF- $\beta 1$ expression, EMT or myofibroblast transdifferentiation in in vitro models of fibrosis. In vivo studies have also demonstrated that Sal $B$ protects from fibrosis and inflammation in bleomycin and paraquat models probably by upregulating Nrf2. As it is usual in this kind of compound, there is no clinical trial testing the effects of Sal B on its own.

Nevertheless, in 2017 it was started an open label clinical trial of Chinese herbal medicine for IPF ("The Effectiveness of an Empirical Chinese Medicine Formulation for Idiopathic Pulmonary Fibrosis: an Open Label Clinical Trial"), whose aim was to determine whether treatment with the herbal formula PROLUNG could improve IPF symptoms, respiratory function and the quality of life compared with pretreatment baseline. The primary outcome was the annual rate of change in FVC. The PROLUNG formula contained, among others, Radix Salviae Miltiorrhizae, the main bioactive compound of which is Sal B. Unfortunately, the trial was terminated in 2021 due to difficulties recruiting eligible patients (ClinicalTrials.gov Identifier: NCT03274544) Summarized in Table 4.

\subsubsection{Epigallocatechin Gallate}

Epigallocatechin gallate (EGCG) is a polyphenol, the ester from epigallocatechin and gallic acid, and the major biological component of green tea, even though it can be also found in some other vegetables such as onions, hazelnuts and plums (Tsai et al., 2019). EGCG has a potent radical scavenging activity towards both superoxide and hydroxyl radicals, as well as, peroxyl radicals, nitric oxide, carbon-centered ROS and lipid oxidation products (Salah et al., 1995; Nanjo et al., 1999; Zhang et al., 2007a). Several studies have shown that EGCG acts not only as an antioxidant but also as an antiapoptotic, anti-inflammatory and antifibrotic agent (Nagai et al., 2002a; Sriram et al., 2009b; Oz, 2017; Minnelli et al., 2018). Another study suggests that EGCG can act as an antioxidant directly but also indirectly by increasing the activity of other antioxidants or enzymes (Negishi et al., 2004; Zhang et al., 2007a). This catechin may also participate in the regulation of mitochondrial metabolism (Shi et al., 2018b) (Figure 3).

\subsubsection{In vitro Cellular Studies}

The protective role of EGCG was investigated in vitro inducing fibroblast cell lines with TGF- $\beta 1$. Simultaneous treatment with EGCG inhibited the increased fibroblast proliferation, reduced hydroxyproline levels and decreased expression of MMP-2 and -9, $p$-Smad, $\alpha$-SMA and type I collagen. Thus, EGCG inhibited fibroblast activation and collagen accumulation by inhibiting TGF- $\beta 1$ signalling (Sriram et al., 2015). Another experimental study explored the effect of EGCG on gene expression in pulmonary fibroblasts from IPF patients. The gene expression changes observed were mainly involved in the biosynthesis and metabolism of cholesterol, suggesting that EGCG may exercise its effects through regulation of the cholesterol-associated genes (Tsai et al., 2019).

Despite there are not many in vitro studies that explore the therapeutic potential of EGCG in pulmonary fibrosis, there are several that investigate its effects in inflammatory processes. For instance, EGCG is shown to inhibit neutrophil elastase and elastase-mediated activation of MMP-9 (Sartor et al., 2002). Another in vitro study has also revealed that EGCG suppresses ROS activity and inhibits apoptosis and chemokine-induced chemotaxis in activated neutrophils (Donà et al., 2003). In addition, EGCG is demonstrated to reduce neutrophil transmigration through monolayers of endothelial cells (Hofbauer et al., 1999).

\subsubsection{In vivo Animal Studies}

In 2003, Donà et al. (2003) demonstrated that both oral EGCG and green tea extract block neutrophil recruitment and neutrophil-mediated angiogenesis in vivo in an inflammatory angiogenesis mouse model induced by macrophage inflammatory protein-2 and LPS. They also showed that oral administration of green tea extract reduced inflammatory cell infiltration and the patchy fibrosis in pulmonary fibrosis and inflammation mouse model induced by intratracheal instillation of fluorescein isothiocyanate (FITC) (Donà et al., 2003).

Further studies demonstrated that EGCG administration alleviates the oxidative stress generated during bleomycininduced pulmonary fibrosis in rat models. Furthermore, administration of this compound improved body weight and enzymic and non-enzymic antioxidants. It also decreased levels of ROS, lipid peroxidation, hydroxyproline, and the activity of myeloperoxidase. On the other hand, it increased cell counts. EGCG treatment also decreased the increased expression of nuclear factor-kB, TNF- $\alpha$, IL-1b, MMP-2, and 9, TGF- $\beta 1$, Smads, and $a-S M A$; restored the activities of antioxidant enzymes such as GST and NQO1; and induced Nrf2 (Sriram et al., 2008; Sriram et al., 2009a; Sriram et al., 2015).

A study from 2014 showed that EGCG treatment provides antioxidant, anti-inflammatory, and anti-proliferative effects that protect against irradiation-induced pulmonary fibrosis in rats. Treatment with EGCG reduced mortality rates and lung index scores; improved histological changes in the lung; reduced collagen depositions and MDA content; enhanced SOD 


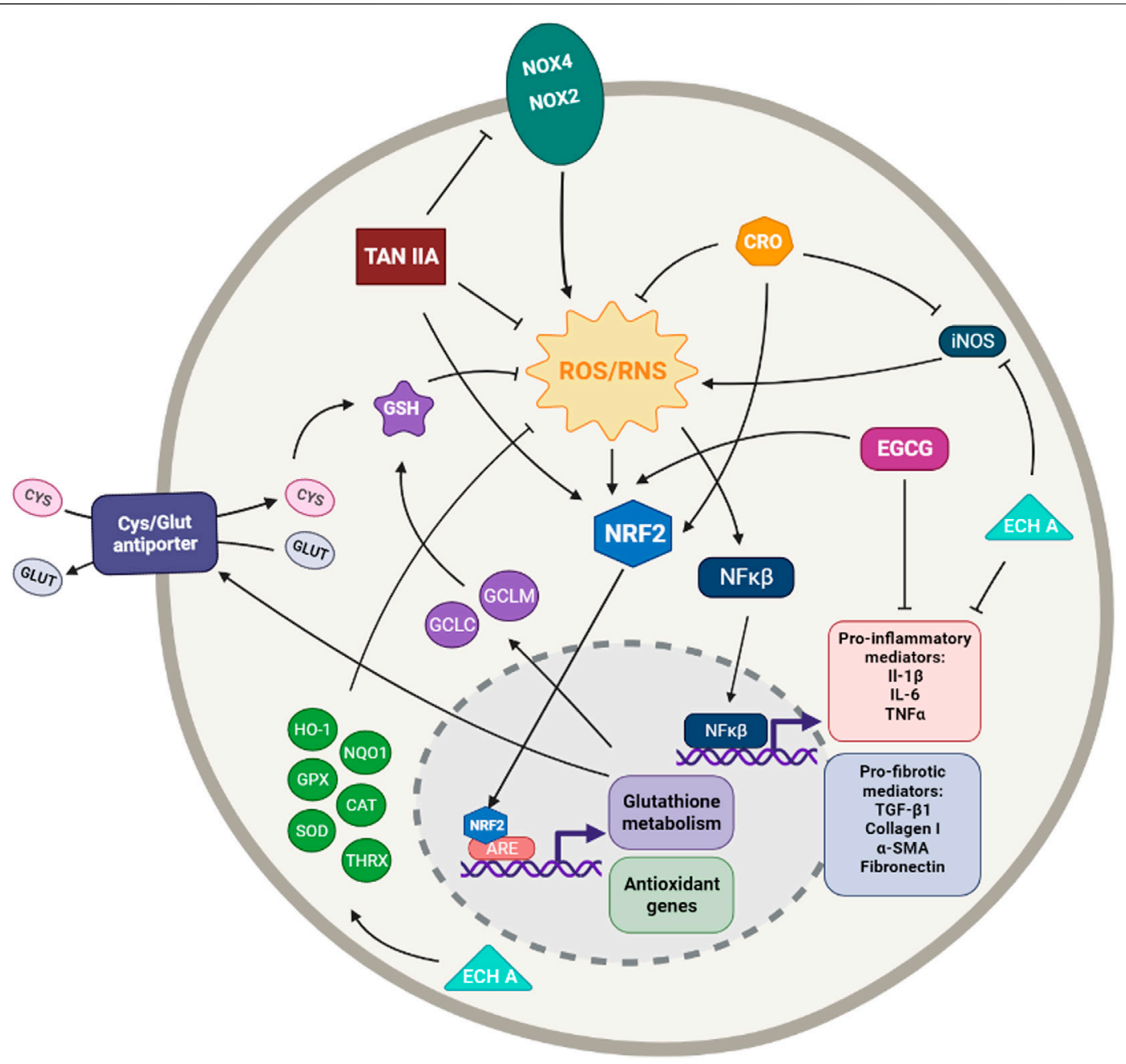

FIGURE 3 | Simplified diagram of the principal molecular mechanisms of the antioxidant enhancers Epigallocatechin (EGCG), Tanshinone IIA (TAN IIA), Crocin $(\mathrm{CRO})$ and Echinochrome A (ECH A). aSMA: alpha smooth muscle actin; ARE: antioxidant responsive element; CAT: catalase; CYS: cysteine; GCLC: glutamate cysteine ligase catalytic subunit; GCLM: glutamate cysteine ligase modifier subunit; GLUT: glutamate; GPX: glutathione peroxidase; GSH: glutathione; HO-1: heme oxygenase 1; IL-1 $\beta$ : interleuquina 1beta; IL-6: interleuquina 6; iNOS: inducible nitrogen oxide synthase; NFk $\beta$ : nuclear factor kappa beta; NOX1,2,4: NADPH oxidases; NQO1: $\mathrm{NAD}(\mathrm{P}) \mathrm{H}$ :quinone oxidoreductase 1; NRF2: nuclear factor erythroid 2-related factor 2; ROS/RNS: reactive oxygen species/reactive nitrogen species; TGF- $\beta 1$ : transforming growth factor beta 1; TNFa: tumoral necrosis factor alpha; SIRT: sirtuine 1; SOD: supeoxide dismutase Created with Biorender.com.

activity; inhibited (myo) fibroblast proliferation; protected alveolar epithelial type II (AE2) cells; and regulated serum levels of TGF- $\beta 1$, IL-6, IL-10, and TNF- $\alpha$. Treatment with EGCG also activated Nrf2 and its downstream antioxidant enzymes HO-1 and NQO-1 (You et al., 2014).

\subsubsection{Human Clinical Trials}

It has been demonstrated, as we have reviewed above, in in vitro studies that treatment with EGCG inhibits fibroblast proliferation, among others fibrotic processes, and, mainly, inflammatory processes. In several in vivo assays, it has been reported that EGCG provides antioxidant, anti-inflammatory and antifibrotic protection in different IPF models mainly via activation of the Nrf2 pathway.

Based on of these preclinical studies, in 2018, started an open label trial to test the effects of oral EGCG treatment on lung tissues and serum samples obtained from 20 patients with IPF and it is titled "Fibroblast Specific Inhibition of LOXL2 and TGFbeta1 Signaling in Patients With Pulmonary Fibrosis." Half of the patients were given orally EGCG before they underwent biopsy, and the other half did not receive the treatment. EGCG treatment reversed profibrotic biomarkers in their diagnostic biopsies: type I collagen, snail family transcriptional repressor and phosphorylated SMAD3 levels were significantly lower in treated patients. This study is in an early phase; therefore, future results are expected in coming years (Chapman et al., 2020) (ClinicalTrials.gov Identifier: NCT03928847) Summarized in Table 4.

The same authors that conducted the open label study extended these findings to advanced pulmonary fibrosis using cultured precision-cut lung slices from explants of IPF patients undergoing transplantation. They discovered EGCG attenuate 
TGF- $\beta 1$ signalling and new collagen accumulation and activated MMP-dependent collagen I turnover (Wei et al., 2021).

\subsubsection{Tanshinone IIA and Sodium Tanshinone IIA Sulfonate}

Tanshinone IIA (TanIIA) is an active compound in Salvia miltiorrhizae Bunge, also known as Danshen, with numerous pharmacological activities, including antioxidant, antiinflammatory, anticancer, and cardio-cerebrovascular protection activities (Cai et al., 2016). Due to the strong liposubility of TIIA, some researchers use its water-soluble derivative form, Sodium tanshinone IIA sulfonate (STS), which is reported to have superior bio-availability and similar pharmacological activity to TanIIA (Chen et al., 2016; Chen et al., 2017). It has also been reported that TanIIa exerts its cytoprotective effect through inhibition of ROS via activation of the Nrf2 pathway (Zhang and Wang, 2007) (Figure 3).

\subsubsection{In vitro Cellular Studies}

TanIIA was reported to suppress TGF- $\beta 1$-induced EMT and collagen I production in lung alveolar epithelial cells (Tang et al., 2015). Another study demonstrated in mouse embryonic fibroblasts that TanIIA inhibits myofibroblast activation through restoring redox homeostasis by activating Nrf2 and suppressing Nox4. Additionally, it was demonstrated TanIIA may activate Nrf2/GSH signalling to restrain myofibroblast proliferation by limiting glutamate availability to support cell growth (An et al., 2019). A more recent study has demonstrated that TanIIA inhibits silica-induced EMT and reduces oxidative stress via activation of the Nrf2 pathway in human alveolar epithelial cells and human bronchial epithelial cells (Feng et al., 2020b).

Similarly, STS was reported to ameliorate silica-induced cell proliferation and oxidative stress via activation of the Nrf2 and thioredoxin system in a coculture model of macrophages and pulmonary fibroblasts (Zhu et al., 2016). More recently, in vitro studies with pulmonary fibroblasts have reported that STS inhibits inflammation via downregulation of IL- $1 \beta$ and TNF- $\alpha$. Additionally, STS was reported to inhibit TGF- $\beta 1$-induced proliferation and $\alpha$-SMA and collagen I overexpression in pulmonary fibroblasts (Jiang et al., 2020).

\subsubsection{In vivo Animal Studies}

Wu et al. (2014) showed that TanIIA treatment attenuates bleomycin-induced pulmonary fibrosis and inflammation and decreases expression of TGF- $\beta 1$ via modulating angiotensinconverting enzyme 2/angiotensin-(1-7) axis in rats. Later, other studies demonstrated that TanIIA mitigates bleomycininduced pulmonary fibrosis, myofibroblast activation, collagen deposition, inflammatory cell infiltration and pro-inflammatory cytokine release in murine models (He et al., 2015; Tang et al., 2015; An et al., 2019). Additionally, it was also reported that TanIIA treatment reduces oxidative stress biomarker MDA levels and inhibits COX-2-associated oxidative reaction and iNOSderived NO production (He et al., 2015). Furthermore, several studies have demonstrated that TanIIA attenuates silica-induced pulmonary fibrosis in rats via TGF- $\beta 1 / \mathrm{Smad}$ signalling suppression, Nox4 inhibition and Nrf2/ARE signalling activation. They also reported an Nrf2-mediated inhibition of EMT and a decrease in oxidative stress biomarkers (Feng et al., 2019; Feng et al., 2020a; Feng et al., 2020b).

In 1994, Wang, He and Zhang studied the effects of STS treatment against bleomycin-induced pulmonary fibrosis in rats. They revealed STS decreases levels of lipid peroxides and hydroxyproline, ameliorating fibrosis (Wang et al., 1994). More recent studies have demonstrated that STS reduces ROS and MDA production and collagen deposition, thereby attenuating silica-induced pulmonary fibrosis in rats, via activation of the Nrf2 and thioredoxin system (Zhu et al., 2016; Zhu et al., 2020).

\subsubsection{Human Clinical Trials}

Despite the promising preclinical results that have demonstrated TanIIA activates the Nrf2 pathway and ameliorates different fibrotic processes in IPF models, there are no clinical trials on TanIIA. On the other hand, there are some clinical trials on STS regarding various diseases but none regarding pulmonary fibrosis.

\subsubsection{Resveratrol}

Resveratrol (3,5,4-trihydroxystilbene) is a nonflavonoid polyphenolic compound found in multiple plant species, including grapes and peanuts. Resveratrol has been reported to exert a vast number of health benefits, such as antioxidant, antiinflammatory, antifibrotic, antiviral, and anticancer activities, through many different mechanisms of action (Tomé-Carneiro et al., 2013; Ma and Li, 2020). Several studies have highlighted the therapeutic effects of resveratrol against lung diseases mainly by decreasing oxidant stress and inhibiting inflammatory responses (Conte et al., 2015; Ma and $\mathrm{Li}, 2020$ ). One of the protective mechanisms of resveratrol par excellence is the activation of the Nrf2 pathway and, therefore, the induction of the expression of several antioxidants enzymes and the regulation of GSH homeostasis (Zhu et al., 2017) (Figure 4).

\subsubsection{In vitro Cellular Studies}

Resveratrol was demonstrated to inhibit both fibroblast proliferation and differentiation into myofibroblast. In addition, different results demonstrated that resveratrol represses TGF- $\beta 1$ induced collagen production, lung fibroblast proliferation (both normal and IPF lung fibroblasts) and attenuates $\alpha$-SMA expression (Fagone et al., 2011). He et al. (2012) demonstrated that resveratrol suppresses oxidative stress and fibrogenic responses induced by paraquat (a fibrosis inducer herbicide) through activation of the Nrf2 pathway and, thus, inducing cytoprotective genes, such as HO- 1 and NQO1. A posterior study showed resveratrol was able to repress and reverse myofibroblasts TGF- $\beta$ - and/or CXCL12mediated transformation (Mehrzadi et al., 2020). Resveratrol was also reported to inhibit the liberation of inflammatory cytokines such as IL-8 and IL-6 in lung epithelial cells (Gauliard et al., 2008).

\subsubsection{In vivo Animal Studies}

Resveratrol has been shown to produce antifibrotic effects in murine models of various diseases such as renal, cardiac, and 


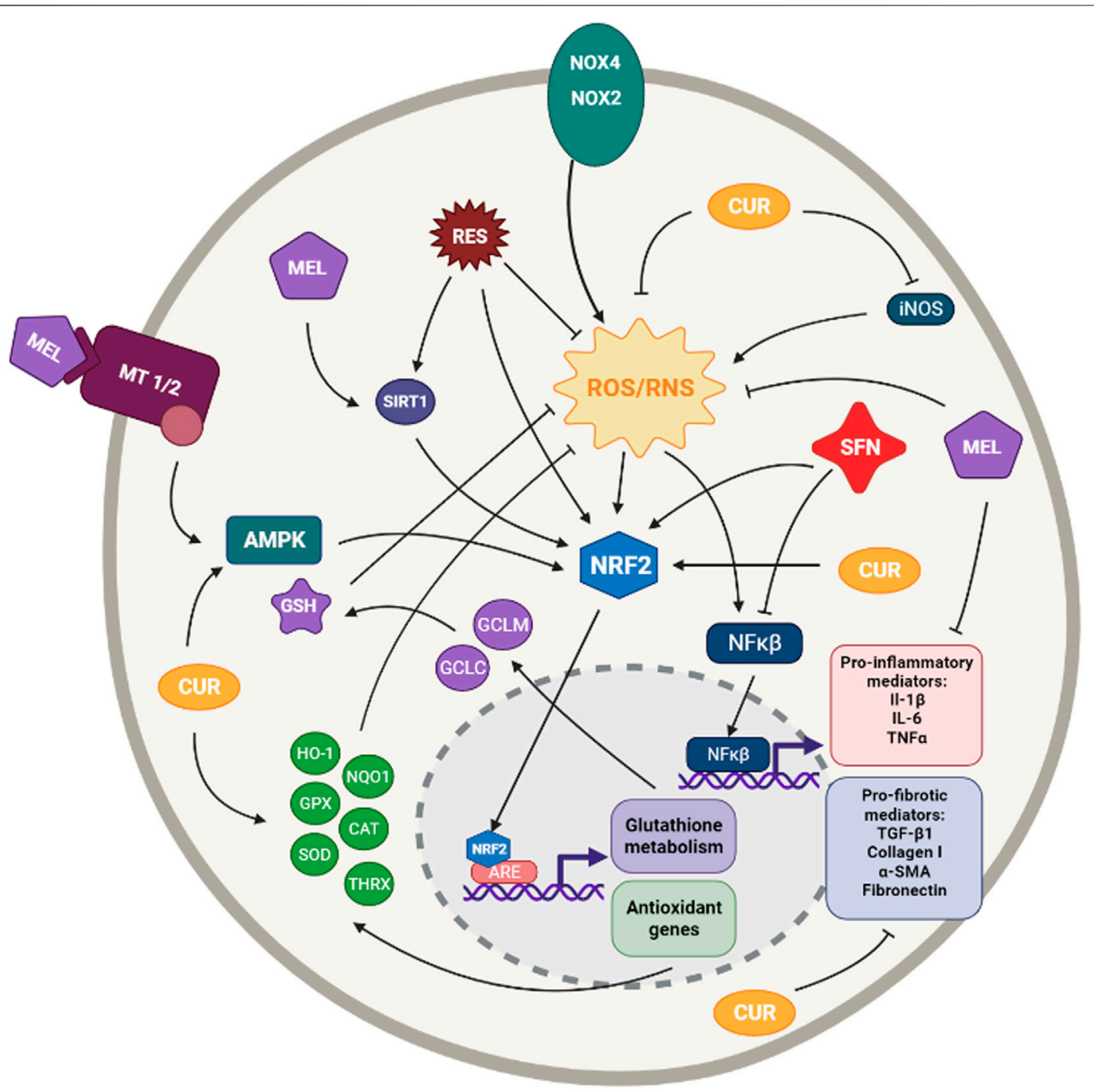

FIGURE 4 | Simplified diagram of the principal molecular mechanisms of the antioxidant enhancers Resveratrol (RES), Sulforaphane (SFN), Melatonin (MEL) and Curcumin (CUR). aSMA: alpha smooth muscle actin; AMPK: AMP-activated protein kinase; ARE: antioxidant responsive element CAT: catalase; CYS: cysteine; GCLC: glutamate cysteine ligase catalytic subunit; GCLM: glutamate cysteine ligase modifier subunit; GLUT: glutamate; GPX: glutathione peroxidase; GSH: glutathione; HO-1: heme oxygenase 1; IL-1 $\beta$ : interleuquina 1beta; IL-6: interleuquina 6; iNOS: inducible nitrogen oxide synthase; NFk $\beta$ : nuclear factor kappa beta; NOX1,2,4: NADPH oxidases; NQO1: NAD(P)H:quinone oxidoreductase 1; NRF2: nuclear factor erythroid 2-related factor 2; ROS/RNS: reactive oxygen species/reactive nitrogen species; TGF- $\beta$ 1: transforming growth factor beta 1; TNFa: tumoral necrosis factor alpha; SIRT: sirtuine 1; SOD: supeoxide dismutase Created with Biorender.com.

hepatic fibrosis (Conte et al., 2015). In the context of pulmonary fibrosis, resveratrol was demonstrated to ameliorate oxidative injury and fibrosis induced by bleomycin due to its antioxidant properties (Sener et al., 2007). Similarly, posteriors studies confirmed the promising potential of resveratrol on the treatment of fibrosis in the same bleomycin-induced pulmonary fibrosis rat model (Akgedik et al., 2012; Wang et al., 2018). Further studies demonstrated that treatment with resveratrol ameliorates LPS-induced EMT and pulmonary fibrosis through suppression of oxidative stress and TGF- $\beta 1 /$ Smad signalling pathway (Zhang et al., 2015). Additionally, resveratrol has been reported to abolish bleomycin- and particulate matter-induced lung inflammation and fibrosis (Impellizzeri et al., 2015; Ding et al., 2019).

\subsubsection{Human Clinical Trials}

It has been demonstrated resveratrol is able to inhibit several fibrotic processes through suppression of oxidative stress in in vitro and in vivo assays, as we have explained above. Nevertheless, it seems the obtained results have not provided sufficient preclinical evidence to consider resveratrol a good candidate for human trials. Indeed, none of the clinical trials on resveratrol registered in https://clinicaltrials.gov regards lung diseases.

\subsubsection{Sulforaphane}

Sulforaphane (SFN) is an organosulfur compound, mainly found in cruciferous vegetables, with indirect antioxidant activity via the Nrf2-mediated induction of phase II 
detoxifying enzymes (Elbarbry and Elrody, 2011; Kim and Park, 2016) (Figure 4).

\subsubsection{In vitro Cellular Studies}

SFN treatment was reported to decrease oxidants and to induce Nrf2 expression, antioxidants, and myofibroblast dedifferentiation in normal and IPF fibroblasts (Artaud-Macari et al., 2013). Various studies in human and rat alveolar epithelial cells have also demonstrated that activation of the Nrf2 antioxidant pathway by SFN protects against ROS production and TGF- $\beta 1$-induced EMT (Zhou et al., 2016; Zhang et al., 2018d; Qu et al., 2019). SFN has also been proved to attenuate TGF- $\beta 1$ induced expression of fibrosis-related proteins, such as fibronectin, collagen I, collagen IV, and $\alpha$-SMA in human alveolar epithelial cells and human fibroblasts (Kyung et al., 2018; Liu et al., 2021).

\subsubsection{In vivo Animal Studies}

Several studies have reported that SFN has antifibrotic and antioxidant activity in various animal models (Elbarbry and Elrody, 2011). SFN treatment of bleomycin-induced pulmonary fibrosis attenuates fibrosis, apoptosis and lung oxidative stress by increasing the expression of antioxidant enzymes, NQO1, HO-1, SOD and catalase, via upregulation of Nrf2 gene expression (Yan et al., 2017). Another study reported that SFN decreases bleomycin-induced fibronectin expression, TGF- $\beta 1$ expression, and the levels of collagen I in bleomycininduced pulmonary fibrosis mouse model (Kyung et al., 2018).

\subsubsection{Human Clinical Trials}

As we have mentioned above, several in vitro and in vivo studies using SFN have reported promising results in pulmonary fibrosis models via the activation of Nrf2, which is its main target. Nevertheless, there are no clinical trials on IPF. On the other hand, SFN has been used in several clinical trials to treat a wide variety of diseases such as cancer, neurological disorders, asthma, allergies and Chronic Obstructive Pulmonary Disease (COPD).

\subsubsection{Melatonin}

Melatonin (N-acetyl-5-methoxytryptamine) is the main secretory product of the pineal gland and, along with its metabolites, is a potent antioxidant with lipophilic and hydrophilic characteristics (Reiter et al., 2016; Hosseinzadeh et al., 2018b). Melatonin can exert its antioxidant effects by either directly scavenging ROS and RNS or by indirectly up-regulating the expression and activities of endogenous antioxidants (Reiter et al., 2016). The antioxidant actions of melatonin are both receptor-dependent and independent (Reiter et al., 2007). In addition to regulating oxidative stress, melatonin modulates a variety of molecular pathways such as circadian biology, inflammation, proliferation, apoptosis and cellular injury (Wang, 2009; Jin et al., 2014; Vriend and Reiter, 2015; Hosseinzadeh et al., 2018a). Several studies have revealed that melatonin is able to induce the expression of GSH and various antioxidant enzymes such as catalase, SOD, and GPx, as well as to activate the Nrf2 signalling pathway (Swiderska-Kołacz et al., 2006; SantofimiaCastaño et al., 2015; Goc et al., 2017) (Figure 4).

\subsubsection{In vitro Cellular Studies}

Various studies have reported that melatonin treatment upregulates Nrf2 expression, reduces ROS production and MDA levels, and prevents LPS- or TGF- $\beta 1$-induced EMT in alveolar epithelial cells (Yu et al., 2016; Ding et al., 2020). Melatonin has also been reported to inhibit the expression of TGF- $\beta 1$, collagen I and SMAD3 phosphorylation in pulmonary cells exposed to cigarette smoke and LPS (Shin et al., 2017). Different studies have also demonstrated that melatonin suppresses acrolein-induced IL-8 production in human pulmonary fibroblasts (Kim et al., 2012) and inhibits TGF$\beta 1$-induced fibrogenesis in mouse lung fibroblasts (Zhao et al., 2018). It also attenuates chromium-induced lung injury by reducing the production of oxidative stress and inflammatory mediators and by inhibiting cell apoptosis via activation of the Nrf2 signalling pathway in mouse lung epithelial cells (Han et al., 2019). Additionally, it has been reported that lipid-core nanocapsules of melatonin reduced oxidative DNA damage detected in alveolar epithelial cells treated with paraquat (Charão et al., 2015).

\subsubsection{In vivo Animal Studies}

Several studies have investigated the effects of melatonin on bleomycin-induced pulmonary fibrosis in murine models and have found that melatonin prevents lung fibrosis development by suppressing oxidative stress and protein and lipid peroxidation (Arslan et al., 2002; Genovese et al., 2005; Yildirim et al., 2006; Karimfar et al., 2015; Zhao et al., 2018). Melatonin has also been reported to inhibit endoplasmic reticulum stress and EMT in bleomycin-induced pulmonary fibrosis in mice (Zhao et al., 2014). Furthermore, treatment with melatonin has been shown to attenuate chromium-induced lung injury via activating the Nrf2 pathway in rats (Han et al., 2019) and also to reduce leukocyte and macrophage inflammation and fibrosis in carbon tetrachloride-induced oxidative lung damage in rats (Taslidere et al., 2014).

\subsubsection{Human Clinical Trials}

Despite the several in vitro and in vivo assays demonstrating that melatonin reduces different processes involved in fibrosis, such as apoptosis or fibrogenesis, there are no clinical trials regarding pulmonary fibrosis.

\subsubsection{Curcumin}

Curcumin (diferuloylmethane) is a polyphenol compound, contained in the spice turmeric and isolated from the rhizome of the plant Curcuma longa. Curcumin has been found to have a multitude of pharmacological properties such as anticancer, antiviral, antiarthritic, anti-amyloid, antioxidant, and antiinflammatory properties. The underlying mechanisms of these effects appear to involve the regulation of various molecular targets, including transcription factors, growth factors, inflammatory cytokines, protein kinases and other enzymes. Curcumin exerts its antioxidant activities directly, by scavenging superoxide anion and hydroxyl radicals, and indirectly by, among others, activating the Nrf2 pathway and inducing the expression of different antioxidant enzymes such as 
HO-1 (Lee et al., 2010b; Zhou et al., 2011; Lelli et al., 2017) (Figure 4).

\subsubsection{In vitro Cellular Studies}

Several studies demonstrated that curcumin inhibits collagen I deposition, expression of $\alpha$-SMA and vimentin, as well as proliferation and differentiation in TGF- $\beta$-induced human and mouse lung fibroblasts or IPF fibroblasts (Smith et al., 2010; Liu et al., 2016b; Chen et al., 2019; Saidi et al., 2019; Chun-Bin et al., 2020). Curcumin has also been reported to protect lung mesenchymal stem cells from $\mathrm{H}_{2} \mathrm{O}_{2}$ and to block the radiation-induced generation of ROS by upregulating the expression of Nrf2 and HO-1 (Lee et al., 2010b; Ke et al., 2020).

\subsubsection{In vivo Animal Studies}

Numerous in vivo experiments have demonstrated the antifibrotic potential of curcumin. Treatment with curcumin has been reported to inhibit the release of inflammatory cytokines, the expression of fibronectin, vimentin and TGF- $\beta 1$, the hydroxyproline content, the ECM accumulation, the collagen I and IV deposition, the production of TNF- $\alpha$, superoxide, NO and MDA as well as to raise the expression of SOD and GPX in bleomycin-induced pulmonary fibrosis murine models (Punithavathi et al., 2000; Zhou et al., 2006a; Zhou et al., 2006b; Zhang et al., 2007b; Xu et al., 2007; Chen et al., 2008; Zhao et al., 2008; Smith et al., 2010; Durairaj et al., 2020).

Other pulmonary fibrosis models such as paraquat-, silica particles-, radiation-, aspiration material- and amiodaroneinduced models have revealed that curcumin is able to reduce the levels of TGF- $\beta 1$, TNF- $\alpha$, IL- 6 and collagen type I, and to decrease the generation of ROS, hydroxyproline content, MDA and MPO and iNOS activity, to increase the activity of SOD, GPx and HO-1 (Thresiamma et al., 1998; Punithavathi et al., 2003; Xu et al., 2007; Guzel et al., 2009; Jiang et al., 2009; Lee et al., 2010b; Cho et al., 2013; Li et al., 2015; Barsan et al., 2021).

\subsubsection{Human Clinical Trials}

Curcumin has been reported to have antioxidant and antifibrotic potentials both in vitro and in different animal models, as we have seen before. Furthermore, it has been tested in various clinical trials for the treatment of different lung diseases, especially COPD, but none of the clinical trials regards pulmonary fibrosis.

\subsubsection{Pirfenidone}

Pirfenidone (PFD, 5-methyl-1-phenyl-2-[1H]-pyridone) is an oral broad-spectrum drug and is one of the two pharmacological treatments recommended for the treatment of IPF. Although no specific mode of action has been identified, PFD possesses antifibrotic, anti-inflammatory, and antioxidant properties (Poletti et al., 2014; Ruwanpura et al., 2020) (Figure 5).

\subsubsection{In vitro Cellular Studies}

Regarding its antifibrotic potential, cell culture experiments on human lung fibroblasts and alveolar epithelial cells have revealed that PFD is able to inhibit fibroblast proliferation, myofibroblast differentiation, collagen synthesis, fibronectin production, deposition of ECM components, and a-SMA and HSP47 expression (Nakayama et al., 2008; Conte et al., 2014; Ma et al., 2018; Molina-Molina et al., 2018). Various studies have reported that PFD may inhibit the release of proinflammatory cytokines such as IL-6, IL-8, IL- $1 \beta$ and TNF- $\alpha$ and enhance the release of the anti-inflammatory cytokine IL-10, thereby exerting its anti-inflammatory effect (Nakazato et al., 2002; Oku et al., 2002; Spond et al., 2003; Liu et al., 2017a; Ruwanpura et al., 2020).

Regarding its antioxidant properties, PFD has been reported to reduce ROS production, as it is a scavenger of hydroxyl and superoxide anion free radicals (Giri et al., 1999). It has also been reported to inhibit NADPH-dependent lipid peroxidation in sheep liver microsomes (Misra and Rabideau, 2000). A more recent study has reported that PFD improves Nrf2, HO-1 and GPX1 expression and reduces collagen I and Il- 6 levels in TGF$\beta 1$-induced mouse lung fibroblasts (Liu et al., 2017b). A further study has revealed that, contrary to sera from IPF naive patients, sera from PFD treated IPF patients failed to significantly induce both ROS generation and collagen synthesis in primary human pulmonary artery smooth muscle cells, demonstrating the antioxidant properties of PFD (Fois et al., 2018). PFD has also been reported to increase the expression of SOD1, catalase and $\mathrm{Nrf2}$, as well as reduce the increased level of ROS in alveolar epithelial cells exposed to cigarette smoke extract (Ma et al., 2021).

\subsubsection{In vivo Animal Studies}

Several studies have demonstrated the antifibrotic and antiinflammatory effects of PFD in experimental animal models, especially in bleomycin-induced pulmonary fibrosis models. These studies revealed that PFD prevents the accumulation of hydroxyproline, collagen I and III, inflammatory cells and TGF$\beta 1$ in BALF, and/or lung tissue (Iyer et al., 1995; Iyer et al., 2000; Tian et al., 2006; Oku et al., 2008; Myllärniemi and Kaarteenaho, 2015).

In the 1990s, studies in hamster models of fibrosis indicated that PFD ameliorates bleomycin-induced lung fibrosis by suppressing oxidative stress mediators, such as MDA and MPO, and enhancing SOD activity (Iyer et al., 1995; Iyer et al., 1999). PFD has also been reported to attenuate bleomycin-induced pulmonary fibrosis in mice by improving the expression of Nrf2, HO-1 and GPx1 and reducing levels of ROS and MDA in serum, BALF and lung tissues (Liu et al., 2017b). In 2018, a study investigated the effect of PFD in paraquat-induced lung injury and fibrosis in mice and demonstrated that PFD ameliorates lung injury and fibrosis through inhibition of inflammation and oxidative stress, downregulation of profibrotic cytokines and enzymes for ROS production such as Nox1, Nox4, iNOS and through up-regulation of antioxidant enzymes such as SOD, catalase and GPx1 (Pourgholamhossein et al., 2018).

\subsubsection{Human Clinical Trials}

The antioxidant and antifibrotic potential of PFD has been extensively demonstrated both in vitro and in vivo models of IPF, even though we have only highlighted the results regarding its antioxidant potential. The significant number of evidence made PFD a perfect candidate for human clinical trials. 


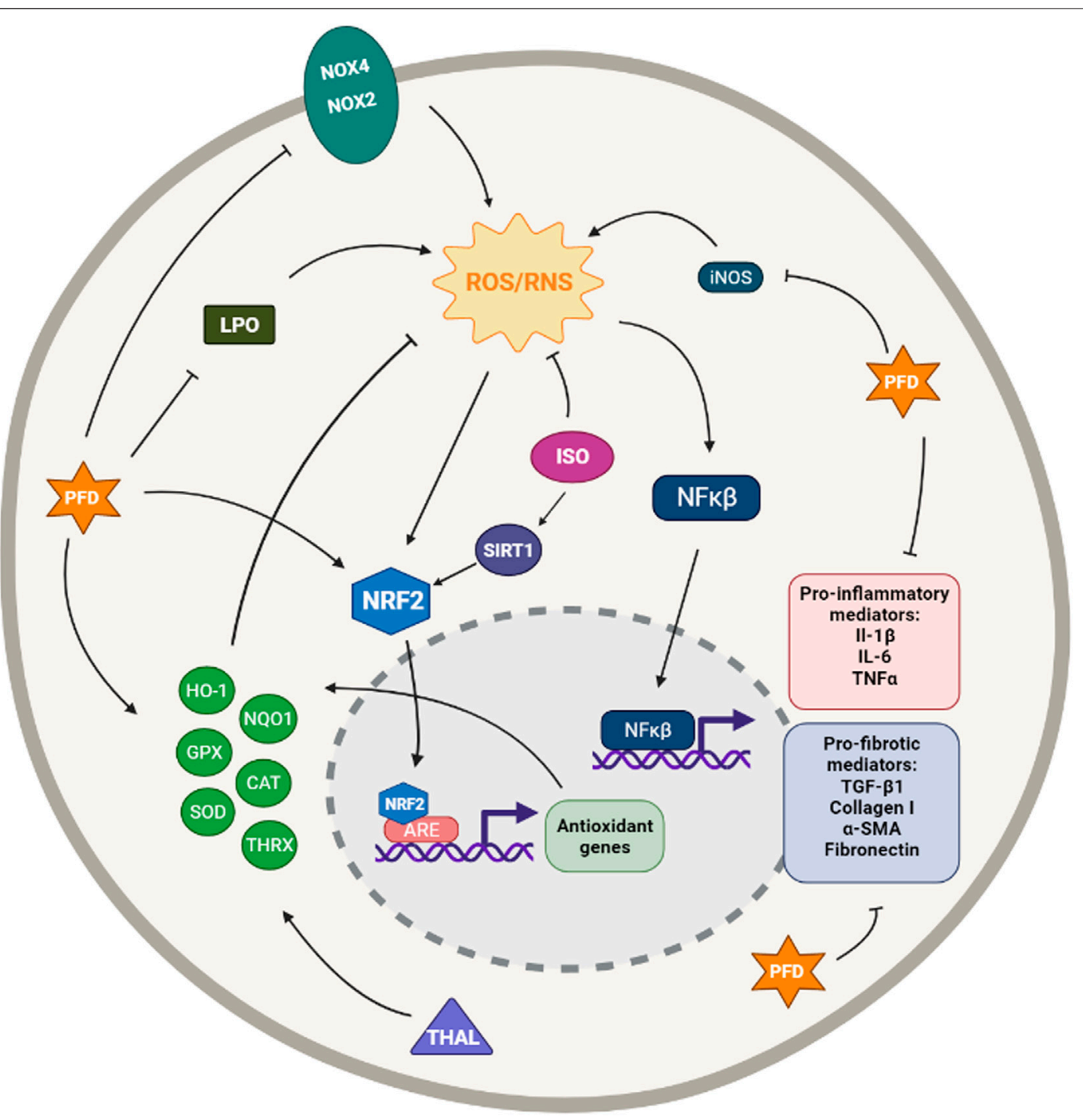

FIGURE 5 | Simplified diagram of the principal molecular mechanisms of the antioxidant enhancers Pirfenidone (PFD), Thalidomide (THAL) and Isorhamnetin (ISO). aSMA: alpha smooth muscle actin; ARE: antioxidant responsive element; CAT: catalase; CYS: cysteine; GLUT: glutamate; GPX: glutathione peroxidase; HO-1: heme oxygenase 1; IL-1 $\beta$ : interleuquina 1beta; IL-6: interleuquina 6; iNOS: inducible nitrogen oxide synthase; LPO: lipoperoxidation; NF $\kappa \beta$ : nuclear factor kappa beta; NOX1,2,4: NADPH oxidases; NQO1: NAD(P)H:quinone oxidoreductase 1; NRF2: nuclear factor erythroid 2-related factor 2; ROS/RNS: reactive oxygen species/ reactive nitrogen species; TGF- $\beta 1$ : transforming growth factor beta 1; THRX: thioredoxin; TNF $\alpha$ : tumoral necrosis factor alpha; SIRT: sirtuine 1; SOD: supeoxide dismutase Created with Biorender.com.

Although there are multiple trials to test the efficacy of PFD in humans for IPF treatment, only four phase III clinical studies of PFD in IPF have been completed and reported (Liu et al., 2017a). Two open-label studies described for the first time the promising results of PFD for the treatment of IPF (Raghu et al., 1999; Nagai et al., 2002b). Later, a phase III trial was conducted in Japan and demonstrated that PFD preserves VC, the primary outcome, and improves progression-free survival time, the second outcome in mild IPF patients (Taniguchi et al., 2010).

Between 2006 and 2011 the CAPACITY (Clinical Studies Assessing Pirfenidone in idiopathic pulmonary fibrosis: Research of Efficacy and Safety Outcomes) phase III trial was conducted. This programme included two similar multinational trials (studies 004 and 006). The results of the two integrated trials showed a significant improvement in the lung function, the primary outcome, but also in progressionfree survival time, in the change in FVC and in the associated death (Noble et al., 2011) (ClinicalTrials.gov Identifier: NCT00287716 and NCT00287729). Another phase III trial, ASCEND (Assessment of Pirfenidone to Confirm Efficacy and Safety in Idiopathic Pulmonary Fibrosis) study was conducted between 2011 and 2014. This trial confirmed that PFD reduces disease progression, as improved lung function, exercise tolerance, and progression-free survival (King et al., 2014) (ClinicalTrials.gov Identifier: NCT01366209) Summarized in Table 4. 


\subsubsection{Thalidomide}

Thalidomide (Thal, $\boldsymbol{\alpha}$-N-phthalimido glutarimide) is a glutamic acid derivative that was initially prescribed as a sedative and antiemetic drug but it was removed from the market for its teratogenic effects (Franks et al., 2004; Sharma et al., 2007). Thal possesses various pharmacological properties, including antiinflammatory, antifibrotic and anti-angiogenic (Chong et al., 2006; Mondello et al., 2009; Zhang et al., 2018a). Although the mechanism of action that underlies these properties is still unclear, Thal may exert its biological activities by modulating inflammatory cytokines, growth factors and nitric oxide (Sampaio et al., 1991; Franks et al., 2004; Amirshahrokhi, 2013) (Figure 5).

\subsubsection{In vitro Cellular Studies}

Thal was reported to reduce IL-18, IL- 8 and TNF- $\alpha$ release from LPS-induced alveolar macrophages (Tavares et al., 1997; Ye et al., 2006). Additionally, several studies have demonstrated that Thal reduces the production of IL- 6 , TGF- $\beta 1$, collagen type I and IV, $\alpha$ SMA, vimentin, MMP-2 and -9, fibronectin and CTGF as well as to inhibit transdifferentiation, EMT and oxidative stress in TGF$\beta 1$-induced human and mouse lung fibroblasts (Tabata et al., 2007; Choe et al., 2010; Amirshahrokhi, 2013; Dong et al., 2017; Wu et al., 2020).

\subsubsection{In vivo Animal Studies}

Various investigations have revealed that Thal prevents bleomycin- or paraquat-induced pulmonary fibrosis in murine models by downregulating the expression of IL-6, IL-8, IL-1 $\beta$, TNF- $\alpha$, TGF- $\beta$, collagen, hydroxyproline, VEGF, $p$-JNK and $\alpha-$ SMA (Tabata et al., 2007; Choe et al., 2010; Amirshahrokhi, 2013; Liu et al., 2014b; Dong et al., 2017). In addition, Thal has been reported to reduce MPO, NO, MDA and ROS and to enhance the activity of SOD and thioredoxin reductase in bleomycin- or paraquat-induced pulmonary fibrosis murine models (Amirshahrokhi, 2013; Dong et al., 2017).

\subsubsection{Human Clinical Trials}

Thal is currently used in the treatment of multiple myeloma, but its use in other diseases is restricted due to its teratogenic effects (Cavallo et al., 2007). Nevertheless, since various preclinical studies demonstrated IPF is able to reduce different fibrotic processes, in 2005 it was started an open label phase II trial. This clinical trial aimed to determine whether Thal can stop the progression of fibrosis in IPF patients ("Treatment of Idiopathic Pulmonary Fibrosis With Thalidomide"). It was conducted between 2005 and 2010 and the primary outcome was to determine the safety, feasibility and efficacy of Thal. However, there are no results available about this study, probably because these are not promising results (ClinicalTrials.gov Identifier: NCT00162760).

On the other hand, there is a phase III trial testing the efficacy of Thal in suppressing the chronic cough of IPF ("Treatment of Chronic Cough in Idiopathic Pulmonary Fibrosis With Thalidomide"). The primary endpoint was the cough-specific quality of life measured by the Cough Quality of Life Questionnaire (CQLQ) and results showed that Thal improved cough and respiratory quality of life in IPF patients (Horton et al., 2012) (ClinicalTrials.gov Identifier: NCT00600028) Summarized in Table 4.

\subsubsection{Other Antioxidant Molecules}

The antioxidant compounds reviewed above are the most studies ones of a large list of molecules able to enhance the antioxidant defence system against the fibrotic process. However, some antioxidant compounds have promising therapeutic results.

For instance, crocin, a natural antioxidant molecule, remarkably decreases TNF- $\alpha$, MDA, TGF- $\beta 1$ and NO levels, up-regulates $\mathrm{Nrf} 2$ and $\mathrm{HO}-1$ and attenuates fibrosis in the lungs of bleomycin-exposed rats (Zaghloul et al., 2019; Mehrabani et al., 2020) (Figure 3). Another recently studied antioxidant is isorhamnetin, a flavonol aglycone isolated from the traditional Chinese medicine Hippophae rhamnoides L. (Shi et al., 2018a). Isorhamnetin has been demonstrated to inhibit bleomycin-induced collagen deposition, reduce type I collagen and a-SMA expression, and alleviate EMT and endoplasmic reticulum stress in vivo and in vitro (Zheng et al., 2019; Luo et al., 2019), as well as to decrease the expression of inflammatory cytokines (Ren et al., 2021; Chi et al., 2016) (Figure 5). Apart from these, another antioxidant molecule is echinochrome A, a quinoid pigment of marine invertebrates that exhibits potent antioxidant properties (Lebedev et al., 2005). It has been reported to have a direct cytoprotective effect under conditions of oxidative stress in pulmonary fibroblasts (Sazonova et al., 2020) and to reduce the severity of bleomycin-induced oxidative stress in the lungs of murine models (Lebed'ko et al., 2015) (Figure 3).

These are just a few examples of the studied antioxidant compounds but, indeed, the number of antioxidant components able to decrease fibrotic process through suppression of oxidative stress is countless and growing.

\subsection{Superoxide Dismutase Mimetics}

As we have mentioned above, SOD enzymes play a critical role in the antioxidant defence of the respiratory system. Thus, several of studies have investigated whether SOD enzymes administration can protect against oxidative stress and ameliorate some lung diseases. Treatment with SODs, encapsulated SODs, liposomal SOD preparations, and recombinant manganese superoxide dismutase, MnSOD, resulted to offer antioxidant protection in fibrosis models; however, these compounds developed some immunogenic complications (Kinnula and Crapo, 2003). Thereby, further studies have opted for synthetic smallmolecular-weight SOD mimetics. These molecules include salen compounds, macrocyclics and metalloporphyrins and have been found to have antioxidant and anti-inflammatory properties (Salvemini et al., 2002).

AEOL 10150 is a broad-spectrum metalloporphyrin SOD mimic and several studies have shown that this agent protects lung tissues from radiation-induced injury in murine and primate models. It also reduces macrophages accumulation, oxidative stress, and collagen deposition (Rabbani et al., 2007; Garofalo et al., 2014; MacVittie et al., 2017; Zhang et al., 2018b). The metalloporphyrin AEOL 10113 has also been reported to reduce 


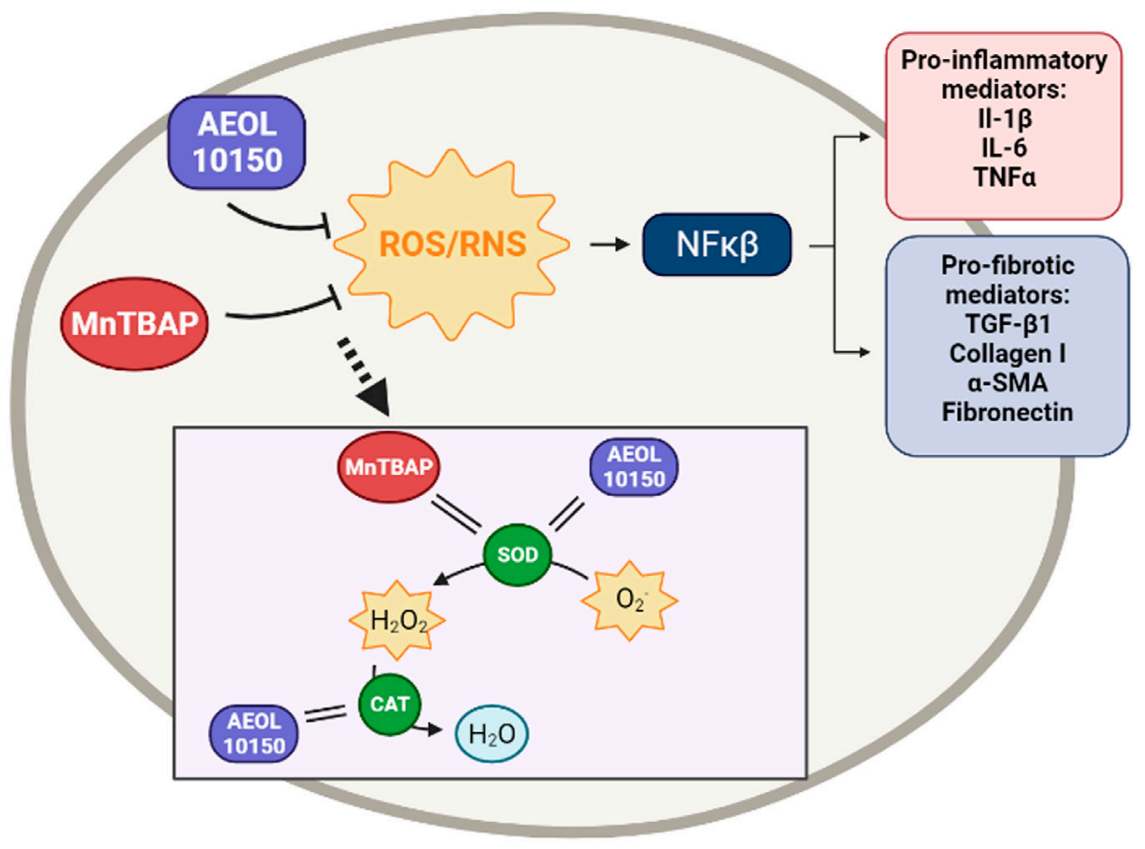

FIGURE 6 | Simplified diagram of the principal molecular mechanisms of the SOD mimetics AEL10150 and MnTBAP. aSMA: alpha smooth muscle actin; CAT: catalase; IL-1 $\beta$ : interleuquina 1beta; IL-6: interleuquina 6; NFк $\beta$ : nuclear factor kappa beta; ROS/RNS: reactive oxygen species/reactive nitrogen species; TGF- $\beta 1$ : transforming growth factor beta 1; TNFa: tumoral necrosis factor alpha; SOD: supeoxide dismutase Created with Biorender.com.

TGF- $\beta$ levels and collagen deposition and to have a protective effect from radiation-induced lung injury (Vujaskovic et al., 2002). MnTBAP is another metalloporphyrin SOD mimic that has been demonstrated to attenuate bleomycin-induced pulmonary fibrosis in in vitro and in vivo models (Oury et al., 2001; Venkatadri et al., 2017). These compounds have; however, not yet been tested in human lung fibrosis (Figure 6).

\section{PITFALLS OF ANTIOXIDANT THERAPIES IN IDIOPATHIC PULMONARY FIBROSIS}

In this review, we have classified the antioxidant drugs into three classes: NOX inhibitors, antioxidants enhancers and ROS scavengers, and SOD mimetics. We have described the in vitro and in vivo results obtained with each drug in the treatment of pulmonary fibrosis. As well as a description of existing clinical trials, if any.

Although all these compounds may seem promising drugs for the treatment of fibrosis, most of them have critical drawbacks, as we will describe below.

Regarding the NOX inhibitors molecules, the classical molecules DPI and Vas2870 have been proven to be useful drugs in preclinical assays to elucidate the role of oxidative stress, specifically NOx molecules, in the development and progression of pulmonary fibrosis and could be helpful in the development of new drugs. However, both compounds have resulted not been suitable options for the treatment of IPF due to their lack of specificity, toxicity, and off-target effects, as they may have unpredictable effects in humans.
In contrast to DPI and Vas2870, the GKTs designed inhibitors are specific for Nox4/Nox1. As we have mentioned, the isoforms Nox1 and Nox4 are implicated in the pathogenesis of IPF. Nox4, in particular, is overexpressed in most of the cells implicated in the pathophysiology of IPF, such as (myo)fibroblasts and epithelial cells, and it contributes to the alteration of different processes such as migration, senescence, differentiation and EMT among others. It is, therefore, logical to think that Nox4 and Nox1 are promising drug targets for IPF. The specificity of these small molecules helps in avoiding off-target effects and in the determination of the effective dose, which is usually lower than in the case of broad-spectrum drugs. Preclinical assays both in vitro and in vivo have provided excellent results, or so the company has reported. Indeed, the GKT37831 compound has completed a phase I clinical trial with enough good results and a phase II clinical trial is ongoing. Thus, this small molecule is probably the most promising option for the treatment of IPF.

Apocynin had been considered as a NOX inhibitor for a long time; however, it has been recently demonstrated that it is a ROS scavenger. Therefore, like many other natural ROS scavengers, such as flavonoids, it has demonstrated beneficial effects in in vitro and in vivo models, but there is a lack of evidence for its efficacy in humans. The last NOX inhibitor mentioned in this review is metformin. In this case, in vitro and in vivo assays have shown that metformin is able to attenuate or reverse lung fibrosis processes; however, retrospective human clinical studies have reported that metformin is ineffective for the treatment of pulmonary fibrosis in diabetics patients with IPF. 
Antioxidant enhancers and ROS scavengers are usually more tolerated than NOX inhibitors, but, on the other hand, their efficacy is also lower.

Among all the antioxidant enhancers, NAC is probably one of the most studied for the treatment of pulmonary fibrosis. Its promising results both in vitro and in vivo suggested that it could be an appropriate option for treating the oxidative stress occurring in IPF. Indeed, it has been reported to be effective in the treatment of other diseases such as Chronic Obstructive Pulmonary Disease (COPD) or bronchitis. However, the successive clinical trials have not reported successful results. On the other hand, the PRECISIONS trial has opened the door to a much more personalised therapy, based on the genetic characteristics of each patient and, probably, it is the key for the treatment of such diseases as IPF, which is characterised by the existence of several phenotypes. Additionally, another recently proposed study aims to test the effectiveness of NAC administered by inhalation. The change in the administration could improve its effectiveness as the drug would act directly in the lungs, where the damage is occurring. However, given all the results, treatment with NAC alone would be very unlikely to be effective in curbing fibrosis.

Many of the antioxidant compounds studied in this review are natural flavonoid or polyphenols compounds such as Quercetin, Sal B, EGCG, TanIIA and STS, resveratrol and curcumin. These compounds have shown a strong antioxidant and, in many cases, anti-inflammatory power in in vitro and in vivo preclinical fibrotic models however their clinical utility as antifibrotic agents is more than questionable. Natural compounds like these are usually very well tolerated with no toxic effects, but, on the other hand, they are less effective than other chemical derived drugs. Furthermore, they have no specific mode of action: they can have a multitude of targets or be ROS scavengers by themselves. The lower efficacy together with the lack of specificity makes it difficult to establish an effective dose to reach an acceptable clinical efficacy. Therefore, these drugs are more indicated for prevention than for treatment of diseases such as IPF and they could be useful in combination with other antifibrotic drugs.

Despite de several in vitro and in vivo assays demonstrating the benefit of using these kinds of antioxidants to treat diseases such as IPF, the reality is that the use of antioxidants in clinical trials has shown to be predominately ineffective (Steinhubl, 2008). The lack of benefit in clinical trials could have different explanations. The easiest explanation is that the chosen compound is not adequate for the disease. Another potential explanation may be that although the compound is adequate, it is tested at inappropriate doses or for inadequate durations (Steinhubl, 2008; M Davies and G Holt, 2018). In most cases, antioxidant compounds need unrealistic doses to have a physiological effect, indeed, it has been reported that they would be present at greater than $10^{13}$ molecules per cell (M Davies and G Holt, 2018). This could be not only because their efficacy is often lower than other drugs, but also because their consumption by ROS is more rapid. Furthermore, it seems illogical to use antioxidant therapies over just a few years to reverse the results of several decades of oxidative stress.
In this review, we also mentioned other three natural compounds, crocin, isorhamnetin and echinocrome A. These three compounds have shown a high antioxidant potential and, since they are natural, are unlikely to generate toxic effects. However, in vitro and in vivo assays with these compounds are scarce, thus, further evidence of their efficacy in fibrotic processes would be needed before they could be considered for clinical trials.

We consider that some of the antioxidants reviewed here deserve special mention, as is the case of SFN. This compound is a natural derivative, but unlike other drugs of this type, has more specific molecular targets. This is an advantage in establishing a dose that achieves sufficient efficacy in humans. One of its most important targets is Nrf2, a key factor in antioxidant defences and highly implicated in diseases related to oxidative stress, for instance, its expression is decreased in some IPF effector cells. Therefore, SFN, since it activates Nrf2, would be a possible candidate for human clinical trials regarding IPF, although more preclinical in vitro and in vivo trials may be needed beforehand.

Another drug that we would like to discuss separately is melatonin, as its origin is different from the rest. Melatonin is a hormone that has been shown to have strong antifibrotic effects due to its antioxidant and anti-inflammatory potential. As it is a hormone produced by the body itself, its use as a drug must be well controlled. Thus, concentration and dose (single or chronic) may be carefully studied. Chronic treatment with melatonin may have the opposite of the desired effects, so it may not be a good option for the treatment of fibrosis, since is a chronic disease. Furthermore, melatonin is heavily involved in circadian rhythms and altering its levels in the body can have detrimental effects. On the other hand, its use could be useful at specific times during the treatment of fibrosis.

In this review, we have also mentioned the PFD, one of the antifibrotic drugs par excellence and one of the two currently approved drugs for the treatment of IPF. As we have reviewed here, several in vitro and in vivo studies have shown that PFD has potent antioxidant effects. However, probably, a large part of these effects is due to its main antifibrotic effect. PFD has several mechanisms of action, many of which are still unknown. Due to the difficulty in determining its specific mechanisms of action, it cannot be said PFD to be a pure antioxidant drug or to have a main antioxidant power.

Another of the drugs already used in clinical practice that we have discussed in this review is Thal. In this case, Thal, in addition to its teratogenicity, which severely limits its use, has been reported ineffective in treating IPF in humans in different clinical trials. Although preclinical studies may suggest that it has anti-fibrotic effects, the reality is that the use of thalidomide for the treatment of IPF is out of the question. Thal is being tested to treat the chronic cough associated with IPF, however, four clinical studies are currently underway investigating P2X3receptor antagonists as potential antitussives, the results are promising and they are safer than Thal (Dicpinigaitis et al., 2020). Therefore, it would also make no sense to use Thal to treat chronic cough when these antagonists are safer and more effective. 
Finally, we have discussed some recently designed SOD mimetics, such as AEOL10150, AEOL 10113 and MnTBAP. These compounds, in contrast to most of the seen above, have a more specific mechanism of action, making it easier to determine the most effective concentration. Furthermore, the use of designed compounds that mimic a biological molecule avoid the complications arising from the use of the biological molecule itself, that, in this case, would be, primarily, the SOD molecule. These compounds, together with the synthetic NOXinhibitors GKTs, are possibly the ones with the most promising future. However, more research is needed on these compounds before they can be considered suitable for clinical trials.

\section{CONCLUDING REMARKS}

Idiopathic pulmonary fibrosis is the major idiopathic interstitial pneumonia with no cause identified and it is characterized by cellular proliferation, interstitial inflammation, and a chronic and progressive fibrosis. It usually does not respond to traditional therapies such as anti-inflammatory and immunomodulatory treatments. Several studies have suggested that increased oxidative stress may play a central role in the development and progression of IPF; indeed, cellular participants in lung fibrosis show, in most cases, an imbalance between oxidants and antioxidants. In addition, the massive number of oxidative stress biomarkers described in patients with IPF have evidenced the involvement of ROS in the pathogenesis of the disease. Regarding this, several ROS scavengers and modulators of the antioxidant machinery have been tested as potential therapeutics for lung fibrosis in preclinical in vitro and in vivo models and in different clinical trials. In this review, we have highlighted the role of oxidative stress in the pathology of lung fibrosis and its underlying mechanisms. However, the principal aim of this review is to analyze the mechanism of action, the efficacy, and the current status of different drugs able to protect against oxidative stress and act as antifibrotic therapy in IPF. Several more antioxidant molecules can be considered as potential

\section{REFERENCES}

Akgedik, R., Akgedik, S., Karamanlı, H., Uysal, S., Bozkurt, B., Ozol, D., et al. (2012). Effect of Resveratrol on Treatment of Bleomycin-Induced Pulmonary Fibrosis in Rats. Inflammation 35, 1732-1741. doi:10.1007/s10753-0129491-0

Amara, N., Goven, D., Prost, F., Muloway, R., Crestani, B., and Boczkowski, J. (2010). NOX4/NADPH Oxidase Expression Is Increased in Pulmonary Fibroblasts from Patients with Idiopathic Pulmonary Fibrosis and Mediates TGFbeta1-Induced Fibroblast Differentiation into Myofibroblasts. Thorax 65, 733-738. doi:10.1136/thx.2009.113456

Amirshahrokhi, K. (2013). Anti-inflammatory Effect of Thalidomide in ParaquatInduced Pulmonary Injury in Mice. Int. Immunopharmacol 17, 210-215. doi:10.1016/j.intimp.2013.06.005

An, L., Peng, L. Y., Sun, N. Y., Yang, Y. L., Zhang, X. W., Li, B., et al. (2019). Tanshinone IIA Activates Nuclear Factor-Erythroid 2-Related Factor 2 to Restrain Pulmonary Fibrosis via Regulation of Redox Homeostasis and Glutaminolysis. Antioxid. Redox Signal. 30, 1831-1848. doi:10.1089/ ars.2018.7569 therapeutics for lung diseases but have not been included in this review due to the lack of enough experimental evidence in lung fibrosis; however, they can be consulted in different reviews (Kinnula et al., 2005; Day, 2008; Kato and Hecker, 2020; Wang et al., 2021).

Despite the evidence of the significance of oxidative stress in the progression and development of IPF, as well as the antifibrotic effect that many antioxidants have been reported to have, it is unlikely that antioxidant monotherapy will be able to reverse or halt IPF progression, as its efficacy is partial. However, the use of antioxidant drugs may serve to improve some aspects of the disease and may be useful in combination with anti-fibrotic drugs. This situation is not unique to IPF but also occurs with other complex diseases such as cancer (Hayes et al., 2020), where antioxidant drug treatments have been used also mainly for prevention or supplementation (Ozben, 2015; Athreya and Xavier, 2017).

Therefore, antioxidant therapies in IPF should probably be focused on complementing other more efficient antifibrotic therapies.

\section{AUTHOR CONTRIBUTIONS}

Conceived and designed revision: CE, JM, MAB, and JC; Analyzed the data: CE, JM, MAB, and JC; Contributed to the writing of the manuscript: $\mathrm{CE}, \mathrm{JM}, \mathrm{MAB}$, and JC. Revision and final approval of the manuscript: CE, JM, MAB, and JC.

\section{FUNDING}

This work was supported by the grants PID 2020-114871RB-I00 (JC), Fondo Europeo de Desarrollo Regional (FEDER) and Instituto de salud carlos III, PI20/01,363 (JM), CIBERES (CB06/06/0027) from the Spanish Government and by research grants from the Regional Government Prometeo 2017/023/UV (JC), from "Generalitat Valenciana".

Arsalane, K., Dubois, C. M., Muanza, T., Bégin, R., Boudreau, F., Asselin, C., et al. (1997). Transforming Growth Factor-Betal Is a Potent Inhibitor of Glutathione Synthesis in the Lung Epithelial Cell Line A549: Transcriptional Effect on the GSH Rate-Limiting Enzyme Gamma-Glutamylcysteine Synthetase. Am. J. Respir. Cel Mol Biol 17, 599-607. doi:10.1165/ajrcmb.17.5.2833

Arslan, S. O., Zerin, M., Vural, H., and Coskun, A. (2002). The Effect of Melatonin on Bleomycin-Induced Pulmonary Fibrosis in Rats. J. Pineal Res. 32, 21-25. doi:10.1034/j.1600-079x.2002.10796.x

Artaud-Macari, E., Goven, D., Brayer, S., Hamimi, A., Besnard, V., MarchalSomme, J., et al. (2013). Nuclear Factor Erythroid 2-related Factor 2 Nuclear Translocation Induces Myofibroblastic Dedifferentiation in Idiopathic Pulmonary Fibrosis. Antioxid. Redox Signal. 18, 66-79. doi:10.1089/ ars.2011.4240

Athreya, K., and Xavier, M. F. (2017). Antioxidants in the Treatment of Cancer. Nutr. Cancer 69, 1099-1104. doi:10.1080/01635581.2017.1362445

Augsburger, F., Filippova, A., Rasti, D., Seredenina, T., Lam, M., Maghzal, G., et al. (2019). Pharmacological Characterization of the Seven Human NOX Isoforms and Their Inhibitors. Redox Biol. 26, 101272. doi:10.1016/j.redox.2019.101272 Baowen, Q., Yulin, Z., Xin, W., Wenjing, X., Hao, Z., Zhizhi, C., et al. (2010). A Further Investigation Concerning Correlation between Anti-fibrotic Effect of 
Liposomal Quercetin and Inflammatory Cytokines in Pulmonary Fibrosis. Eur. J. Pharmacol. 642, 134-139. doi:10.1016/j.ejphar.2010.05.019

Barcellos-Hoff, M. H., and Dix, T. A. (1996). Redox-mediated Activation of Latent Transforming Growth Factor-Beta 1. Mol. Endocrinol. 10, 1077-1083. doi:10.1210/mend.10.9.8885242

Bargagli, E., Penza, F., Vagaggini, C., Magi, B., Perari, M. G., and Rottoli, P. (2007). Analysis of Carbonylated Proteins in Bronchoalveolar Lavage of Patients with Diffuse Lung Diseases. Lung 185, 139-144. doi:10.1007/s00408-007-9001-6

Barratt, S. L., Creamer, A., Hayton, C., and Chaudhuri, N. (2018). Idiopathic Pulmonary Fibrosis (IPF): An Overview. J. Clin. Med. 7, 201. doi:10.3390/ jcm7080201

Barsan, M., Rajnoveanu, A. G., Cocarla, A., Bolfa, P., Login, C. C., Socaciu, A. I., et al. (2021). A Study of Oxidative Stress and Pulmonary Damage after Silica Instillation in Rats and the Effect of Curcumin Administration. Med. $\operatorname{Pr} 72$, 239-247. doi:10.13075/mp.5893.01050

Beeh, K. M., Beier, J., Haas, I. C., Kornmann, O., Micke, P., and Buhl, R. (2002). Glutathione Deficiency of the Lower Respiratory Tract in Patients with Idiopathic Pulmonary Fibrosis. Eur. Respir. J. 19, 1119-1123. doi:10.1183/ 09031936.02.00262402

Behr, J., Bendstrup, E., Crestani, B., Günther, A., Olschewski, H., Sköld, C. M., et al. (2016). Safety and Tolerability of Acetylcysteine and Pirfenidone Combination Therapy in Idiopathic Pulmonary Fibrosis: a Randomised, Double-Blind, Placebo-Controlled, Phase 2 Trial. Lancet Respir. Med. 4, 445-453. doi:10.1016/S2213-2600(16)30044-3

Behr, J., Maier, K., Degenkolb, B., Krombach, F., and Vogelmeier, C. (1997). Antioxidative and Clinical Effects of High-Dose N-Acetylcysteine in Fibrosing Alveolitis. Adjunctive Therapy to Maintenance Immunosuppression. Am. J. Respir. Crit. Care Med. 156, 1897-1901. doi:10.1164/ajrccm.156.6.9706065

Bellocq, A., Azoulay, E., Marullo, S., Flahault, A., Fouqueray, B., Philippe, C., et al. (1999). Reactive Oxygen and Nitrogen Intermediates Increase Transforming Growth Factor-Beta1 Release from Human Epithelial Alveolar Cells through Two Different Mechanisms. Am. J. Respir. Cel Mol Biol 21, 128-136. doi:10.1165/ajrcmb.21.1.3379

Bergeron, A., Soler, P., Kambouchner, M., Loiseau, P., Milleron, B., Valeyre, D., et al. (2003). Cytokine Profiles in Idiopathic Pulmonary Fibrosis Suggest an Important Role for TGF-Beta and IL-10. Eur. Respir. J. 22, 69-76. doi:10.1183/ 09031936.03.00014703

Bernard, K., Hecker, L., Luckhardt, T. R., Cheng, G., and Thannickal, V. J. (2014). NADPH Oxidases in Lung Health and Disease. Antioxid. Redox Signal. 20, 2838-2853. doi:10.1089/ars.2013.5608

Bocchino, M., Agnese, S., Fagone, E., Svegliati, S., Grieco, D., Vancheri, C., et al. (2010). Reactive Oxygen Species Are Required for Maintenance and Differentiation of Primary Lung Fibroblasts in Idiopathic Pulmonary Fibrosis. PLoS One 5, e14003. doi:10.1371/journal.pone.0014003

Boots, A. W., Drent, M., de Boer, V. C., Bast, A., Haenen, G. R., and Haenen, Guido. R. M. M. (2011). Quercetin Reduces Markers of Oxidative Stress and Inflammation in Sarcoidosis. Clin. Nutr. 30, 506-512. doi:10.1016/ j.clnu.2011.01.010

Boots, A. W., Drent, M., Swennen, E. L., Moonen, H. J., Bast, A., and Haenen, G. R. (2009). Antioxidant Status Associated with Inflammation in Sarcoidosis: a Potential Role for Antioxidants. Respir. Med. 103, 364-372. doi:10.1016/ j.rmed.2008.10.007

Boots, A. W., Veith, C., Albrecht, C., Bartholome, R., Drittij, M. J., Claessen, S. M. H., et al. (2020). The Dietary Antioxidant Quercetin Reduces Hallmarks of Bleomycin-Induced Lung Fibrogenesis in Mice. BMC Pulm. Med. 20, 112. doi:10.1186/s12890-020-1142-x

Boots, A. W., Wilms, L. C., Swennen, E. L., Kleinjans, J. C., Bast, A., and Haenen, G. R. (2008). In Vitro and Ex Vivo Anti-inflammatory Activity of Quercetin in Healthy Volunteers. Nutrition 24, 703-710. doi:10.1016/j.nut.2008.03.023

Borok, Z., Buhl, R., Grimes, G. J., Bokser, A. D., Hubbard, R. C., Holroyd, K. J., et al. (1991). Effect of Glutathione Aerosol on Oxidant-Antioxidant Imbalance in Idiopathic Pulmonary Fibrosis. Lancet 338, 215-216. doi:10.1016/01406736(91)90350-x

Bowler, R. P., Nicks, M., Warnick, K., and Crapo, J. D. (2002). Role of Extracellular Superoxide Dismutase in Bleomycin-Induced Pulmonary Fibrosis. Am. J. Physiol. Lung Cel Mol Physiol 282, L719-L726. doi:10.1152/ajplung.00058.2001
Cai, Y., Zhang, W., Chen, Z., Shi, Z., He, C., and Chen, M. (2016). Recent Insights into the Biological Activities and Drug Delivery Systems of Tanshinones. Int. J. Nanomedicine 11, 121-130. doi:10.2147/IJN.S84035

Cameli, P., Carleo, A., Bergantini, L., Landi, C., Prasse, A., and Bargagli, E. (2020). Oxidant/Antioxidant Disequilibrium in Idiopathic Pulmonary Fibrosis Pathogenesis. Inflammation 43, 1-7. doi:10.1007/s10753-019-01059-1

Cantin, A. M., North, S. L., Fells, G. A., Hubbard, R. C., and Crystal, R. G. (1987). Oxidant-Mediated Epithelial Cell Injury in Idiopathic Pulmonary Fibrosis. J Clin Invest 79, 1665-1673. doi:10.1172/JCI113005

Cantin, A. M., Hubbard, R. C., and Crystal, R. G. (1989). Glutathione Deficiency in the Epithelial Lining Fluid of the Lower Respiratory Tract in Idiopathic Pulmonary Fibrosis. Am. Rev. Respir. Dis. 139, 370-372. doi:10.1164/ajrccm/ 139.2.370

Cao, W., Guo, X. W., Zheng, H. Z., Li, D. P., Jia, G. B., and Wang, J. (2012). Current Progress of Research on Pharmacologic Actions of Salvianolic Acid B. Chin. J. Integr. Med. 18, 316-320. doi:10.1007/s11655-012-1052-8

Carnesecchi, S., Deffert, C., Donati, Y., Basset, O., Hinz, B., Preynat-Seauve, O., et al. (2011). A Key Role for NOX4 in Epithelial Cell Death during Development of Lung Fibrosis. Antioxid. Redox Signal. 15, 607-619. doi:10.1089/ ars.2010.3829

Cavallo, F., Boccadoro, M., and Palumbo, A. (2007). Review of Thalidomide in the Treatment of Newly Diagnosed Multiple Myeloma. Ther. Clin. Risk Manag. 3, 543-552.

Cazzola, M., Matera, M. G., Rogliani, P., and Calzetta, L. (2018). Senolytic Drugs in Respiratory Medicine: Is it an Appropriate Therapeutic Approach? Expert Opin. Investig. Drugs 27, 573-581. doi:10.1080/13543784.2018.1492548

Chapman, H. A., Wei, Y., Montas, G., Leong, D., Golden, J. A., Trinh, B. N., et al. (2020). Reversal of TGF $\beta 1$-Driven Profibrotic State in Patients with Pulmonary Fibrosis. N. Engl. J. Med. 382, 1068-1070. doi:10.1056/NEJMc1915189

Charão, M. F., Baierle, M., Gauer, B., Goethel, G., Fracasso, R., Paese, K., et al. (2015). Protective Effects of Melatonin-Loaded Lipid-Core Nanocapsules on Paraquat-Induced Cytotoxicity and Genotoxicity in a Pulmonary Cell Line. Mutat. Res. Genet. Toxicol. Environ. Mutagen 784-785, 1-9. doi:10.1016/ j.mrgentox.2015.04.006

Chen, B., Zhang, D. P., and Gao, W. (2008). Effect of Curcumin on the Expression of Collagen Type I Protein and Transforming Growth Factor-Beta1 mRNA in Pulmonary Fibrosis Rats. Zhonghua Lao Dong Wei Sheng Zhi Ye Bing Za Zhi 26, 257-261. doi:10.17179/excli2016-485

Chen, D., Lin, X. X., Huang, W. H., Zhang, W., Tan, Z. R., Peng, J. B., et al. (2016). Sodium Tanshinone IIA Sulfonate and its Interactions with Human CYP450s. Xenobiotica 46, 1085-1092. doi:10.3109/00498254.2016.1152417

Chen, P. X., Zhang, Y. L., Xu, J. W., Yu, M. H., Huang, J. H., Zhao, L., et al. (2017). Sodium Tanshinone IIA Sulfonate Stimulated Cl- Secretion in Mouse Trachea. PLoS One 12, e0178226. doi:10.1371/journal.pone.0178226

Chen, Y. C., Chen, B. C., Huang, H. M., Lin, S. H., and Lin, C. H. (2019). Activation of PERK in ET-1- and Thrombin-induced Pulmonary Fibroblast Differentiation: Inhibitory Effects of Curcumin. J. Cel Physiol 234, 15977-15988. doi:10.1002/jcp.28256

Cheresh, P., Kim, S.-J., Tulasiram, S., and Kamp, D. W. (2013). Oxidative Stress and Pulmonary Fibrosis. Biochim. Biophys. Acta (Bba) - Mol. Basis Dis. 1832, 1028-1040. doi:10.1016/j.bbadis.2012.11.021

Chi, G., Zhong, W., Liu, Y., Lu, G., Lü, H., Wang, D., et al. (2016). Isorhamnetin Protects Mice from Lipopolysaccharide-Induced Acute Lung Injury via the Inhibition of Inflammatory Responses. Inflamm. Res. 65, 33-41. doi:10.1007/ s00011-015-0887-9

Cho, Y. J., Yi, C. O., Jeon, B. T., Jeong, Y. Y., Kang, G. M., Lee, J. E., et al. (2013). Curcumin Attenuates Radiation-Induced Inflammation and Fibrosis in Rat Lungs. Korean J. Physiol. Pharmacol. 17, 267-274. doi:10.4196/ kjpp.2013.17.4.267

Choe, J. Y., Jung, H. J., Park, K. Y., Kum, Y. S., Song, G. G., Hyun, D. S., et al. (2010). Anti-fibrotic Effect of Thalidomide through Inhibiting TGF-Beta-Induced ERK1/2 Pathways in Bleomycin-Induced Lung Fibrosis in Mice. Inflamm. Res. 59, 177-188. doi:10.1007/s00011-009-0084-9

Choi, S. H., Kim, M., Lee, H. J., Kim, E. H., Kim, C. H., and Lee, Y. J. (2016). Effects of NOX1 on Fibroblastic Changes of Endothelial Cells in Radiation-induced P-ulmonary F-ibrosis. Mol. Med. Rep. 13, 4135-4142. doi:10.3892/ mmr.2016.5090 
Chong, L. W., Hsu, Y. C., Chiu, Y. T., Yang, K. C., and Huang, Y. T. (2006). Antifibrotic Effects of Thalidomide on Hepatic Stellate Cells and Dimethylnitrosamine-Intoxicated Rats. J. Biomed. Sci. 13, 403-418. doi:10.1007/s11373-006-9079-5

Chow, J. M., Shen, S. C., Huan, S. K., Lin, H. Y., and Chen, Y. C. (2005). Quercetin, but Not Rutin and Quercitrin, Prevention of H2O2-Induced Apoptosis via Anti-oxidant Activity and Heme Oxygenase 1 Gene Expression in Macrophages. Biochem. Pharmacol. 69, 1839-1851. doi:10.1016/ j.bcp.2005.03.017

Chow, S., Thomas, P. S., Malouf, M., and Yates, D. H. (2012). Exhaled Breath Condensate (EBC) Biomarkers in Pulmonary Fibrosis. J. Breath Res. 6, 016004. doi:10.1088/1752-7155/6/1/016004

Chun-Bin, S., Yi, Y., Qin-Yi, W., Yang, L., Jing-Ze, Y., Hai-Jing, X., et al. (2020). The Main Active Components of Curcuma Zedoaria Reduces Collagen Deposition in Human Lung Fibroblast via Autophagy. Mol. Immunol. 124, 109-116. doi:10.1016/j.molimm.2020.05.017

Conte, E., Fagone, E., Fruciano, M., Gili, E., Iemmolo, M., and Vancheri, C. (2015). Anti-inflammatory and Antifibrotic Effects of Resveratrol in the Lung. Histol. Histopathol 30, 523-529. doi:10.14670/HH-30.523

Conte, E., Gili, E., Fagone, E., Fruciano, M., Iemmolo, M., and Vancheri, C. (2014). Effect of Pirfenidone on Proliferation, TGF- $\beta$-Induced Myofibroblast Differentiation and Fibrogenic Activity of Primary Human Lung Fibroblasts. Eur. J. Pharm. Sci. 58, 13-19. doi:10.1016/j.ejps.2014.02.014

Cortijo, J., Cerdá-Nicolás, M., Serrano, A., Bioque, G., Estrela, J. M., Santangelo, F., et al. (2001). Attenuation by Oral N-Acetylcysteine of Bleomycin-Induced Lung Injury in Rats. Eur. Respir. J. 17, 1228-1235. doi:10.1183/ 09031936.01.00049701

Crapo, J. D. (2003). Oxidative Stress as an Initiator of Cytokine Release and Cell Damage. Eur. Respir. J. Suppl. 44, 4s-6s. doi:10.1183/09031936.03.00000203a

$\mathrm{Cu}$, A., Ye, Q., Sarria, R., Nakamura, S., Guzman, J., and Costabel, U. (2009). $\mathrm{N}$-acetylcysteine Inhibits TNF-Alpha, sTNFR, and TGF-Betal Release by Alveolar Macrophages in Idiopathic Pulmonary Fibrosis In Vitro. Sarcoidosis Vasc. Diffuse Lung Dis. 26, 147-154.

Cui, Y., Wang, Y., Li, G., Ma, W., Zhou, X. S., Wang, J., et al. (2018). The Nox1/ Nox4 Inhibitor Attenuates Acute Lung Injury Induced by IschemiaReperfusion in Mice. PLoS One 13, e0209444. doi:10.1371/ journal.pone.0209444

Cuzzocrea, S., Mazzon, E., Dugo, L., Serraino, I., Ciccolo, A., Centorrino, T., et al. (2001). Protective Effects of N-Acetylcysteine on Lung Injury and Red Blood Cell Modification Induced by Carrageenan in the Rat. FASEB J. 15, 1187-1200. doi:10.1096/fj.00-0526hyp

D'Andrea, G. (2015). Quercetin: A Flavonol with Multifaceted Therapeutic Applications? Fitoterapia 106, 256-271. doi:10.1016/j.fitote.2015.09.018

Daniil, Z. D., Papageorgiou, E., Koutsokera, A., Kostikas, K., Kiropoulos, T., Papaioannou, A. I., et al. (2006). Serum Levels of Oxidative Stress as a Marker of Disease Severity in Idiopathic Pulmonary Fibrosis. Pulm. Pharmacol. Ther. 21, 26-31. doi:10.1016/j.pupt.2006.10.005

Day, B. J. (2008). Antioxidants as Potential Therapeutics for Lung Fibrosis. Antioxid. Redox Signaling 10, 355-370. doi:10.1089/ars.2007.1916

Demedts, M., Behr, J., Buhl, R., Costabel, U., Dekhuijzen, R., Jansen, H. M., et al. (2005). High-dose Acetylcysteine in Idiopathic Pulmonary Fibrosis. N. Engl. J. Med. 353, 2229-2242. doi:10.1056/NEJMoa042976

Dicpinigaitis, P. V., McGarvey, L. P., and Canning, B. J. (2020). P2X3-Receptor Antagonists as Potential Antitussives: Summary of Current Clinical Trials in Chronic Cough. Lung 198, 609-616. doi:10.1007/s00408-020-00377-8

Ding, S., Wang, H., Wang, M., Bai, L., Yu, P., and Wu, W. (2019). Resveratrol Alleviates Chronic "Real-World" Ambient Particulate Matter-Induced Lung Inflammation and Fibrosis by Inhibiting NLRP3 Inflammasome Activation in Mice. Ecotoxicol Environ. Saf. 182, 109425. doi:10.1016/ j.ecoenv.2019.109425

Ding, Z., Wu, X., Wang, Y., Ji, S., Zhang, W., Kang, J., et al. (2020). Melatonin Prevents LPS-Induced Epithelial-Mesenchymal Transition in Human Alveolar Epithelial Cells via the GSK-3 $\beta /$ Nrf2 Pathway. Biomed. Pharmacother. 132, 110827. doi:10.1016/j.biopha.2020.110827

Donà, M., Dell'Aica, I., Calabrese, F., Benelli, R., Morini, M., Albini, A., et al. (2003). Neutrophil Restraint by green tea: Inhibition of Inflammation, Associated Angiogenesis, and Pulmonary Fibrosis. J. Immunol. 170, 4335-4341. doi:10.4049/jimmunol.170.8.4335
Dong, X., Li, X., Li, M., Chen, M., Fan, Q., and Wei, W. (2017). Antiinflammation and Antioxidant Effects of Thalidomide on Pulmonary Fibrosis in Mice and Human Lung Fibroblasts. Inflammation 40, 1836-1846. doi:10.1007/s10753017-0625-2

Durairaj, P., Venkatesan, S., Narayanan, V., and Babu, M. (2020). Protective Effects of Curcumin on Bleomycin-Induced Changes in Lung Glycoproteins. Mol. Cel Biochem 469, 159-167. doi:10.1007/s11010-020-03737-3

Elbarbry, F., and Elrody, N. (2011). Potential Health Benefits of Sulforaphane: A Review of the Experimental, Clinical and Epidemiological Evidences and Underlying Mechanisms. J. Med. Plant Res. 5, 473.

Fagone, E., Conte, E., Gili, E., Fruciano, M., Pistorio, M. P., Lo Furno, D., et al. (2011). Resveratrol Inhibits Transforming Growth Factor- $\beta$-Induced Proliferation and Differentiation of Ex Vivo Human Lung Fibroblasts into Myofibroblasts through ERK/Akt Inhibition and PTEN Restoration. Exp. Lung Res. 37, 162-174. doi:10.3109/01902148.2010.524722

Felton, V. M., Borok, Z., and Willis, B. C. (2009). N-acetylcysteine Inhibits Alveolar Epithelial-Mesenchymal Transition. Am. J. Physiol. Lung Cel Mol Physiol 297, L805-L812. doi:10.1152/ajplung.00009.2009

Feng, F., Cheng, P., Xu, S., Li, N., Wang, H., Zhang, Y., et al. (2020a). Tanshinone IIA Attenuates Silica-Induced Pulmonary Fibrosis via Nrf2-Mediated Inhibition of EMT and TGF- $\beta 1 /$ Smad Signaling. Chem. Biol. Interact 319, 109024. doi:10.1016/j.cbi.2020.109024

Feng, F., Cheng, P., Zhang, H., Li, N., Qi, Y., Wang, H., et al. (2019). The Protective Role of Tanshinone IIA in Silicosis Rat Model via TGF- $\beta 1 /$ Smad Signaling Suppression, NOX4 Inhibition and Nrf2/ARE Signaling Activation. Drug Des. Devel Ther. 13, 4275-4290. doi:10.2147/DDDT.S230572

Feng, F., Li, N., Cheng, P., Zhang, H., Wang, H., Wang, Y., et al. (2020b). Tanshinone IIA Attenuates Silica-Induced Pulmonary Fibrosis via Inhibition of TGF-B1-Smad Signaling Pathway. Biomed. Pharmacother. 121, 109586. doi:10.1016/j.biopha.2019.109586

Fois, A. G., Posadino, A. M., Giordo, R., Cossu, A., Agouni, A., Rizk, N. M., et al. (2018). Antioxidant Activity Mediates Pirfenidone Antifibrotic Effects in Human Pulmonary Vascular Smooth Muscle Cells Exposed to Sera of Idiopathic Pulmonary Fibrosis Patients. Oxid Med. Cel Longev 2018, 2639081. doi:10.1155/2018/2639081

Formica, J. V., and Regelson, W. (1995). Review of the Biology of Quercetin and Related Bioflavonoids. Food Chem. Toxicol. 33, 1061-1080. doi:10.1016/02786915(95)00077-1

Franks, M. E., Macpherson, G. R., and Figg, W. D. (2004). Thalidomide. The Lancet 363, 1802-1811. doi:10.1016/S0140-6736(04)16308-3

Fu, X., Kassim, S. Y., Parks, W. C., and Heinecke, J. W. (2003). Hypochlorous Acid Generated by Myeloperoxidase Modifies Adjacent Tryptophan and glycine Residues in the Catalytic Domain of Matrix Metalloproteinase-7 (Matrilysin): an Oxidative Mechanism for Restraining Proteolytic Activity during Inflammation. J. Biol. Chem. 278, 28403-28409. doi:10.1074/ jbc.M304739200

Gaggini, F., Laleu, B., Orchard, M., Fioraso-Cartier, L., Cagnon, L., HoungninouMolango, S., et al. (2011). Design, Synthesis and Biological Activity of Original Pyrazolo-Pyrido-Diazepine, -pyrazine and -oxazine Dione Derivatives as Novel Dual Nox4/Nox1 Inhibitors. Bioorg. Med. Chem. 19, 6989-6999. doi:10.1016/ j.bmc.2011.10.016

Gao, F., Kinnula, V. L., Myllärniemi, M., and Oury, T. D. (2008). Extracellular Superoxide Dismutase in Pulmonary Fibrosis. Antioxid. Redox Signaling 10, 343-354. doi:10.1089/ars.2007.1908

Garofalo, M. C., Ward, A. A., Farese, A. M., Bennett, A., Taylor-Howell, C., Cui, W., et al. (2014). A Pilot Study in Rhesus Macaques to Assess the Treatment Efficacy of a Small Molecular Weight Catalytic Metalloporphyrin Antioxidant (AEOL 10150) in Mitigating Radiation-Induced Lung Damage. Health Phys. 106, 73-83. doi:10.1097/HP.0b013e3182a4d967

Gauliard, B., Grieve, D., Wilson, R., Crozier, A., Jenkins, C., Mullen, W. D., et al. (2008). The Effects of Dietary Phenolic Compounds on Cytokine and Antioxidant Production by A549 Cells. J. Med. Food 11, 382-384. doi:10.1089/jmf.2007.593

Genovese, T., Di Paola, R., Mazzon, E., Muià, C., Caputi, A. P., and Cuzzocrea, S. (2005). Melatonin Limits Lung Injury in Bleomycin Treated Mice. J. Pineal Res. 39, 105-112. doi:10.1111/j.1600-079X.2005.00229.x

Geraets, L., Moonen, H. J., Brauers, K., Wouters, E. F., Bast, A., and Hageman, G. J. (2007). Dietary Flavones and Flavonoles Are Inhibitors of poly(ADP-Ribose) 
polymerase-1 in Pulmonary Epithelial Cells. J. Nutr. 137, 2190-2195. doi:10.1093/jn/137.10.2190

Giri, S. N., Leonard, S., Shi, X., Margolin, S. B., and Vallyathan, V. (1999). Effects of Pirfenidone on the Generation of Reactive Oxygen Species In Vitro. J. Environ. Pathol. Toxicol. Oncol. 18, 169-177.

Goc, Z., Szaroma, W., Kapusta, E., and Dziubek, K. (2017). Protective Effects of Melatonin on the Activity of SOD, CAT, GSH-Px and GSH Content in Organs of Mice after Administration of SNP. Chin. J. Physiol. 60, 1-10. doi:10.4077/ CJP.2017.BAF435

Green, D. E., Murphy, T. C., Kang, B. Y., Kleinhenz, J. M., Szyndralewiez, C., Page, P., et al. (2012). The Nox4 Inhibitor GKT137831 Attenuates Hypoxia-Induced Pulmonary Vascular Cell Proliferation. Am. J. Respir. Cel Mol Biol 47, 718-726. doi:10.1165/rcmb.2011-0418OC

Griffith, B., Pendyala, S., Hecker, L., Lee, P. J., Natarajan, V., and Thannickal, V. J. (2009). NOX Enzymes and Pulmonary Disease. Antioxid. Redox Signal 11, 2505-2516. doi:10.1089/ars.2009.2599

Guzel, A., Kanter, M., Aksu, B., Basaran, U. N., Yalçin, O., Guzel, A., et al. (2009). Preventive Effects of Curcumin on Different Aspiration Material-Induced Lung Injury in Rats. Pediatr. Surg. Int. 25, 83-92. doi:10.1007/s00383-008$2282-x$

Hagiwara, S. I., Ishii, Y., and Kitamura, S. (2000). Aerosolized Administration of N-Acetylcysteine Attenuates Lung Fibrosis Induced by Bleomycin in Mice. Am. J. Respir. Crit. Care Med. 162, 225-231. doi:10.1164/ajrccm.162.1.9903129

Han, B., Li, S., Lv, Y., Yang, D., Li, J., Yang, Q., et al. (2019). Dietary Melatonin Attenuates Chromium-Induced Lung Injury via Activating the Sirt1/Pgc-1 $\alpha /$ Nrf2 Pathway. Food Funct. 10, 5555-5565. doi:10.1039/c9fo01152h

Harijith, A., Natarajan, V., and Fu, P. (2017). The Role of Nicotinamide Adenine Dinucleotide Phosphate Oxidases in Lung Architecture Remodeling. Antioxidants (Basel) 6, 104. doi:10.3390/antiox6040104

Hayes, J. D., Dinkova-Kostova, A. T., and Tew, K. D. (2020). Oxidative Stress in Cancer. Cancer Cell 38, 167-197. doi:10.1016/j.ccell.2020.06.001

He, C., Larson-Casey, J. L., Davis, D., Hanumanthu, V. S., Longhini, A. L. F., Thannickal, V. J., et al. (2019). NOX4 Modulates Macrophage Phenotype and Mitochondrial Biogenesis in Asbestosis. JCI Insight 4, e126551. doi:10.1172/ jci.insight. 126551

He, H., Tang, H., Gao, L., Wu, Y., Feng, Z., Lin, H., et al. (2015). Tanshinone IIA Attenuates Bleomycin-Induced Pulmonary Fibrosis in Rats. Mol. Med. Rep. 11, 4190-4196. doi:10.3892/mmr.2015.3333

He, X., Wang, L., Szklarz, G., Bi, Y., and Ma, Q. (2012). Resveratrol Inhibits Paraquat-Induced Oxidative Stress and Fibrogenic Response by Activating the Nuclear Factor Erythroid 2-related Factor 2 Pathway. J. Pharmacol. Exp. Ther. 342, 81-90. doi:10.1124/jpet.112.194142

Hecker, L., Logsdon, N. J., Kurundkar, D., Kurundkar, A., Bernard, K., Hock, T., et al. (2014). Reversal of Persistent Fibrosis in Aging by Targeting Nox4-Nrf2 Redox Imbalance. Sci. Transl Med. 6, 231ra47. doi:10.1126/ scitranslmed.3008182

Hecker, L., Vittal, R., Jones, T., Jagirdar, R., Luckhardt, T. R., Horowitz, J. C., et al. (2009). NADPH Oxidase-4 Mediates Myofibroblast Activation and Fibrogenic Responses to Lung Injury. Nat. Med. 15, 1077-1081. doi:10.1038/nm.2005

Heumüller, S., Wind, S., Barbosa-Sicard, E., Schmidt, H. H., Busse, R., Schröder, K., et al. (2008). Apocynin Is Not an Inhibitor of Vascular NADPH Oxidases but an Antioxidant. Hypertension 51, 211-217. doi:10.1161/ HYPERTENSIONAHA.107.100214

Hofbauer, R., Frass, M., Gmeiner, B., Handler, S., Speiser, W., and Kapiotis, S. (1999). The green tea Extract Epigallocatechin Gallate Is Able to Reduce Neutrophil Transmigration through Monolayers of Endothelial Cells. Wien Klin Wochenschr 111, 278-282.

Horton, M. R., Santopietro, V., Mathew, L., Horton, K. M., Polito, A. J., Liu, M. C., et al. (2012). Thalidomide for the Treatment of Cough in Idiopathic Pulmonary Fibrosis: a Randomized Trial. Ann. Intern. Med. 157, 398-406. doi:10.7326/ 0003-4819-157-6-201209180-00003

Hosseinzadeh, A., Javad-Moosavi, S. A., Reiter, R. J., Hemati, K., Ghaznavi, H., and Mehrzadi, S. (2018a). Idiopathic Pulmonary Fibrosis (IPF) Signaling Pathways and Protective Roles of Melatonin. Life Sci. 201, 17-29. doi:10.1016/ j.lfs. 2018.03.032

Hosseinzadeh, A., Javad-Moosavi, S. A., Reiter, R. J., Yarahmadi, R., Ghaznavi, H., and Mehrzadi, S. (2018b). Oxidative/nitrosative Stress, Autophagy and Apoptosis as Therapeutic Targets of Melatonin in Idiopathic Pulmonary
Fibrosis. Expert Opin. Ther. Targets 22, 1049-1061. doi:10.1080/ 14728222.2018 .1541318

Hsu, Y. C., Wang, L. F., and Chien, Y. W. (2007). Nitric Oxide in the Pathogenesis of Diffuse Pulmonary Fibrosis. Free Radic. Biol. Med. 42, 599-607. doi:10.1016/ j.freeradbiomed.2006.11.031

Huetsch, J. C., Suresh, K., and Shimoda, L. A. (2019). Regulation of Smooth Muscle Cell Proliferation by NADPH Oxidases in Pulmonary Hypertension. Antioxidants (Basel) 8, 56. doi:10.3390/antiox8030056

Hybertson, B. M., Gao, B., Bose, S. K., and McCord, J. M. (2011). Oxidative Stress in Health and Disease: the Therapeutic Potential of Nrf2 Activation. Mol. Aspects Med. 32, 234-246. doi:10.1016/j.mam.2011.10.006

Impellizzeri, D., Talero, E., Siracusa, R., Alcaide, A., Cordaro, M., Maria Zubelia, J., et al. (2015). Protective Effect of Polyphenols in an Inflammatory Process Associated with Experimental Pulmonary Fibrosis in Mice. Br. J. Nutr. 114, 853-865. doi:10.1017/S0007114515002597

Iyer, S. N., Gurujeyalakshmi, G., and Giri, S. N. (1999). Effects of Pirfenidone on Transforming Growth Factor-Beta Gene Expression at the Transcriptional Level in Bleomycin Hamster Model of Lung Fibrosis. J. Pharmacol. Exp. Ther. $291,367-373$

Iyer, S. N., Hyde, D. M., and Giri, S. N. (2000). Anti-inflammatory Effect of Pirfenidone in the Bleomycin-Hamster Model of Lung Inflammation. Inflammation 24, 477-491. doi:10.1023/a:1007068313370

Iyer, S. N., Wild, J. S., Schiedt, M. J., Hyde, D. M., Margolin, S. B., and Giri, S. N. (1995). Dietary Intake of Pirfenidone Ameliorates Bleomycin-Induced Lung Fibrosis in Hamsters. J. Lab Clin. Med. 125, 779-785.

Izumi, S., Iikura, M., and Hirano, S. (2012). Prednisone, Azathioprine, and N-Acetylcysteine for Pulmonary Fibrosis. N. Engl. J. Med. 367, 870-871. doi:10.1056/NEJMc1207471

Jack, C. I., Jackson, M. J., Johnston, I. D., and Hind, C. R. (1996). Serum Indicators of Free Radical Activity in Idiopathic Pulmonary Fibrosis. Am. J. Respir. Crit. Care Med. 153, 1918-1923. doi:10.1164/ajrccm.153.6.8665056

Jackson, R., Ramos, C., Gupta, C., and Gomez-Marin, O. (2010). Exercise Decreases Plasma Antioxidant Capacity and Increases Urinary Isoprostanes of IPF Patients. Respir. Med. 104, 1919-1928. doi:10.1016/j.rmed.2010.07.021

Jain, M., Rivera, S., Monclus, E. A., Synenki, L., Zirk, A., Eisenbart, J., et al. (2013). Mitochondrial Reactive Oxygen Species Regulate Transforming Growth Factor- $\beta$ Signaling. J. Biol. Chem. 288, 770-777. doi:10.1074/jbc.M112.431973

Jardine, H., MacNee, W., Donaldson, K., and Rahman, I. (2002). Molecular Mechanism of Transforming Growth Factor (TGF)-betal-induced Glutathione Depletion in Alveolar Epithelial Cells. Involvement of AP-1/ ARE and Fra-1. J. Biol. Chem. 277, 21158-21166. doi:10.1074/jbc.M112145200

Jarman, E. R., Khambata, V. S., Cope, C., Jones, P., Roger, J., Ye, L. Y., et al. (2014). An Inhibitor of NADPH Oxidase-4 Attenuates Established Pulmonary Fibrosis in a Rodent Disease Model. Am. J. Respir. Cell Mol Biol 50, 158-169. doi:10.1165/rcmb.2013-0174OC

Ji, L., Liu, R., Zhang, X. D., Chen, H. L., Bai, H., Wang, X., et al. (2010). $\mathrm{N}$-acetylcysteine Attenuates Phosgene-Induced Acute Lung Injury via UpRegulation of Nrf2 Expression. Inhal Toxicol. 22, 535-542. doi:10.3109/ 08958370903525183

Jiang, J. X., Chen, X., Serizawa, N., Szyndralewiez, C., Page, P., Schröder, K., et al. (2012). Liver Fibrosis and Hepatocyte Apoptosis Are Attenuated by GKT137831, a Novel NOX4/NOX1 Inhibitor In Vivo. Free Radic. Biol. Med. 53, 289-296. doi:10.1016/j.freeradbiomed.2012.05.007

Jiang, L., Wang, J., Ju, J., and Dai, J. (2020). Salvianolic Acid B and Sodium Tanshinone II A Sulfonate Prevent Pulmonary Fibrosis through Antiinflammatory and Anti-fibrotic Process. Eur. J. Pharmacol. 883, 173352. doi:10.1016/j.ejphar.2020.173352

Jiang, Z. Y., Zou, L., Shi, S. S., Lu, Y. R., Dong, J., Yang, C. H., et al. (2009). Effects of Curcumin on TNF-Alpha and TGF-Beta1 in Serum and Lung Tissue of SiO2Induced Fibrosis in Mice. Xi Bao Yu Fen Zi Mian Yi Xue Za Zhi 25, 399-401.

Jin, H., Wang, Y., Zhou, L., Liu, L., Zhang, P., Deng, W., et al. (2014). Melatonin Attenuates Hypoxic Pulmonary Hypertension by Inhibiting the Inflammation and the Proliferation of Pulmonary Arterial Smooth Muscle Cells. J. Pineal Res. 57, 442-450. doi:10.1111/jpi.12184

Justice, J. N., Nambiar, A. M., Tchkonia, T., LeBrasseur, N. K., Pascual, R., Hashmi, S. K., et al. (2019). Senolytics in Idiopathic Pulmonary Fibrosis: Results from a First-In-Human, Open-Label, Pilot Study. EBioMedicine 40, 554-563. doi:10.1016/j.ebiom.2018.12.052 
Kang, S. K., Rabbani, Z. N., Folz, R. J., Golson, M. L., Huang, H., Yu, D., et al. (2003). Overexpression of Extracellular Superoxide Dismutase Protects Mice from Radiation-Induced Lung Injury. Int. J. Radiat. Oncol. Biol. Phys. 57, 1056-1066. doi:10.1016/s0360-3016(03)01369-5

Karimfar, M. H., Rostami, S., Haghani, K., Bakhtiyari, S., and Noori-Zadeh, A. (2015). Melatonin Alleviates Bleomycin-Induced Pulmonary Fibrosis in Mice. J. Biol. Regul. Homeost Agents 29, 327-334.

Kato, K., and Hecker, L. (2020). NADPH Oxidases: Pathophysiology and Therapeutic Potential in Age-Associated Pulmonary Fibrosis. Redox Biol. 33, 101541. doi:10.1016/j.redox.2020.101541

Ke, S., Zhang, Y., Lan, Z., Li, S., Zhu, W., and Liu, L. (2020). Curcumin Protects Murine Lung Mesenchymal Stem Cells from H2O2 by Modulating the Akt/ Nrf2/HO-1 Pathway. J. Int. Med. Res. 48, 300060520910665. doi:10.1177/ 0300060520910665

Kilic, T., Parlakpinar, H., Taslidere, E., Yildiz, S., Polat, A., Vardi, N., et al. (2015). Protective and Therapeutic Effect of Apocynin on Bleomycin-Induced Lung Fibrosis in Rats. Inflammation 38, 1166-1180. doi:10.1007/s10753-014-0081-1

Kim, G. D., Lee, S. E., Kim, T. H., Jin, Y. H., Park, Y. S., and Park, C. S. (2012). Melatonin Suppresses Acrolein-Induced IL-8 Production in Human Pulmonary Fibroblasts. J. Pineal Res. 52, 356-364. doi:10.1111/j.1600079X.2011.00950.x

Kim, J. K., and Park, S. U. (2016). Current Potential Health Benefits of Sulforaphane. EXCLI J. 15, 571-577. doi:10.17179/excli2016-485

Kim, S. J., Cheresh, P., Jablonski, R. P., Morales-Nebreda, L., Cheng, Y., Hogan, E., et al. (2016). Mitochondrial Catalase Overexpressed Transgenic Mice Are Protected against Lung Fibrosis in Part via Preventing Alveolar Epithelial Cell Mitochondrial DNA Damage. Free Radic. Biol. Med. 101, 482-490. doi:10.1016/j.freeradbiomed.2016.11.007

Kim, S. K., Rho, S. J., Kim, S. H., Kim, S. Y., Song, S. H., Yoo, J. Y., et al. (2019). Protective Effects of Diphenyleneiodonium, an NADPH Oxidase Inhibitor, on Lipopolysaccharide-Induced Acute Lung Injury. Clin. Exp. Pharmacol. Physiol. 46, 153-162. doi:10.1111/1440-1681.13050

King, T. E., Bradford, W. Z., Castro-Bernardini, S., Fagan, E. A., Glaspole, I., Glassberg, M. K., et al. (2014). A Phase 3 Trial of Pirfenidone in Patients with Idiopathic Pulmonary Fibrosis. N. Engl. J. Med. 370, 2083-2092. doi:10.1056/ NEJMoa1402582

Kinnula, V. L., and Crapo, J. D. (2003). Superoxide Dismutases in the Lung and Human Lung Diseases. Am. J. Respir. Crit. Care Med. 167, 1600-1619. doi:10.1164/rccm.200212-1479SO

Kinnula, V. L., Fattman, C. L., Tan, R. J., and Oury, T. D. (2005). Oxidative Stress in Pulmonary Fibrosis: a Possible Role for Redox Modulatory Therapy. Am. J. Respir. Crit. Care Med. 172, 417-422. doi:10.1164/ rccm.200501-017PP

Kinnula, V. L., Hodgson, U. A., Lakari, E. K., Tan, R. J., Sormunen, R. T., Soini, Y. M., et al. (2006). Extracellular Superoxide Dismutase Has a Highly Specific Localization in Idiopathic Pulmonary Fibrosis/usual Interstitial Pneumonia. Histopathology 49, 66-74. doi:10.1111/j.1365-2559.2006.02470.x

Kliment, C. R., and Oury, T. D. (2010). Oxidative Stress, Extracellular Matrix Targets, and Idiopathic Pulmonary Fibrosis. Free Radic. Biol. Med. 49, 707-717. doi:10.1016/j.freeradbiomed.2010.04.036

Kurundkar, A., and Thannickal, V. J. (2016). Redox Mechanisms in Age-Related Lung Fibrosis. Redox Biol. 9, 67-76. doi:10.1016/j.redox.2016.06.005

Kuwano, K., Nakashima, N., Inoshima, I., Hagimoto, N., Fujita, M., Yoshimi, M., et al. (2003). Oxidative Stress in Lung Epithelial Cells from Patients with Idiopathic Interstitial Pneumonias. Eur. Respir. J. 21, 232-240. doi:10.1183/ 09031936.03.00063203

Kyung, S. Y., Kim, D. Y., Yoon, J. Y., Son, E. S., Kim, Y. J., Park, J. W., et al. (2018). Sulforaphane Attenuates Pulmonary Fibrosis by Inhibiting the EpithelialMesenchymal Transition. BMC Pharmacol. Toxicol. 19, 13. doi:10.1186/ s40360-018-0204-7

Laleu, B., Gaggini, F., Orchard, M., Fioraso-Cartier, L., Cagnon, L., HoungninouMolango, S., et al. (2010). First in Class, Potent, and Orally Bioavailable NADPH Oxidase Isoform 4 (Nox4) Inhibitors for the Treatment of Idiopathic Pulmonary Fibrosis. J. Med. Chem. 53, 7715-7730. doi:10.1021/ jm100773e

Larios, J. M., Budhiraja, R., Fanburg, B. L., and Thannickal, V. J. (2001). Oxidative Protein Cross-Linking Reactions Involving L-Tyrosine in Transforming
Growth Factor-Beta1-Stimulated Fibroblasts. J. Biol. Chem. 276, 17437-17441. doi:10.1074/jbc.M100426200

Lawson, J. A., FitzGerald, G. A., and Rokach, J. (1999). Isoprostanes: Formation, Analysis and Use As Indices of Lipid Peroxidation in Vivo. J Biol Chem. 274, 24441-24444. doi:10.1074/jbc.274.35.24441

Lebed'ko, O. A., Ryzhavskii, B. Y., and Demidova, O. V. (2015). Effect of Antioxidant Echinochrome A on Bleomycin-Induced Pulmonary Fibrosis. Bull Exp. Biol. Med. 159, 351-354. doi:10.1007/s10517-015-2960-3

Lebedev, A. V., Ivanova, M. V., and Levitsky, D. O. (2005). Echinochrome, a Naturally Occurring Iron Chelator and Free Radical Scavenger in Artificial and Natural Membrane Systems. Life Sci. 76, 863-875. doi:10.1016/j.lfs.2004.10.007

Lederer, D. J., and Martinez, F. J. (2018). Idiopathic Pulmonary Fibrosis. N. Engl. J. Med. 378, 1811-1823. doi:10.1056/NEJMra1705751

Lee, C. F., Qiao, M., Schröder, K., Zhao, Q., and Asmis, R. (2010a). Nox4 Is a Novel Inducible Source of Reactive Oxygen Species in Monocytes and Macrophages and Mediates Oxidized Low Density Lipoprotein-Induced Macrophage Death. Circ. Res. 106, 1489-1497. doi:10.1161/CIRCRESAHA.109.215392

Lee, E. S., Lee, H. E., Shin, J. Y., Yoon, S., and Moon, J. O. (2003). The Flavonoid Quercetin Inhibits Dimethylnitrosamine-Induced Liver Damage in Rats. J. Pharm. Pharmacol. 55, 1169-1174. doi:10.1211/0022357021396

Lee, H. C., Yin, P. H., Chi, C. W., and Wei, Y. H. (2002). Increase in Mitochondrial Mass in Human Fibroblasts under Oxidative Stress and during Replicative Cell Senescence. J. Biomed. Sci. 9, 517-526. doi:10.1007/BF02254978

Lee, J. C., Kinniry, P. A., Arguiri, E., Serota, M., Kanterakis, S., Chatterjee, S., et al. (2010b). Dietary Curcumin Increases Antioxidant Defenses in Lung, Ameliorates Radiation-Induced Pulmonary Fibrosis, and Improves Survival in Mice. Radiat. Res. 173, 590-601. doi:10.1667/RR1522.1

Lehmann, M., Korfei, M., Mutze, K., Klee, S., Skronska-Wasek, W., Alsafadi, H. N., et al. (2017). Senolytic Drugs Target Alveolar Epithelial Cell Function and Attenuate Experimental Lung Fibrosis Ex Vivo. Eur. Respir. J. 50, 1602367. doi:10.1183/13993003.02367-2016

Lelli, D., Sahebkar, A., Johnston, T. P., and Pedone, C. (2017). Curcumin Use in Pulmonary Diseases: State of the Art and Future Perspectives. Pharmacol. Res. 115, 133-148. doi:10.1016/j.phrs.2016.11.017

Lenz, A. G., Costabel, U., and Maier, K. L. (1996). Oxidized BAL Fluid Proteins in Patients with Interstitial Lung Diseases. Eur. Respir. J. 9, 307-312. doi:10.1183/ 09031936.96.09020307

Lenz, A. G., Hinze-Heyn, H., Schneider, A., Behr, J., Häussinger, K., Heindi, S., et al. (2004). Influence of Inflammatory Mechanisms on the Redox Balance in Interstitial Lung Diseases. Respir. Med. 98, 737-745. doi:10.1016/j.rmed.2004.02.007

Li, D., Cong, Z., Yang, C., and Zhu, X. (2020). Inhibition of LPS-Induced Nox2 Activation by VAS2870 Protects Alveolar Epithelial Cells through Eliminating ROS and Restoring Tight Junctions. Biochem. Biophys. Res. Commun. 524, 575-581. doi:10.1016/j.bbrc.2020.01.134

Li, H., Liu, B., Li, P., Feng, L., Ma, H., Xuan, S., et al. (2015). Inhibitory Effects of Curcumin on Inflammatory Cytokines in Rats with Paraquat Poisoning. Zhonghua Lao Dong Wei Sheng Zhi Ye Bing Za Zhi 33, 689-692.

Li, S., Yang, X., Li, W., Li, J., Su, X., Chen, L., et al. (2012). N-acetylcysteine Downregulation of Lysyl Oxidase Activity Alleviating Bleomycin-Induced Pulmonary Fibrosis in Rats. Respiration 84, 509-517. doi:10.1159/000340041

Liguori, I., Russo, G., Curcio, F., Bulli, G., Aran, L., Della-Morte, D., et al. (2018). Oxidative Stress, Aging, and Diseases. Clin. Interv. Aging 13, 757-772. doi:10.2147/CIA.S158513

Liu, B., Cao, B., Zhang, D., Xiao, N., Chen, H., Li, G. Q., et al. (2016a). Salvianolic Acid B Protects against Paraquat-Induced Pulmonary Injury by Mediating Nrf2/Nox4 Redox Balance and TGF- $\beta 1 /$ Smad3 Signaling. Toxicol. Appl. Pharmacol. 309, 111-120. doi:10.1016/j.taap.2016.08.004

Liu, D., Gong, L., Zhu, H., Pu, S., Wu, Y., Zhang, W., et al. (2016b). Curcumin Inhibits Transforming Growth Factor $\beta$ Induced Differentiation of Mouse Lung Fibroblasts to Myofibroblasts. Front Pharmacol. 7, 419. doi:10.3389/ fphar.2016.00419

Liu, M., Xu, H., Zhang, L., Zhang, C., Yang, L., Ma, E., et al. (2018a). Salvianolic Acid B Inhibits Myofibroblast Transdifferentiation in Experimental Pulmonary Fibrosis via the Up-Regulation of Nrf2. Biochem. Biophys. Res. Commun. 495, 325-331. doi:10.1016/j.bbrc.2017.11.014

Liu, M., Zheng, M., Xu, H., Liu, L., Li, Y., Xiao, W., et al. (2015). Anti-pulmonary Fibrotic Activity of Salvianolic Acid B Was Screened by a Novel Method Based 
on the Cyto-Biophysical Properties. Biochem. Biophys. Res. Commun. 468, 214-220. doi:10.1016/j.bbrc.2015.10.127

Liu, N., Cao, F., Li, Q., Zhang, Y., Zhang, Z., and Guan, W. (2014a). Study of Quercetin on Pulmonary Fibrosis by Silica Particles. Wei Sheng Yan Jiu 43, 814-818.

Liu, P., Luo, G., Dodson, M., Schmidlin, C. J., Wei, Y., Kerimoglu, B., et al. (2021). The NRF2-Loc344887 Signaling axis Suppresses Pulmonary Fibrosis. Redox Biol. 38, 101766. doi:10.1016/j.redox.2020.101766

Liu, Q., Chu, H., Ma, Y., Wu, T., Qian, F., Ren, X., et al. (2016c). Salvianolic Acid B Attenuates Experimental Pulmonary Fibrosis through Inhibition of the TGF- $\beta$ Signaling Pathway. Sci. Rep. 6, 27610. doi:10.1038/srep27610

Liu, Q., Shi, X., Tang, L., Xu, W., Jiang, S., Ding, W., et al. (2018b). Salvianolic Acid B Attenuates Experimental Pulmonary Inflammation by Protecting Endothelial Cells against Oxidative Stress Injury. Eur. J. Pharmacol. 840, 9-19. doi:10.1016/ j.ejphar.2018.09.030

Liu, R. M., Liu, Y., Forman, H. J., Olman, M., and Tarpey, M. M. (2004). Glutathione Regulates Transforming Growth Factor-Beta-Stimulated Collagen Production in Fibroblasts. Am. J. Physiol. Lung Cell Mol Physiol 286, L121-L128. doi:10.1152/ajplung.00231.2003

Liu, R. M., Vayalil, P. K., Ballinger, C., Dickinson, D. A., Huang, W. T., Wang, S., et al. (2012). Transforming Growth Factor $\beta$ Suppresses Glutamate-Cysteine Ligase Gene Expression and Induces Oxidative Stress in a Lung Fibrosis Model. Free Radic. Biol. Med. 53, 554-563. doi:10.1016/j.freeradbiomed.2012.05.016

Liu, X., Qian, L., Nan, H., Cui, M., Hao, X., and Du, Y. (2014b). Function of the Transforming Growth Factor-B1/c-Jun N-Terminal Kinase Signaling Pathway in the Action of Thalidomide on a Rat Model of Pulmonary Fibrosis. Exp. Ther. Med. 7, 669-674. doi:10.3892/etm.2013.1457

Liu, Y., Lu, F., Kang, L., Wang, Z., and Wang, Y. (2017b). Pirfenidone Attenuates Bleomycin-Induced Pulmonary Fibrosis in Mice by Regulating Nrf2/Bach1 Equilibrium. BMC Pulm. Med. 17, 63. doi:10.1186/s12890-017-0405-7

Liu, Y. M., Nepali, K., and Liou, J. P. (2017a). Idiopathic Pulmonary Fibrosis: Current Status, Recent Progress, and Emerging Targets. J. Med. Chem. 60, 527-553. doi:10.1021/acs.jmedchem.6b00935

Luo, W., Liu, Q., Jiang, N., Li, M., and Shi, L. (2019). Isorhamnetin Inhibited Migration and Invasion via Suppression of Akt/ERK-Mediated Epithelial-ToMesenchymal Transition (EMT) in A549 Human Non-small-cell Lung Cancer Cells. Biosci. Rep. 39, BSR20190159. doi:10.1042/BSR20190159

M Davies, A., and G Holt, A. (2018). Why Antioxidant Therapies Have Failed in Clinical Trials. J. Theor. Biol. 457, 1-5. doi:10.1016/j.jtbi.2018.08.014

Ma, B. N., and Li, X. J. (2020). Resveratrol Extracted from Chinese Herbal Medicines: A Novel Therapeutic Strategy for Lung Diseases. Chin. Herb Med. 12, 349-358. doi:10.1016/j.chmed.2020.07.003

Ma, Y., Luo, L., Liu, X., Li, H., Zeng, Z., He, X., et al. (2021). Pirfenidone Mediates Cigarette Smoke Extract Induced Inflammation and Oxidative Stress In Vitro and In Vivo. Int. Immunopharmacol 96, 107593. doi:10.1016/ j.intimp.2021.107593

Ma, Z., Zhao, C., Chen, Q., Yu, C., Zhang, H., Zhang, Z., et al. (2018). Antifibrotic Effects of a Novel Pirfenidone Derivative In Vitro and In Vivo. Pulm. Pharmacol. Ther. 53, 100-106. doi:10.1016/j.pupt.2018.10.006

MacVittie, T. J., Gibbs, A., Farese, A. M., Barrow, K., Bennett, A., Taylor-Howell, C., et al. (2017). AEOL 10150 Mitigates Radiation-Induced Lung Injury in the Nonhuman Primate: Morbidity and Mortality Are Administration Scheduledependent. Radiat. Res. 187, 298-318. doi:10.1667/RR4413.1

Malli, F., Bardaka, F., Tsilioni, I., Karetsi, E., Gourgoulianis, K. I., and Daniil, Z. (2013). 8-isoprostane Levels in Serum and Bronchoalveolar Lavage in Idiopathic Pulmonary Fibrosis and Sarcoidosis. Food Chem. Toxicol. 61, 160-163. doi:10.1016/j.fct.2013.05.016

Manjeet K, R., and Ghosh, B. (1999). Quercetin Inhibits LPS-Induced Nitric Oxide and Tumor Necrosis Factor-Alpha Production in Murine Macrophages. Int. J. Immunopharmacol 21, 435-443. doi:10.1016/s0192-0561(99)00024-7

Manni, M. L., and Oury, T. D. (2014). "Oxidative Stress and Pulmonary Fibrosis," in Systems Biology Of Free Radicals And AntioxidantsAnonymous (Berlin, Heidelberg: Springer Berlin Heidelberg), 1611-1631. doi:10.1007/978-3-64230018-9_122

Manoury, B., Nenan, S., Leclerc, O., Guenon, I., Boichot, E., Planquois, J. M., et al. (2005). The Absence of Reactive Oxygen Species Production Protects Mice against Bleomycin-Induced Pulmonary Fibrosis. Respir. Res. 6, 11. doi:10.1186/ 1465-9921-6-11
Markart, P., Luboeinski, T., Korfei, M., Schmidt, R., Wygrecka, M., Mahavadi, P., et al. (2009). Alveolar Oxidative Stress Is Associated with Elevated Levels of Nonenzymatic Low-Molecular-Weight Antioxidants in Patients with Different Forms of Chronic Fibrosing Interstitial Lung Diseases. Antioxid. Redox Signal. 11, 227-240. doi:10.1089/ars.2008.2105

Martinez, F. J., Martinez, F. J., de Andrade, J. A., Anstrom, K. J., King, T. E., and Raghu, G. (2014). Randomized Trial of Acetylcysteine in Idiopathic Pulmonary Fibrosis. N. Engl. J. Med. 370, 2093-2101. doi:10.1056/NEJMoa1401739

Martinez, J. A., Ramos, S. G., Meirelles, M. S., Verceze, A. V., Arantes, M. R., and Vannucchi, H. (2008). Effects of Quercetin on Bleomycin-Induced Lung Injury: a Preliminary Study. J. Bras Pneumol 34, 445-452. doi:10.1590/s180637132008000700003

Masamune, A., Watanabe, T., Kikuta, K., Satoh, K., and Shimosegawa, T. (2008). NADPH Oxidase Plays a Crucial Role in the Activation of Pancreatic Stellate Cells. Am. J. Physiol. Gastrointest. Liver Physiol. 294, G99-G108. doi:10.1152/ ajpgi.00272.2007

Mata, M., Ruíz, A., Cerdá, M., Martinez-Losa, M., Cortijo, J., Santangelo, F., et al. (2003). Oral N-Acetylcysteine Reduces Bleomycin-Induced Lung Damage and Mucin Muc5ac Expression in Rats. Eur. Respir. J. 22, 900-905. doi:10.1183/ 09031936.03.00018003

Matsuzawa, Y., Kawashima, T., Kuwabara, R., Hayakawa, S., Irie, T., Yoshida, T., et al. (2015). Change in Serum Marker of Oxidative Stress in the Progression of Idiopathic Pulmonary Fibrosis. Pulm. Pharmacol. Ther. 32, 1-6. doi:10.1016/ j.pupt.2015.03.005

Mazur, W., Lindholm, P., Vuorinen, K., Myllärniemi, M., Salmenkivi, K., and Kinnula, V. L. (2010). Cell-specific Elevation of NRF2 and Sulfiredoxin-1 as Markers of Oxidative Stress in the Lungs of Idiopathic Pulmonary Fibrosis and Non-specific Interstitial Pneumonia. APMIS 118, 703-712. doi:10.1111/j.16000463.2010.02646.x

Mehrabani, M., Goudarzi, M., Mehrzadi, S., Siahpoosh, A., Mohammadi, M., Khalili, H., et al. (2020). Crocin: a Protective Natural Antioxidant against Pulmonary Fibrosis Induced by Bleomycin. Pharmacol. Rep. 72, 992-1001. doi:10.1007/s43440-019-00023-y

Mehrzadi, S., Hosseini, P., Mehrabani, M., Siahpoosh, A., Goudarzi, M., Khalili, H., et al. (2020). Attenuation of Bleomycin-Induced Pulmonary Fibrosis in Wistar Rats by Combination Treatment of Two Natural Phenolic Compounds: Quercetin and Gallic Acid. Nutr. Cancer 73, 2039-2049. doi:10.1080/ 01635581.2020 .1820053

Meyer, A., Buhl, R., Kampf, S., and Magnussen, H. (1995). Intravenous N-Acetylcysteine and Lung Glutathione of Patients with Pulmonary Fibrosis and Normals. Am. J. Respir. Crit. Care Med. 152, 1055-1060. doi:10.1164/ ajrccm.152.3.7663783

Meyer, A., Buhl, R., and Magnussen, H. (1994). The Effect of Oral N-Acetylcysteine on Lung Glutathione Levels in Idiopathic Pulmonary Fibrosis. Eur. Respir. J. 7, 431-436. doi:10.1183/09031936.94.07030431

Michiels, C. (2003). Endothelial Cell Functions. J. Cel Physiol 196, 430-443. doi:10.1002/jcp.10333

Minnelli, C., Moretti, P., Fulgenzi, G., Mariani, P., Laudadio, E., Armeni, T., et al. (2018). A Poloxamer-407 Modified Liposome Encapsulating Epigallocatechin3-Gallate in the Presence of Magnesium: Characterization and Protective Effect against Oxidative Damage. Int. J. Pharm. 552, 225-234. doi:10.1016/ j.ijpharm.2018.10.004

Misra, H. P., and Rabideau, C. (2000). Pirfenidone Inhibits NADPH-dependent Microsomal Lipid Peroxidation and Scavenges Hydroxyl Radicals. Mol. Cel Biochem 204, 119-126. doi:10.1023/a:1007023532508

Molina-Molina, M., Machahua-Huamani, C., Vicens-Zygmunt, V., Llatjós, R., Escobar, I., Sala-Llinas, E., et al. (2018). Anti-fibrotic Effects of Pirfenidone and Rapamycin in Primary IPF Fibroblasts and Human Alveolar Epithelial Cells. BMC Pulm. Med. 18, 63. doi:10.1186/s12890-018-0626-4

Mondello, S., Mazzon, E., Di Paola, R., Crisafulli, C., Mondello, P., Buemi, M., et al. (2009). Thalidomide Suppresses Sclerosing Encapsulating Peritonitis in a Rat Experimental Model. Shock 32, 332-339. doi:10.1097/SHK.0b013e3181994974

Muramatsu, Y., Sugino, K., Ishida, F., Tatebe, J., Morita, T., and Homma, S. (2016). Effect of Inhaled N-Acetylcysteine Monotherapy on Lung Function and Redox Balance in Idiopathic Pulmonary Fibrosis. Respir. Investig. 54, 170-178. doi:10.1016/j.resinv.2015.11.004

Murthy, S., Adamcakova-Dodd, A., Perry, S. S., Tephly, L. A., Keller, R. M., Metwali, N., et al. (2009). Modulation of Reactive Oxygen Species by Rac1 or 
Catalase Prevents Asbestos-Induced Pulmonary Fibrosis. Am. J. Physiol. Lung Cel Mol Physiol 297, L846-L855. doi:10.1152/ajplung.90590.2008

Myllärniemi, M., and Kaarteenaho, R. (2015). Pharmacological Treatment of Idiopathic Pulmonary Fibrosis - Preclinical and Clinical Studies of Pirfenidone, Nintedanib, and N-Acetylcysteine. Eur. Clin. Respir. J. 2, 26385. doi:10.3402/ecri.v2.26385

Nagai, K., Jiang, M. H., Hada, J., Nagata, T., Yajima, Y., Yamamoto, S., et al. (2002a). Epigallocatechin Gallate Protects against NO Stress-Induced Neuronal Damage after Ischemia by Acting as an Anti-oxidant. Brain Res. 956, 319-322. doi:10.1016/s0006-8993(02)03564-3

Nagai, S., Hamada, K., Shigematsu, M., Taniyama, M., Yamauchi, S., and Izumi, T. (2002b). Open-label Compassionate Use One Year-Treatment with Pirfenidone to Patients with Chronic Pulmonary Fibrosis. Intern. Med. 41, 1118-1123. doi:10.2169/internalmedicine.41.1118

Nakamura, T., Matsushima, M., Hayashi, Y., Shibasaki, M., Imaizumi, K., Hashimoto, N., et al. (2011). Attenuation of Transforming Growth Factor$\beta$-Stimulated Collagen Production in Fibroblasts by Quercetin-Induced Heme Oxygenase-1. Am. J. Respir. Cel Mol Biol 44, 614-620. doi:10.1165/rcmb.2010$0338 \mathrm{OC}$

Nakayama, S., Mukae, H., Sakamoto, N., Kakugawa, T., Yoshioka, S., Soda, H., et al. (2008). Pirfenidone Inhibits the Expression of HSP47 in TGF-Beta1-Stimulated Human Lung Fibroblasts. Life Sci. 82, 210-217. doi:10.1016/j.lfs.2007.11.003

Nakazato, H., Oku, H., Yamane, S., Tsuruta, Y., and Suzuki, R. (2002). A Novel Anti-fibrotic Agent Pirfenidone Suppresses Tumor Necrosis Factor-Alpha at the Translational Level. Eur. J. Pharmacol. 446, 177-185. doi:10.1016/s00142999(02)01758-2

Nanjo, F., Mori, M., Goto, K., and Hara, Y. (1999). Radical Scavenging Activity of tea Catechins and Their Related Compounds. Biosci. Biotechnol. Biochem. 63, 1621-1623. doi:10.1271/bbb.63.1621

Negishi, H., Xu, J. W., Ikeda, K., Njelekela, M., Nara, Y., and Yamori, Y. (2004). Black and green tea Polyphenols Attenuate Blood Pressure Increases in StrokeProne Spontaneously Hypertensive Rats. J. Nutr. 134, 38-42. doi:10.1093/jn/ 134.1.38

Nelson, K. K., and Melendez, J. A. (2004). Mitochondrial Redox Control of Matrix Metalloproteinases. Free Radic. Biol. Med. 37, 768-784. doi:10.1016/ j.freeradbiomed.2004.06.008

Noble, P. W., Albera, C., Bradford, W. Z., Costabel, U., Glassberg, M. K., Kardatzke, D., et al. (2011). Pirfenidone in Patients with Idiopathic Pulmonary Fibrosis (CAPACITY): Two Randomised Trials. Lancet 377, 1760-1769. doi:10.1016/ S0140-6736(11)60405-4

O’Donnell, B. V., Tew, D. G., Jones, O. T., and England, P. J. (1993). Studies on the Inhibitory Mechanism of Iodonium Compounds with Special Reference to Neutrophil NADPH Oxidase. Biochem. J. 290, 41-49. doi:10.1042/bj2900041

Oku, H., Nakazato, H., Horikawa, T., Tsuruta, Y., and Suzuki, R. (2002). Pirfenidone Suppresses Tumor Necrosis Factor-Alpha, Enhances Interleukin-10 and Protects Mice from Endotoxic Shock. Eur. J. Pharmacol. 446, 167-176. doi:10.1016/s0014-29990201757-0

Oku, H., Shimizu, T., Kawabata, T., Nagira, M., Hikita, I., Ueyama, A., et al. (2008). Antifibrotic Action of Pirfenidone and Prednisolone: Different Effects on Pulmonary Cytokines and Growth Factors in Bleomycin-Induced Murine Pulmonary Fibrosis. Eur. J. Pharmacol. 590, 400-408. doi:10.1016/ j.ejphar.2008.06.046

Oldham, J. M., Ma, S. F., Martinez, F. J., Anstrom, K. J., Raghu, G., Schwartz, D. A., et al. (2015). TOLLIP, MUC5B, and the Response to N-Acetylcysteine Among Individuals with Idiopathic Pulmonary Fibrosis. Am. J. Respir. Crit. Care Med. 192, 1475-1482. doi:10.1164/rccm.201505-1010OC

Osborn-Heaford, H. L., Ryan, A. J., Murthy, S., Racila, A.-M., He, C., Sieren, J. C., et al. (2012). Mitochondrial Racl GTPase Import and Electron Transfer from Cytochrome C Are Required for Pulmonary Fibrosis. J. Biol. Chemistry 287, 3301-3312. doi:10.1074/jbc.M111.308387

Otoupalova, E., Smith, S., Cheng, G., and Thannickal, V. J. (2020). Oxidative Stress in Pulmonary Fibrosis. Compr. Physiol. 10, 509-547. doi:10.1002/cphy.c190017

Oury, T. D., Thakker, K., Menache, M., Chang, L. Y., Crapo, J. D., and Day, B. J. (2001). Attenuation of Bleomycin-Induced Pulmonary Fibrosis by a Catalytic Antioxidant Metalloporphyrin. Am. J. Respir. Cel Mol Biol 25, 164-169. doi:10.1165/ajrcmb.25.2.4235

Oz, H. S. (2017). Chronic Inflammatory Diseases and Green Tea Polyphenols. Nutrients 9, 561. doi:10.3390/nu9060561
Ozben, T. (2015). Antioxidant Supplementation on Cancer Risk and during Cancer Therapy: an Update. Curr. Top. Med. Chem. 15, 170-178. doi:10.2174/ 1568026615666141209160918

Pache, J. C., Carnesecchi, S., Deffert, C., Donati, Y., Herrmann, F. R., BarazzoneArgiroffo, C., et al. (2011). NOX-4 Is Expressed in Thickened Pulmonary Arteries in Idiopathic Pulmonary Fibrosis. Nat. Med. 17, 31-33. doi:10.1038/ nm0111-31

Panduri, V., Liu, G., Surapureddi, S., Kondapalli, J., Soberanes, S., de Souza-Pinto, N. C., et al. (2009). Role of Mitochondrial hOGG1 and Aconitase in OxidantInduced Lung Epithelial Cell Apoptosis. Free Radic. Biol. Med. 47, 750-759. doi:10.1016/j.freeradbiomed.2009.06.010

Parmentier, M., Drost, E., and Hirani, N. (1999). Thiol Antioxidantsinhibit Neutrophil Chemotaxis by Decreasing Release of IL-8 from Macrophages and Pulmonary Epithelial Cells. Am J. Respir. Crit. Care. Med., 159, A286, (New York, NY: Amer Lung Assoc).

Peng, H., Liu, Y., Wang, J., Zhao, X., and Wang, X. (2013). Effect of Quercetin on the Expression of TGF-Betal in Human Embryonic Lung Fibroblasts Activated by the Silicotic Alveolar Macrophages. Wei Sheng Yan Jiu 42, 99-102.

Petersen, S. V., Oury, T. D., Ostergaard, L., Valnickova, Z., Wegrzyn, J., Thøgersen, I. B., et al. (2004). Extracellular Superoxide Dismutase (EC-SOD) Binds to Type I Collagen and Protects against Oxidative Fragmentation. J. Biol. Chem. 279, 13705-13710. doi:10.1074/jbc.M310217200

Phan, S. H. (2002). The Myofibroblast in Pulmonary Fibrosis. Chest 122, 286S-289S. doi:10.1378/chest.122.6_suppl.286s

Phan, T. T., Lim, I. J., Sun, L., Chan, S. Y., Bay, B. H., Tan, E. K., et al. (2003). Quercetin Inhibits Fibronectin Production by Keloid-Derived Fibroblasts. Implication for the Treatment of Excessive Scars. J. Dermatol. Sci. 33, 192-194. doi:10.1016/j.jdermsci.2003.08.008

Pociask, D. A., Sime, P. J., and Brody, A. R. (2004). Asbestos-derived Reactive Oxygen Species Activate TGF-Betal. Lab. Invest. 84, 1013-1023. doi:10.1038/ labinvest.3700109

Poletti, V., Ravaglia, C., and Tomassetti, S. (2014). Pirfenidone for the Treatment of Idiopathic Pulmonary Fibrosis. Expert Rev. Respir. Med. 8, 539-545. doi:10.1586/17476348.2014.915750

Pourgholamhossein, F., Rasooli, R., Pournamdari, M., Pourgholi, L., SamarehFekri, M., Ghazi-Khansari, M., et al. (2018). Pirfenidone Protects against Paraquat-Induced Lung Injury and Fibrosis in Mice by Modulation of Inflammation, Oxidative Stress, and Gene Expression. Food Chem. Toxicol. 112, 39-46. doi:10.1016/j.fct.2017.12.034

Psathakis, K., Mermigkis, D., Papatheodorou, G., Loukides, S., Panagou, P., Polychronopoulos, V., et al. (2006). Exhaled Markers of Oxidative Stress in Idiopathic Pulmonary Fibrosis. Eur. J. Clin. Invest. 36, 362-367. doi:10.1111/ j.1365-2362.2006.01636.x

Punithavathi, D., Venkatesan, N., and Babu, M. (2000). Curcumin Inhibition of Bleomycin-Induced Pulmonary Fibrosis in Rats. Br. J. Pharmacol. 131, 169-172. doi:10.1038/sj.bjp.0703578

Punithavathi, D., Venkatesan, N., and Babu, M. (2003). Protective Effects of Curcumin against Amiodarone-Induced Pulmonary Fibrosis in Rats. $\mathrm{Br}$. J. Pharmacol. 139, 1342-1350. doi:10.1038/sj.bjp.0705362

Qu, J., Zhang, Z., Zhang, P., Zheng, C., Zhou, W., Cui, W., et al. (2019). Downregulation of HMGB1 Is Required for the Protective Role of Nrf2 in EMT-Mediated PF. J. Cel Physiol 234, 8862-8872. doi:10.1002/jcp.27548

Rabbani, Z. N., Anscher, M. S., Folz, R. J., Archer, E., Huang, H., Chen, L., et al. (2005). Overexpression of Extracellular Superoxide Dismutase Reduces Acute Radiation Induced Lung Toxicity. BMC Cancer 5, 59. doi:10.1186/1471-24075-59

Rabbani, Z. N., Batinic-Haberle, I., Anscher, M. S., Huang, J., Day, B. J., Alexander, E., et al. (2007). Long-term Administration of a Small Molecular Weight Catalytic Metalloporphyrin Antioxidant, AEOL 10150, Protects Lungs from Radiation-Induced Injury. Int. J. Radiat. Oncol. Biol. Phys. 67, 573-580. doi:10.1016/j.ijrobp.2006.09.053

Radomska-Leśniewska, D. M., Skopińska-Rózewska, E., Jankowska-Steifer, E., Sobiecka, M., Sadowska, A. M., Hevelke, A., et al. (2010). N-acetylcysteine Inhibits IL-8 and MMP-9 Release and ICAM-1 Expression by Bronchoalveolar Cells from Interstitial Lung Disease Patients. Pharmacol. Rep. 62, 131-138. doi:10.1016/s1734-1140(10)70250-4

Raghu, G., Johnson, W. C., Lockhart, D., and Mageto, Y. (1999). Treatment of Idiopathic Pulmonary Fibrosis with a New Antifibrotic Agent, Pirfenidone: 
Results of a Prospective, Open-Label Phase II Study. Am. J. Respir. Crit. Care Med. 159, 1061-1069. doi:10.1164/ajrccm.159.4.9805017

Rahman, I., Skwarska, E., Henry, M., Davis, M., O’Connor, C. M., FitzGerald, M. X., et al. (1999). Systemic and Pulmonary Oxidative Stress in Idiopathic Pulmonary Fibrosis. Free Radic. Biol. Med. 27, 60-68. doi:10.1016/s08915849(99)00035-0

Rangarajan, S., Bernard, K., and Thannickal, V. J. (2017). Mitochondrial Dysfunction in Pulmonary Fibrosis. Ann. Am. Thorac. Soc. 14, S383-S388. doi:10.1513/AnnalsATS.201705-370AW

Rangarajan, S., Bone, N. B., Zmijewska, A. A., Jiang, S., Park, D. W., Bernard, K., et al. (2018). Metformin Reverses Established Lung Fibrosis in a Bleomycin Model. Nat. Med. 24, 1121-1127. doi:10.1038/s41591-018-0087-6

Reiter, R. J., Mayo, J. C., Tan, D. X., Sainz, R. M., Alatorre-Jimenez, M., and Qin, L. (2016). Melatonin as an Antioxidant: under Promises but over Delivers. J. Pineal Res. 61, 253-278. doi:10.1111/jpi.12360

Reiter, R. J., Tan, D. X., Manchester, L. C., Pilar Terron, M., Flores, L. J., and Koppisepi, S. (2007). Medical Implications of Melatonin: Receptor-Mediated and Receptor-independent Actions. Adv. Med. Sci. 52, 11-28.

Ren, J., Li, J., Liu, X., Feng, Y., Gui, Y., Yang, J., et al. (2016). Quercetin Inhibits Fibroblast Activation and Kidney Fibrosis Involving the Suppression of Mammalian Target of Rapamycin and $\beta$-catenin Signaling. Sci. Rep. 6, 23968. doi: $10.1038 /$ srep 23968

Ren, X., Han, L., Li, Y., Zhao, H., Zhang, Z., Zhuang, Y., et al. (2021). Isorhamnetin Attenuates TNF- $\alpha$-Induced Inflammation, Proliferation, and Migration in Human Bronchial Epithelial Cells via MAPK and NF-Kb Pathways. Anat. Rec. (Hoboken) 304, 901-913. doi:10.1002/ar.24506

Rhyu, D. Y., Yang, Y., Ha, H., Lee, G. T., Song, J. S., Uh, S. T., et al. (2005). Role of Reactive Oxygen Species in TGF-Betal-Induced Mitogen-Activated Protein Kinase Activation and Epithelial-Mesenchymal Transition in Renal Tubular Epithelial Cells. J. Am. Soc. Nephrol. 16, 667-675. doi:10.1681/ ASN.2004050425

Ricciardolo, F. L., Di Stefano, A., Sabatini, F., and Folkerts, G. (2006). Reactive Nitrogen Species in the Respiratory Tract. Eur. J. Pharmacol. 533, 240-252. doi:10.1016/j.ejphar.2005.12.057

Ricciardolo, F. L., Sterk, P. J., Gaston, B., and Folkerts, G. (2004). Nitric Oxide in Health and Disease of the Respiratory System. Physiol. Rev. 84, 731-765. doi:10.1152/physrev.00034.2003

Richeldi, L., Collard, H. R., and Jones, M. G. (1941). Idiopathic Pulmonary Fibrosis. Lancet 389, 1941-1952.

Rottoli, P., Magi, B., Cianti, R., Bargagli, E., Vagaggini, C., Nikiforakis, N., et al. (2005). Carbonylated Proteins in Bronchoalveolar Lavage of Patients with Sarcoidosis, Pulmonary Fibrosis Associated with Systemic Sclerosis and Idiopathic Pulmonary Fibrosis. Proteomics 5, 2612-2618. doi:10.1002/ pmic.200401206

Ruwanpura, S. M., Thomas, B. J., and Bardin, P. G. (2020). Pirfenidone: Molecular Mechanisms and Potential Clinical Applications in Lung Disease. Am. J. Respir. Cel Mol Biol 62, 413-422. doi:10.1165/rcmb.2019-0328TR

Saidi, A., Kasabova, M., Vanderlynden, L., Wartenberg, M., Kara-Ali, G. H., Marc, D., et al. (2019). Curcumin Inhibits the TGF- $\beta 1$-dependent Differentiation of Lung Fibroblasts via PPAR $\gamma$-Driven Upregulation of Cathepsins B and L. Sci. Rep. 9, 491. doi:10.1038/s41598-018-36858-3

Sakamoto, S., Kataoka, K., Kondoh, Y., Kato, M., Okamoto, M., Mukae, H., et al. (2021). Pirfenidone Plus Inhaled N-Acetylcysteine for Idiopathic Pulmonary Fibrosis: a Randomised Trial. Eur. Respir. J. 57, 2000348. doi:10.1183/ 13993003.00348-2020

Salah, N., Miller, N. J., Paganga, G., Tijburg, L., Bolwell, G. P., and Rice-Evans, C. (1995). Polyphenolic Flavanols as Scavengers of Aqueous Phase Radicals and as Chain-Breaking Antioxidants. Arch. Biochem. Biophys. 322, 339-346. doi:10.1006/abbi.1995.1473

Saleh, D., Barnes, P. J., and Giaid, A. (1997). Increased Production of the Potent Oxidant Peroxynitrite in the Lungs of Patients with Idiopathic Pulmonary Fibrosis. Am. J. Respir. Crit. Care Med. 155, 1763-1769. doi:10.1164/ ajrccm.155.5.9154889

Salvemini, D., Riley, D. P., and Cuzzocrea, S. (2002). SOD Mimetics Are Coming of Age. Nat. Rev. Drug Discov. 1, 367-374. doi:10.1038/nrd796

Sampaio, E. P., Sarno, E. N., Galilly, R., Cohn, Z. A., and Kaplan, G. (1991). Thalidomide Selectively Inhibits Tumor Necrosis Factor Alpha Production by
Stimulated Human Monocytes. J. Exp. Med. 173, 699-703. doi:10.1084/ jem.173.3.699

Santofimia-Castaño, P., Clea Ruy, D., Garcia-Sanchez, L., Jimenez-Blasco, D., Fernandez-Bermejo, M., Bolaños, J. P., et al. (2015). Melatonin Induces the Expression of Nrf2-Regulated Antioxidant Enzymes via PKC and Ca2+ Influx Activation in Mouse Pancreatic Acinar Cells. Free Radic. Biol. Med. 87, 226-236. doi:10.1016/j.freeradbiomed.2015.06.033

Sartor, L., Pezzato, E., and Garbisa, S. (2002). Epigallocatechin-3-gallate Inhibits Leukocyte Elastase: Potential of the Phyto-Factor in Hindering Inflammation, Emphysema, and Invasion. J. Leukoc. Biol. 71, 73-79.

Sato, N., Takasaka, N., Yoshida, M., Tsubouchi, K., Minagawa, S., Araya, J., et al. (2016). Metformin Attenuates Lung Fibrosis Development via NOX4 Suppression. Respir. Res. 17, 107. doi:10.1186/s12931-016-0420-x

Sazonova, E. N., Kuznetsova, M. S., Vasileva, E. A., Mishchenko, N. P., Tsimbalist, N. A., and Lebed'ko, O. A. (2020). Cytoprotective Effect of Echinochrome A in Primary Culture of Pulmonary Fibroblasts from Albino Rats under Conditions of Oxidative Stress. Bull. Exp. Biol. Med. 169, 582-585. doi:10.1007/s10517-02004933-3

Schafer, M. J., White, T. A., Iijima, K., Haak, A. J., Ligresti, G., Atkinson, E. J., et al. (2017). Cellular Senescence Mediates Fibrotic Pulmonary Disease. Nat. Commun. 8, 14532. doi:10.1038/ncomms14532

Sellarés, J., and Rojas, M. (2019). Quercetin in Idiopathic Pulmonary Fibrosis: Another Brick in the Senolytic Wall. Am. J. Respir. Cell Mol Biol 60, 3-4. doi:10.1165/rcmb.2018-0267ED

Sener, G., Topaloğlu, N., Sehirli, A. O., Ercan, F., and Gedik, N. (2007). Resveratrol Alleviates Bleomycin-Induced Lung Injury in Rats. Pulm. Pharmacol. Ther. 20, 642-649. doi:10.1016/j.pupt.2006.07.003

Serrano-Mollar, A., Closa, D., Prats, N., Blesa, S., Martinez-Losa, M., Cortijo, J., et al. (2003). In Vivo antioxidant Treatment Protects against BleomycinInduced Lung Damage in Rats. Br. J. Pharmacol. 138, 1037-1048. doi:10.1038/s.bjp.0705138

Shahzeidi, S., Sarnstrand, B., Jeffery, P. K., McAnulty, R. J., and Laurent, G. J. (1991). Oral N-Acetylcysteine Reduces Bleomycin-Induced Collagen Deposition in the Lungs of Mice. Eur. Respir. J. 4, 845-852.

Sharma, N. L., Sharma, V. C., Mahajan, V. K., Shanker, V., Ranjan, N., and Gupta, M. (2007). Thalidomide: an Experience in Therapeutic Outcome and Adverse Reactions. J. Dermatolog Treat 18, 335-340. doi:10.1080/09546630701386993

Shi, H., He, J., Li, X., Han, J., Wu, R., Wang, D., et al. (2018a). Isorhamnetin, the Active Constituent of a Chinese Herb Hippophae Rhamnoides L, Is a Potent Suppressor of Dendritic-Cell Maturation and Trafficking. Int. Immunopharmacol 55, 216-222. doi:10.1016/j.intimp.2017.12.014

Shi, W., Li, L., Ding, Y., Yang, K., Chen, Z., Fan, X., et al. (2018b). The Critical Role of Epigallocatechin Gallate in Regulating Mitochondrial Metabolism. Future Med. Chem. 10, 795-809. doi:10.4155/fmc-2017-0204

Shimizu, Y., Dobashi, K., Sano, T., and Yamada, M. (2014). ROCK Activation in Lung of Idiopathic Pulmonary Fibrosis with Oxidative Stress. Int. J. Immunopathol Pharmacol. 27, 37-44. doi:10.1177/039463201402700106

Shin, N. R., Park, J. W., Lee, I. C., Ko, J. W., Park, S. H., Kim, J. S., et al. (2017). Melatonin Suppresses Fibrotic Responses Induced by Cigarette Smoke via Downregulation of TGF-B1. Oncotarget 8, 95692-95703. doi:10.18632/ oncotarget. 21680

Smith, M. R., Gangireddy, S. R., Narala, V. R., Hogaboam, C. M., Standiford, T. J., Christensen, P. J., et al. (2010). Curcumin Inhibits Fibrosis-Related Effects in IPF Fibroblasts and in Mice Following Bleomycin-Induced Lung Injury. Am. J. Physiol. Lung Cell Mol Physiol 298, L616-L625. doi:10.1152/ ajplung.00002.2009

Spagnolo, P., Kreuter, M., Maher, T. M., Wuyts, W., Bonella, F., Corte, T. J., et al. (2018). Metformin Does Not Affect Clinically Relevant Outcomes in Patients with Idiopathic Pulmonary Fibrosis. Respiration 96, 314-322. doi:10.1159/ 000489668

Spond, J., Case, N., Chapman, R. W., Crawley, Y., Egan, R. W., Fine, J., et al. (2003). Inhibition of Experimental Acute Pulmonary Inflammation by Pirfenidone. Pulm. Pharmacol. Ther. 16, 207-214. doi:10.1016/S1094-5539(03)00026-9

Sriram, N., Kalayarasan, S., Manikandan, R., Arumugam, M., and Sudhandiran, G. (2015). Epigallocatechin Gallate Attenuates Fibroblast Proliferation and Excessive Collagen Production by Effectively Intervening TGF-B1 Signalling. Clin. Exp. Pharmacol. Physiol. 42, 849-859. doi:10.1111/1440-1681.12428 
Sriram, N., Kalayarasan, S., and Sudhandiran, G. (2008). Enhancement of Antioxidant Defense System by Epigallocatechin-3-Gallate during Bleomycin Induced Experimental Pulmonary Fibrosis. Biol. Pharm. Bull 31, 1306-1311. doi:10.1248/bpb.31.1306

Sriram, N., Kalayarasan, S., and Sudhandiran, G. (2009a). Epigallocatechin-3gallate Augments Antioxidant Activities and Inhibits Inflammation during Bleomycin-Induced Experimental Pulmonary Fibrosis through Nrf2-Keap1 Signaling. Pulm. Pharmacol. Ther. 22, 221-236. doi:10.1016/j.pupt.2008.12.010

Sriram, N., Kalayarasan, S., and Sudhandiran, G. (2009b). Epigallocatechin-3gallate Exhibits Anti-fibrotic Effect by Attenuating Bleomycin-Induced Glycoconjugates, Lysosomal Hydrolases and Ultrastructural Changes in Rat Model Pulmonary Fibrosis. Chem. Biol. Interact 180, 271-280. doi:10.1016/ j.cbi.2009.02.017

Steinhubl, S. R. (2008). Why Have Antioxidants Failed in Clinical Trials? Am. J. Cardiol. 101, 14D-19D. doi:10.1016/j.amjcard.2008.02.003

Sturrock, A., Cahill, B., Norman, K., Huecksteadt, T. P., Hill, K., Sanders, K., et al. (2006). Transforming Growth Factor-Betal Induces Nox4 NAD(P)H Oxidase and Reactive Oxygen Species-dependent Proliferation in Human Pulmonary Artery Smooth Muscle Cells. Am. J. Physiol. Lung Cell Mol Physiol 290, L661-L673. doi:10.1152/ajplung.00269.2005

Sugiura, H., Ichikawa, T., Liu, X., Kobayashi, T., Wang, X. Q., Kawasaki, S., et al. (2009). N-acetyl-L-cysteine Inhibits TGF-Betal-Induced Profibrotic Responses in Fibroblasts. Pulm. Pharmacol. Ther. 22, 487-491. doi:10.1016/ j.pupt.2009.04.002

Swiderska-Kołacz, G., Klusek, J., and Kołataj, A. (2006). The Effect of Melatonin on Glutathione and Glutathione Transferase and Glutathione Peroxidase Activities in the Mouse Liver and Kidney In Vivo. Neuro Endocrinol. Lett. 27, 365-368.

Tabata, C., Tabata, R., Kadokawa, Y., Hisamori, S., Takahashi, M., Mishima, M., et al. (2007). Thalidomide Prevents Bleomycin-Induced Pulmonary Fibrosis in Mice. J. Immunol. 179, 708-714. doi:10.4049/jimmunol.179.1.708

Takano, M., Deguchi, J., Senoo, S., Izumi, M., Kawami, M., and Yumoto, R. (2020). Suppressive Effect of Quercetin against Bleomycin-Induced EpithelialMesenchymal Transition in Alveolar Epithelial Cells. Drug Metab. Pharmacokinet. 35, 522-526. doi:10.1016/j.dmpk.2020.08.001

Tanaka, T., Saito, Y., Matsuda, K., Kamio, K., Abe, S., Kubota, K., et al. (2017). Cyclic Mechanical Stretch-Induced Oxidative Stress Occurs via a NOXdependent Mechanism in Type II Alveolar Epithelial Cells. Respir. Physiol. Neurobiol. 242, 108-116. doi:10.1016/j.resp.2017.04.007

Tang, H., He, H., Ji, H., Gao, L., Mao, J., Liu, J., et al. (2015). Tanshinone IIA Ameliorates Bleomycin-Induced Pulmonary Fibrosis and Inhibits Transforming Growth Factor-beta- $\beta$-dependent Epithelial to Mesenchymal Transition. J. Surg. Res. 197, 167-175. doi:10.1016/j.jss.2015.02.062

Tanigawa, S., Fujii, M., and Hou, D. X. (2007). Action of Nrf2 and Keap1 in AREMediated NQO1 Expression by Quercetin. Free Radic. Biol. Med. 42, 1690-1703. doi:10.1016/j.freeradbiomed.2007.02.017

Taniguchi, H., Ebina, M., Kondoh, Y., Ogura, T., Azuma, A., Suga, M., et al. (2010). Pirfenidone in Idiopathic Pulmonary Fibrosis. Eur. Respir. J. 35, 821-829. doi:10.1183/09031936.00005209

Taslidere, E., Esrefoglu, M., Elbe, H., Cetin, A., and Ates, B. (2014). Protective Effects of Melatonin and Quercetin on Experimental Lung Injury Induced by Carbon Tetrachloride in Rats. Exp. Lung Res. 40, 59-65. doi:10.3109/ 01902148.2013 .866181

Tavares, J. L., Wangoo, A., Dilworth, P., Marshall, B., Kotecha, S., and Shaw, R. J. (1997). Thalidomide Reduces Tumour Necrosis Factor-Alpha Production by Human Alveolar Macrophages. Respir. Med. 91, 31-39. doi:10.1016/s09546111(97)90134-7

ten Freyhaus, H., Huntgeburth, M., Wingler, K., Schnitker, J., Bäumer, A. T., Vantler, M., et al. (2006). Novel Nox Inhibitor VAS2870 Attenuates PDGFdependent Smooth Muscle Cell Chemotaxis, but Not Proliferation. Cardiovasc. Res. 71, 331-341. doi:10.1016/j.cardiores.2006.01.022

Teng, R. J., Du, J., Welak, S., Guan, T., Eis, A., Shi, Y., et al. (2012). Cross Talk between NADPH Oxidase and Autophagy in Pulmonary Artery Endothelial Cells with Intrauterine Persistent Pulmonary Hypertension. Am. J. Physiol. Lung Cell Mol Physiol 302, L651-L663. doi:10.1152/ajplung.00177.2011

Thannickal, V. J., Lee, D. Y., White, E. S., Cui, Z., Larios, J. M., Chacon, R., et al. (2003). Myofibroblast Differentiation by Transforming Growth Factor-Beta1 Is Dependent on Cell Adhesion and Integrin Signaling via Focal Adhesion Kinase. J. Biol. Chem. 278, 12384-12389. doi:10.1074/jbc.M208544200
Thomas, D. D., Ridnour, L. A., Isenberg, J. S., Flores-Santana, W., Switzer, C. H., Donzelli, S., et al. (2008). The Chemical Biology of Nitric Oxide: Implications in Cellular Signaling. Free Radic. Biol. Med. 45, 18-31. doi:10.1016/ j.freeradbiomed.2008.03.020

Thresiamma, K. C., George, J., and Kuttan, R. (1998). Protective Effect of Curcumin, Ellagic Acid and Bixin on Radiation Induced Genotoxicity. J. Exp. Clin. Cancer Res. 17, 431-434.

Tian, X. L., Yao, W., Guo, Z. J., Gu, L., and Zhu, Y. J. (2006). Low Dose Pirfenidone Suppresses Transforming Growth Factor Beta-1 and Tissue Inhibitor of Metalloproteinase-1, and Protects Rats from Lung Fibrosis Induced by Bleomycina. Chin Med. Sci. J. 21, 145-151.

Tomé-Carneiro, J., Larrosa, M., González-Sarrías, A., Tomás-Barberán, F., GarcíaConesa, M., and Espín, J. (2013). Resveratrol and Clinical Trials: The Crossroad from In Vitro Studies to Human Evidence. Cpd 19, 6064-6093. doi:10.2174/ 13816128113199990407

Tsai, M. J., Chang, W. A., Liao, S. H., Chang, K. F., Sheu, C. C., and Kuo, P. L. (2019). The Effects of Epigallocatechin Gallate (EGCG) on Pulmonary Fibroblasts of Idiopathic Pulmonary Fibrosis (IPF)-A Next-Generation Sequencing and Bioinformatic Approach. Int. J. Mol. Sci. 20, 1958. doi:10.3390/ijms20081958

Veith, C., Drent, M., Bast, A., van Schooten, F. J., and Boots, A. W. (2017). The Disturbed Redox-Balance in Pulmonary Fibrosis Is Modulated by the Plant Flavonoid Quercetin. Toxicol. Appl. Pharmacol. 336, 40-48. doi:10.1016/ j.taap.2017.10.001

Venkatadri, R., Iyer, A. K., Ramesh, V., Wright, C., Castro, C. A., Yakisich, J. S., et al. (2017). MnTBAP Inhibits Bleomycin-Induced Pulmonary Fibrosis by Regulating VEGF and Wnt Signaling. J. Cell Physiol 232, 506-516. doi:10.1002/ jcp. 25608

Verma, R., Kushwah, L., Gohel, D., Patel, M., Marvania, T., and Balakrishnan, S. (2013). Evaluating the Ameliorative Potential of Quercetin against the Bleomycin-Induced Pulmonary Fibrosis in Wistar Rats. Pulm. Med. 2013 921724. doi:10.1155/2013/921724

Virdis, A., Gesi, M., and Taddei, S. (2016). Impact of Apocynin on Vascular Disease in Hypertension. Vascul Pharmacol. 87, 1-5. doi:10.1016/j.vph.2016.08.006

Vriend, J., and Reiter, R. J. (2015). Melatonin Feedback on Clock Genes: a Theory Involving the Proteasome. J. Pineal Res. 58, 1-11. doi:10.1111/jpi.12189

Vujaskovic, Z., Batinic-Haberle, I., Rabbani, Z. N., Feng, Q. F., Kang, S. K., Spasojevic, I., et al. (2002). A Small Molecular Weight Catalytic Metalloporphyrin Antioxidant with Superoxide Dismutase (SOD) Mimetic Properties Protects Lungs from Radiation-Induced Injury. Free Radic. Biol. Med. 33, 857-863. doi:10.1016/s0891-5849(02)00980-2

Vuorinen, K., Ohlmeier, S., Leppäranta, O., Salmenkivi, K., Myllärniemi, M., and Kinnula, V. L. (2008). Peroxiredoxin II Expression and its Association with Oxidative Stress and Cell Proliferation in Human Idiopathic Pulmonary Fibrosis. J. Histochem. Cytochem. 56, 951-959. doi:10.1369/ jhc. 2008.951806

Waghray, M., Cui, Z., Horowitz, J. C., Subramanian, I. M., Martinez, F. J., Toews, G. B., et al. (2005). Hydrogen Peroxide Is a Diffusible Paracrine Signal for the Induction of Epithelial Cell Death by Activated Myofibroblasts. FASEB j. 19, 1-16. doi:10.1096/fj.04-2882fje

Walters, D. M., Cho, H. Y., and Kleeberger, S. R. (2008). Oxidative Stress and Antioxidants in the Pathogenesis of Pulmonary Fibrosis: a Potential Role for Nrf2. Antioxid. Redox Signal 10, 321-332. doi:10.1089/ars.2007.1901

Wan, W. Y., Hollins, F., Haste, L., Woodman, L., Hirst, R. A., Bolton, S., et al. (2016). NADPH Oxidase-4 Overexpression Is Associated with Epithelial Ciliary Dysfunction in Neutrophilic Asthma. Chest 149, 1445-1459. doi:10.1016/ j.chest.2016.01.024

Wang, C. M., He, Q. Z., and Zhang, R. X. (1994). Effects of Tanshionone to Bleomycin Induced Pulmonary Fibrosis of Rats on Histological Changes and Production of Lipid Peroxides and Hydroxyproline. Zhonghua Jie He He $\mathrm{HuXi}$ Za Zhi 17, 308320-320.

Wang, J., He, F., Chen, L., Li, Q., Jin, S., Zheng, H., et al. (2018). Resveratrol Inhibits Pulmonary Fibrosis by Regulating miR-21 through MAPK/AP-1 Pathways. Biomed. Pharmacother. 105, 37-44. doi:10.1016/j.biopha.2018.05.104

Wang, L., Li, S., Yao, Y., Yin, W., and Ye, T. (2021). The Role of Natural Products in the Prevention and Treatment of Pulmonary Fibrosis: a Review. Food Funct. 12, 990-1007. doi:10.1039/D0FO03001E

Wang, Q., Zhu, H., Zhou, W. G., Guo, X. C., Wu, M. J., Xu, Z. Y., et al. (2013). $\mathrm{N}$-acetylcysteine-pretreated Human Embryonic Mesenchymal Stem Cell 
Administration Protects against Bleomycin-Induced Lung Injury. Am. J. Med. Sci. 346, 113-122. doi:10.1097/MAJ.0b013e318266e8d8

Wang, X. (2009). The Antiapoptotic Activity of Melatonin in Neurodegenerative Diseases. CNS Neurosci. Ther. 15, 345-357. doi:10.1111/j.17555949.2009.00105.x

Watchorn, T., Mulier, B., and MacNee, W. (1998). Does Increasingintracellular Glutathione Inhibit Cytokine-Induced Nitric Oxide Release and NF-kB Activation. Am J Respir Crit Care Med, 157, A889.

Wei, Y., Dong, W., Jackson, J., Ho, T. C., Le Saux, C. J., Brumwell, A., et al. (2021). Blocking LOXL2 and TGF $\beta 1$ Signalling Induces Collagen I Turnover in Precision-Cut Lung Slices Derived from Patients with Idiopathic Pulmonary Fibrosis. Thorax 76, 729-732. doi:10.1136/thoraxjnl-2020215745

Wingler, K., Altenhoefer, S. A., Kleikers, P. W., Radermacher, K. A., Kleinschnitz, C., and Schmidt, H. H. (2012). VAS2870 Is a Pan-NADPH Oxidase Inhibitor. Cell Mol Life Sci 69, 3159-3160. doi:10.1007/s00018-0121107-1

Wu, H., Li, Y., Wang, Y., Xu, D., Li, C., Liu, M., et al. (2014). Tanshinone IIA Attenuates Bleomycin-Induced Pulmonary Fibrosis via Modulating Angiotensin-Converting Enzyme 2/Angiotensin-(1-7) axis in Rats. Int. J. Med. Sci. 11, 578-586. doi:10.7150/ijms.8365

Wu, Y., Liu, L., Zhang, J., Huang, L., Huang, S., and He, J. (2020). Thalidomide Inhibits the Gene Promoter of Connective Tissue Growth Factor in Human Embryonic Lung Fibroblasts. Ann. Palliat. Med. 9, 2516-2523. doi:10.21037/ apm-19-398

Xiao, Z., Liu, W., Mu, Y. P., Zhang, H., Wang, X. N., Zhao, C. Q., et al. (2020). Pharmacological Effects of Salvianolic Acid B against Oxidative Damage. Front Pharmacol. 11, 572373. doi:10.3389/fphar.2020.572373

Xu, M., Deng, B., Chow, Y. L., Zhao, Z. Z., and Hu, B. (2007). Effects of Curcumin in Treatment of Experimental Pulmonary Fibrosis: a Comparison with Hydrocortisone. J. Ethnopharmacol 112, 292-299. doi:10.1016/ j.jep.2007.03.011

Yan, B., Ma, Z., Shi, S., Hu, Y., Ma, T., Rong, G., et al. (2017). Sulforaphane Prevents Bleomycin-induced $\mathrm{P}$-ulmonary F-ibrosis in $\mathrm{M}$-ice by I-nhibiting $\mathrm{O}$-xidative S-tress via $\mathrm{N}$-uclear F-actor E-rythroid 2-related F-actor-2 A-ctivation. Mol. Med. Rep. 15, 4005-4014. doi:10.3892/mmr.2017.6546

Ye, Q., Chen, B., Tong, Z., Nakamura, S., Sarria, R., Costabel, U., et al. (2006). Thalidomide Reduces IL-18, IL-8 and TNF-Alpha Release from Alveolar Macrophages in Interstitial Lung Disease. Eur. Respir. J. 28, 824-831. doi:10.1183/09031936.06.00131505

Yildirim, Z., Kotuk, M., Erdogan, H., Iraz, M., Yagmurca, M., Kuku, I., et al. (2006). Preventive Effect of Melatonin on Bleomycin-Induced Lung Fibrosis in Rats. J. Pineal Res. 40, 27-33. doi:10.1111/j.1600-079X.2005.00272.x

Yoon, Y. S., Lee, J. H., Hwang, S. C., Choi, K. S., and Yoon, G. (2005). TGF Beta1 Induces Prolonged Mitochondrial ROS Generation through Decreased Complex IV Activity with Senescent Arrest in Mv1Lu Cells. Oncogene 24, 1895-1903. doi:10.1038/sj.onc.1208262

You, H., Wei, L., Sun, W. L., Wang, L., Yang, Z. L., Liu, Y., et al. (2014). The green tea Extract Epigallocatechin-3-Gallate Inhibits Irradiation-Induced Pulmonary Fibrosis in Adult Rats. Int. J. Mol. Med. 34, 92-102. doi:10.3892/ ijmm.2014.1745

Yu, N., Sun, Y. T., Su, X. M., He, M., Dai, B., and Kang, J. (2016). Melatonin Attenuates TGF $\beta 1$-Induced Epithelial-Mesenchymal Transition in Lung Alveolar Epithelial Cells. Mol. Med. Rep. 14, 5567-5572. doi:10.3892/ mmr.2016.5950

Zaghloul, M. S., Said, E., Suddek, G. M., and Salem, H. A. (2019). Crocin Attenuates Lung Inflammation and Pulmonary Vascular Dysfunction in a Rat Model of Bleomycin-Induced Pulmonary Fibrosis. Life Sci. 235, 116794. doi:10.1016/ j.lfs.2019.116794

Zeidler, P., Hubbs, A., Battelli, L., and Castranova, V. (2004). Role of Inducible Nitric Oxide Synthase-Derived Nitric Oxide in Silica-Induced Pulmonary Inflammation and Fibrosis. J. Toxicol. Environ. Health A. 67, 1001-1026. doi:10.1080/15287390490447296

Zhang, B., Safa, R., Rusciano, D., and Osborne, N. N. (2007a). Epigallocatechin Gallate, an Active Ingredient from green tea, Attenuates Damaging Influences to the Retina Caused by Ischemia/reperfusion. Brain Res. 1159, 40-53. doi:10.1016/j.brainres.2007.05.029
Zhang, D. P., Qiu, H., Zhuang, Y., and Meng, F. Q. (2007b). The Effect of Curcumin on Bleomycin-Induced Pulmonary Fibrosis in Rats. Zhonghua Jie He He Hu Xi Za Zhi 30, 197-201.

Zhang, H., Yang, Y., Wang, Y., Wang, B., and Li, R. (2018a). Renal-protective Effect of Thalidomide in Streptozotocin-Induced Diabetic Rats through Antiinflammatory Pathway. Drug Des. Devel Ther. 12, 89-98. doi:10.2147/ DDDT.S149298

Zhang, H., Yin, G., Jiang, H., and Zhang, C. (2013). High-dose N-Acetylcysteine Decreases Silica-Induced Lung Fibrosis in the Rat. J. Int. Med. Res. 41, 1179-1186. doi:10.1177/0300060513488503

Zhang, H. S., and Wang, S. Q. (2007). Nrf2 Is Involved in the Effect of Tanshinone IIA on Intracellular Redox Status in Human Aortic Smooth Muscle Cells. Biochem. Pharmacol. 73, 1358-1366. doi:10.1016/ j.bcp.2007.01.004

Zhang, L., He, Y. L., Li, Q. Z., Hao, X. H., Zhang, Z. F., Yuan, J. X., et al. (2014a). N-acetylcysteine Alleviated Silica-Induced Lung Fibrosis in Rats by Down-Regulation of ROS and Mitochondrial Apoptosis Signaling. Toxicol. Mech. Methods 24, 212-219. doi:10.3109/ 15376516.2013.879974

Zhang, M., Cao, S. R., Zhang, R., Jin, J. L., and Zhu, Y. F. (2014b). The Inhibitory Effect of Salvianolic Acid B on TGF-B1-Induced Proliferation and Differentiation in Lung Fibroblasts. Exp. Lung Res. 40, 172-185. doi:10.3109/01902148.2014.895070

Zhang, M., Feng, Z. S., and Deng, Z. T. (2011). Effect of Salvianolic Acid B on TGFBeta1-Induced Human Embryonic Lung Fibroblast's Biological Behavior. Zhongguo Zhong Xi Yi Jie He Za Zhi 31, 1401-1404.

Zhang, T., Liu, M., Gao, Y., Li, H., Song, L., Hou, H., et al. (2021). Salvianolic Acid B Inhalation Solution Enhances Antifibrotic and Anticoagulant Effects in a Rat Model of Pulmonary Fibrosis. Biomed. Pharmacother. 138, 111475. doi:10.1016/j.biopha.2021.111475

Zhang, X., Cai, Y., Zhang, W., and Chen, X. (2018c). Quercetin Ameliorates Pulmonary Fibrosis by Inhibiting SphK1/S1P Signaling. Biochem. Cell Biol 96, 742-751. doi:10.1139/bcb-2017-0302

Zhang, X. R., Zhou, W. X., and Zhang, Y. X. (2018b). Improvements in SOD Mimic AEOL-10150, a Potent Broad-Spectrum Antioxidant. Mil. Med. Res. 5, 30. doi:10.1186/s40779-018-0176-3

Zhang, Y. Q., Liu, Y. J., Mao, Y. F., Dong, W. W., Zhu, X. Y., and Jiang, L. (2015). Resveratrol Ameliorates Lipopolysaccharide-Induced Epithelial Mesenchymal Transition and Pulmonary Fibrosis through Suppression of Oxidative Stress and Transforming Growth Factor-B1 Signaling. Clin. Nutr. 34, 752-760. doi:10.1016/j.clnu.2014.08.014

Zhang, Z., Qu, J., Zheng, C., Zhang, P., Zhou, W., Cui, W., et al. (2018d). Nrf2 Antioxidant Pathway Suppresses Numb-Mediated Epithelial-Mesenchymal Transition during Pulmonary Fibrosis. Cell Death Dis 9, 83. doi:10.1038/ s41419-017-0198-x

Zhao, C. J., Niu, J. Z., Wang, J. F., Zhou, G., and Tang, B. H. (2008). Effects of Curcumin on Bleomycin-Induced Damages in Pulmonary Functions in Rats. Zhongguo Zhong Yao Za Zhi 33, 1434-1438.

Zhao, H., Wu, Q. Q., Cao, L. F., Qing, H. Y., Zhang, C., Chen, Y. H., et al. (2014). Melatonin Inhibits Endoplasmic Reticulum Stress and Epithelial-Mesenchymal Transition during Bleomycin-Induced Pulmonary Fibrosis in Mice. PLoS One 9, e97266. doi:10.1371/journal.pone.0097266

Zhao, X., Sun, J., Su, W., Shan, H., Zhang, B., Wang, Y., et al. (2018). Melatonin Protects against Lung Fibrosis by Regulating the Hippo/YAP Pathway. Int. J. Mol. Sci. 19, 1118. doi:10.3390/ijms19041118

Zheng, Q., Tong, M., Ou, B., Liu, C., Hu, C., and Yang, Y. (2019). Isorhamnetin Protects against Bleomycin-Induced Pulmonary Fibrosis by Inhibiting Endoplasmic Reticulum Stress and Epithelial-Mesenchymal Transition. Int. J. Mol. Med. 43, 117-126. doi:10.3892/ijmm.2018.3965

Zhou, G., Niu, J. Z., Wang, J. F., Chen, W. T., Liu, T. X., Li, Y. S., et al. (2006a). Experimental Study on Effect of Curcumin on Inhibiting Injury of Free Radical in Pulmonary Fibrosis Rats. Zhongguo Zhong Yao Za Zhi 31, 669-672.

Zhou, G., Wang, J. F., Niu, J. Z., Lu, Y. S., Chen, W. T., Li, Z. H., et al. (2006b). Experimental Study on Protective Effects of Curcumin on Exaggerated Extracellular Matrix Accumulation of Pulmonary Fibrosis Rats. Zhongguo Zhong Yao Za Zhi 31, 570-573. 
Zhou, H., Beevers, C. S., and Huang, S. (2011). The Targets of Curcumin. Curr. Drug Targets 12, 332-347. doi:10.2174/138945011794815356

Zhou, W., Mo, X., Cui, W., Zhang, Z., Li, D., Li, L., et al. (2016). Nrf2 Inhibits Epithelial-Mesenchymal Transition by Suppressing Snail Expression during Pulmonary Fibrosis. Sci. Rep. 6, 38646. doi:10.1038/srep38646

Zhu, X.-d., Lei, X.-p., and Dong, W.-b. (2017). Resveratrol as a Potential Therapeutic Drug for Respiratory System Diseases. Dddt 11, 3591-3598. doi:10.2147/DDDT.S148868

Zhu, Z., Li, Q., Xu, C., Zhao, J., Li, S., Wang, Y., et al. (2020). Sodium Tanshinone IIA Sulfonate Attenuates Silica-Induced Pulmonary Fibrosis in Rats via Activation of the Nrf2 and Thioredoxin System. Environ. Toxicol. Pharmacol. 80, 103461. doi:10.1016/j.etap.2020.103461

Zhu, Z., Wang, Y., Liang, D., Yang, G., Chen, L., Niu, P., et al. (2016). Sodium Tanshinone IIA Sulfonate Suppresses Pulmonary Fibroblast Proliferation and Activation Induced by Silica: Role of the Nrf2/Trx Pathway. Toxicol. Res. (Camb) 5, 116-125. doi:10.1039/c5tx00291e
Conflict of Interest: The authors declare that the research was conducted in the absence of any commercial or financial relationships that could be construed as a potential conflict of interest.

Publisher's Note: All claims expressed in this article are solely those of the authors and do not necessarily represent those of their affiliated organizations, or those of the publisher, the editors and the reviewers. Any product that may be evaluated in this article, or claim that may be made by its manufacturer, is not guaranteed or endorsed by the publisher.

Copyright $\odot 2022$ Estornut, Milara, Bayarri, Belhadj and Cortijo. This is an openaccess article distributed under the terms of the Creative Commons Attribution License (CC BY). The use, distribution or reproduction in other forums is permitted, provided the original author(s) and the copyright owner(s) are credited and that the original publication in this journal is cited, in accordance with accepted academic practice. No use, distribution or reproduction is permitted which does not comply with these terms. 


\section{GLOSSARY}

6MWD 6-min walk distance

3-NT 3-nitrotyrosine

AEC alveolar epithelial cells

ARE antioxidant response element

BALF bronchoalveolar lavage fluid

b.i.d bis in die, twice a day

COPD chronic obstructive pulmonary disease

COX-2 cyclooxygenase 2

CQLQ Cough Quality of Life Questionnaire

CRP -score clinical, radiologic and physiologic score

DLCO diffusing capacity of the lungs for carbon monoxide

DPI Diphenyleneiodonium

EBC expired breath condensate

ECM extracellular matrix

EC-SOC extracellular SOD

EGCG Epigallocatechin gallate

ELF epithelial lining fluid

EMT epithelial-to-mesenchymal transition

eNOS endothelial NOS

ERK extracellular signal-regulated kinase

FEV forced expiratory volume

FITC fluorescein isothiocyanate

FVC forced vital capacity

GCL glutamate cysteine ligases

GCLC glutamate cysteine ligase catalytic subunit

GCLM glutamate cysteine ligase modifier subunit

GPx glutathione peroxidase

GSH glutathione

GSSG oxidized glutathione

GST glutathione S-transferase

HO-1 heme oxygenase I

HSP heat shock protein

IL interleuquin

iNOS inducible NOS

IPF idiopathic pulmonary fibrosis

JNK c-Jun N-terminal kinase

KEAP1 Kelch like-ECH-associated protein 1

LPS lipopolysaccharide

MDA malondialdehyde

MMP matrix metalloproteinase
MPO myeloperoxidase

MUC mucin

NAC n-acetyl cysteine

NFא $\boldsymbol{\beta}$ nuclear factor kappa beta

nNOS neural NOS

NO nitric oxide

NOS nitric oxide synthase

NOX NADPH oxidase

NQO1 NADPH oxidoreductase I

NRF2 nuclear factor erythroid 2-related factor 2

PFD pirfenidone

PFS progression-free survival

PrxII peroxiredoxin II

Quer quercetin

RNS reactive nitrogen species

ROS reactive oxygen species

Sal B Salvianolic acid B

SF-36 36-Item Short Form Survey

SFN sulforaphane

SGRQ St. George's Respiratory Questionnaire

SOD superoxide dismutase

SpO2 oxygen saturation by pulse oximetry

SRX1 sulfiredoxin-1

STS sodium anshinone IIA sulfate

TAC total antioxidant capacity

TanIIA tanshinone IIA

TBARS thiobarbituric acid reactive substances

TEAC trolox equivalent antioxidant capacity

TGF- $\boldsymbol{\beta}$ transforming growth factor beta

tGSH total glutathione

Thal thalidomide

t.i.d ter in die, three times a day

TLC total lung capacity

TNF- $\boldsymbol{\alpha}$ tumoral necrosis factor Alpha

TOLLIP toll-interacting protein

TRX thioredoxin

VAS visual analog scale of cough

VC vital capacity

VSMCs vascular smooth muscle cells

WHOQOL-BREF World Health Organization Quality of Life abbreviated version

a-SMA smooth muscle actine alpha 